\title{
Balancing Immediate and Long-Term Defense Investments
}

\author{
Jonathan P. Wong
}

This document was submitted as a dissertation in April 2016 in partial fulfillment of the requirements of the doctoral degree in public policy analysis at the Pardee RAND Graduate School. The faculty committee that supervised and approved the dissertation consisted of Christopher G. Pernin (Chair), Igor Mikolic-Torreira, and Matthew W. Lewis.

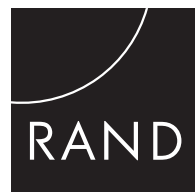


For more information on this publication, visit http://www.rand.org/pubs/rgs_dissertations/RGSD378.html

Published by the RAND Corporation, Santa Monica, Calif.

(C) Copyright 2016 RAND Corporation

RAND $^{\circledR}$ is a registered trademark

\section{Limited Print and Electronic Distribution Rights}

This document and trademark(s) contained herein are protected by law. This representation of RAND intellectual property is provided for noncommercial use only. Unauthorized posting of this publication online is prohibited. Permission is given to duplicate this document for personal use only, as long as it is unaltered and complete. Permission is required from RAND to reproduce, or reuse in another form, any of its research documents for commercial use. For information on reprint and linking permissions, please visit www.rand.org/pubs/permissions.html.

The RAND Corporation is a research organization that develops solutions to public policy challenges to help make communities throughout the world safer and more secure, healthier and more prosperous. RAND is nonprofit, nonpartisan, and committed to the public interest.

RAND's publications do not necessarily reflect the opinions of its research clients and sponsors.

Support RAND

Make a tax-deductible charitable contribution at

www.rand.org/giving/contribute

www.rand.org 


\section{Table of Contents}

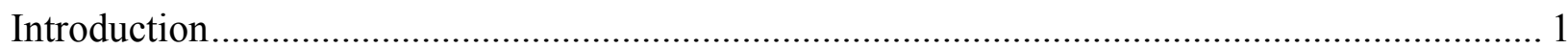

Chapter One: Exploring Rapid Acquisition Policies ....................................................... 9

Chapter Two: Immediate Investments in the DoD Procurement Budget ................................ 27

Chapter Three: Rapid Acquisition in Practice ................................................................. 50

Chapter Four: Recommendations and Conclusions …................................................ 76

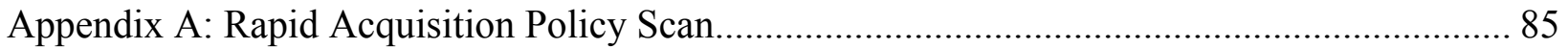

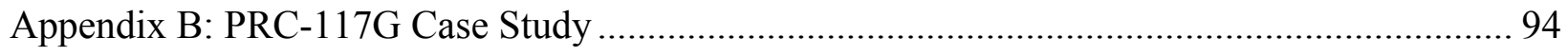

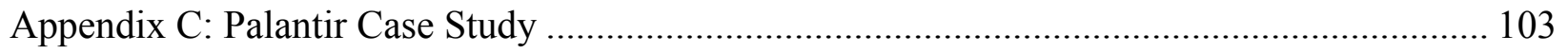

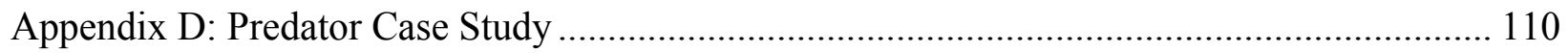

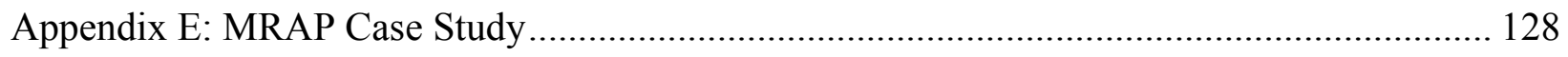

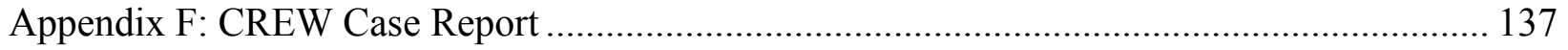

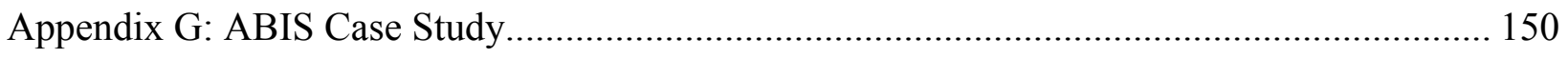

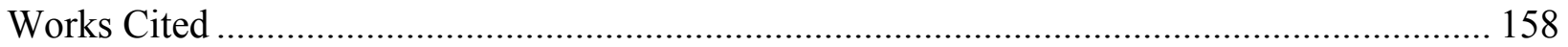





\section{Acknowledgments}

This work would not be possible without the contributions of numerous individuals.

To my committee members, Dr. Chris Pernin, Dr. Matt Lewis, and Dr. Igor MikolicTorreira, and my external reviewer Dr. Matthew Schaffer: Thank you for firmly pushing me towards asking the harder questions, answering them more thoroughly, and ensuring that I did not lose sight of the policies and people in the process.

To the numerous and anonymous individuals in the Department of Defense, industry, academia, and the unaffiliated: Thank you for taking the time to answer my cold calls, sit for interviews, review my work, and offer me feedback. Thanks especially to my fellow Marines, upon whom I leaned heavily to provide introductions to otherwise impenetrable organizations.

To my funders at Project AIR FORCE, the Arroyo Center, and the National Security Research Division: Thank you for underwriting this endeavor with generous funding. In particular, thank you to Michael Kennedy, Tim Bonds, Bruce Held, Dr. Cynthia Cook, and Dr. Chris Mouton for judging that my research ideas were worth investing in.

To the fellows and researchers at Pardee RAND and the RAND Corporation: Thank you for entrusting me with tasks on your projects, helping me with my coursework, lending an ear when needed, and never saying no to a cup of coffee. In particular, thanks to Dr. Ben Connable for introducing me to Pardee RAND and trusting me repeatedly to do critical work on your projects.

Lastly, to my wife Jenny: You endured Iraq, Quantico, Los Angeles, and countless work-filled evenings and weekends to support this. Thanks and onward to our next chapter, with our newborn son in tow. 

The US Department of Defense's (DoD) process for allocating resources for acquiring weapons systems is optimized for long-term investments, guided by the DoD's forecast of future threats, conflicts, adversaries, and possible US responses to them. This dissertation examines how the DoD acquisition bureaucracy responds to unforeseen conflicts and adversaries by making immediate procurement investments.

This dissertation uses the recent wars in Iraq and Afghanistan to examine the DoD's bureaucratic response. The dissertation analyzes the DoD's policies for making immediate investments by comparing them to a framework for organizational flexibility. Next, the dissertation examines the DoD's ability to make the best use of those policies by using examining changes in the DoD's procurement budget during the wars. This is done using a framework for categorizing the DoD's procurement investments based on their immediacy. Lastly, the dissertation examines six individual immediate investment cases to understand how DoD policies, bureaucratic behavior, and technological capacity interact to meet these immediate operational demands

This dissertation finds that the DoD was developed a surprisingly nimble and risktolerant process for making most immediate investments. The DoD did require extensive senior leader intervention to make investments that were previously judged to be unnecessary. The dissertation also found that the DoD's process relied on the entrepreneurship and organizational savvy of individual program officers to identify funding sources and enlist stakeholder support. This research concludes by recommending marginal changes to DoD policy, including granting greater flexibility to DoD components to spend previously allocated resources, allowing more bottom-up input to the immediate investment process, and anticipating the need for single-purpose task forces to provide senior leader intervention in contentious cases. 



\section{Introduction}

This dissertation was inspired by the Department of Defense's (DoD) long odyssey to develop its next generation of tactical radios and the way in which the wars in Iraq and Afghanistan played an unexpected role in moving that process along. When the first American troops crossed the border into Iraq in 2003, each infantry platoon went into battle with a single tactical radio in a backpack, known as a PRC-119. This radio could only monitor one frequency, lacked the ability to talk to aircraft, and could only send and receive audio transmissions. Communications between units in the platoon was accomplished largely through shouting and hand signals. By 2004, troops still carried the PRC-119, supplemented with commercial walkie-talkies with limited range. ${ }^{1}$

By 2007, however, progress was visible. Platoons now deployed to Iraq boasting five tactical radios, including the handheld PRC-148 that could be dropped into water up to 20 meters deep and could also talk to aircraft. By 2012, platoons frequently carried 12 handheld, solar-rechargeable PRC-152 radios to communicate within the platoon along with the PRC-117G radio, which could be plugged into a laptop computer to form an adhoc computer network. Pictures, maps, and other information could be exchanged between platoons and with their parent units. Some platoons even possessed equipment that allowed them to see live aerial surveillance video feeds from the aircraft to which they were talking (although this was less common). Platoons that could only talk on one ground frequency in 2003 could now effectively communicate within their units and across other units and aircraft using voice and data on a variety of frequencies. This improved communication capability enabled ground forces to expand their control over much larger swaths of territory than the areas with which commanders were previously comfortable. $^{2}$

While one part of the DoD was achieving these steady improvements in capability, another part was spending billions of dollars on another, strikingly similar military communications project. The DoD's Joint Tactical Radio System (JTRS) started in 1997 with an ambitious goal: to develop a universal radio that used software instead of hardware to encrypt, send, and receive information. This would make radios upgradable in ways that old, hardware-defined radios could not be. It would also help the military

\footnotetext{
${ }^{1}$ Sandra I. Erwin, "Army, Marines Buying Loads of Radios," National Defense, September 2005.

2 Sean Gallagher, "How to blow \$6 billion on a tech project," Ars Technica, June 18, $2012 \mathrm{a}$.
} 
replace many existing radios that were not compatible with one another. JTRS was imagined to be lightweight, versatile, and capable of serving as a portable computer network that could enable military units to communicate with voice and data.

Unfortunately, the scope and ambition of these goals were simply too great for existing technology to accomplish. Billions of dollars were spent to develop JTRS into a system that could be mass-produced, but to no avail. ${ }^{3}$ In the meantime, Harris Communications embarked on a self-funded research and development effort that set out to achieve most (but not all) of the goals of JTRS. The PRC-117G was among the results. While they did not replace all of the radios that JTRS sought out to, they were solid products that were used to good effect in Iraq and Afghanistan. JTRS was ultimately cancelled in 2011, leaving the Harris radios as the de facto standard. ${ }^{4}$

Despite the issues faced by the JTRS program, this modernization of military communications did not happen randomly. The organizational and operational forces that shaped that outcome are phenomena that deserve to be explored in depth. As the Department of Defense continues its attempts to reform the acquisition process, this will be particularly important.

\section{Immediate Investments and Rapid Acquisitions Can Be Paradoxically Successful}

Conventional wisdom characterizes defense acquisition as inefficient at best and wasteful at worst. The most negative assessments characterize weapons such as the F111, the Crusader self-propelled gun, and the Expeditionary Fighting Vehicle (EFV) as weapons that cost too much, are unable to perform as promised, and are often behind schedule. $^{5}$

3

${ }^{4}$ Frank Kendall, Oct 132011.

${ }^{5}$ Thomas McNaugher describes a host of acquisition problems such as the emphasis on performance over reliability, the tendency to design weapon systems by consensus, and other issues that resulted in costly and poorly-performing weapons. McNaugher cites the F-111 fighter in the 1960s, the M2 Bradley Infantry Fighting Vehicle and the Sergeant York air defense gun in the 1980s as examples where these forces were at play. Those same forces plagued the Crusader and the Expeditionary Fighting Vehicle programs until they were cancelled, and are currently at work in the F-35 program. See Thomas L. McNaugher, New Weapons Old Politics: America's Military Procurement Muddle, ed., Washington, D.C., Brookings, 1989. Also see Edward N. Luttwak, The Pentagon and the Art of War, ed., New York, Simon \& Schuster, 1985. For an in-depth treatment of the M-2 Bradley, see James G. Burton, The Pentagon Wars: Reformers Challenge the Old Guard, ed., Annapolis, MD., Naval Institute Press, 1993. Finally, the F-111 program's initial struggles are described in-depth by Robert Art in Robert J. Art, The TFX Decision: McNamara and the Military, ed., Boston, Little Brown, 1968. 
Yet the past 14 years of war has resulted in weapons that $d o$ work. The Harris radios described earlier allowed US troops in Iraq and Afghanistan to communicate with unprecedented ease. Communications were not the only area in which these wars have motivated change. When the US invaded Iraq in 2003, troops rode military trucks lined with sandbags to protect against small arms fire and shrapnel. By 2007, most of these trucks were outfitted with bespoke armor. By 2008, troops mounted trucks called MRAPs (Mine Resistant Ambush Protected) that were purposefully designed to withstand roadside bombs and sported powerful electronic jammers to disrupt remote-controlled detonations. This rapid and iterative evolution of US military materiel stands in contrast to the conventional wisdom of defense acquisitions. ${ }^{6}$ Thus, it is important to ask two general questions:

- How did the DoD acquire weapons differently during the Iraq and Afghanistan wars than in the peacetime years prior to these conflicts?

And more importantly,

- What lessons can we learn from these experiences?

As a starting point, it is important to note that the successes of Harris radios and MRAPs happened outside of the conventional Defense Acquisitions System (DAS), through means that are collectively known as rapid acquisition initiatives. McNaugher argues that normal acquisition channels are meant to be conservative, methodical exercises that attempt to balance timeliness, cost-savings, and the effectiveness of the weapon itself. ${ }^{7}$ By contrast, rapid acquisition initiatives purposely take shortcuts to save time, implicitly sacrificing some level of cost-savings, effectiveness or both. ${ }^{8}$

\footnotetext{
${ }^{6}$ This is not to say that conventional acquisition process lacks any value, or that immediate investments in rapid acquisition should be the only framework to use in defense acquisitions.

${ }^{7}$ McNaugher, ed.

${ }^{8}$ This can include developing a system outside of the DAS (e.g., the Advanced Concept Technology Demonstration process, which can be transitioned into the conventional process), alternative methods of funding programs (e.g., the Joint Improvised Explosive Device Defeat Organization or JIEDDO), and others. For an overview of the different shortcuts that rapid acquisition initiatives can take, see Report of the Defense Science Board Task Force on the Fulfillment of Urgent Operational Needs, Washington, D.C.: Defense Science Board, July, 2009, http://www.acq.osd.mil/dsb/reports/ADA503382.pdf (as of Dec 14, 2014). and Government Accountability Office, DOD's Urgent Needs Processes Need a More Comprehensive Approach and Evaluation for Potential Consolidation: Government Accountability Office, GAO-11-273, March 2011.
} 


\section{Why Examine Rapid Acquisition?}

What is so compelling about the machinations and administrative "inside baseball" of the Pentagon and its procurement process? A considerable literature in regard to weapons acquisition already exists. Nevertheless, there are several compelling reasons to further examine the procurement process, and the unique circumstances of the Iraq and Afghanistan Wars in shaping that process.

First, the need for acquisition reform continues. Americans have been dissatisfied with military acquisitions in the modern sense of the term since the end of World War II. ${ }^{9}$ Failed programs such as the F-111, the Crusader self-propelled gun, and others illustrate the disappointing results of the system. Despite intense acquisition reform efforts in the 1960s and 1980s, fundamental shortcomings persist. ${ }^{10}$ Unfortunately, the continued need to study acquisition reform is evident.

Additionally, this dissertation's particular focus on immediate investments examines a relatively unexplored part of defense acquisition that has implications for future conflict. As former Secretary of the Navy Richard Danzig noted, the lack of a clear existential adversary (a condition that has been the case since 1989) and the proliferation of numerous smaller threats requires the DoD to be flexible and responsive in its procurement activities. ${ }^{11}$ This fluid operating environment requires defense scholars to move beyond examinations of large, long-term weapons procurement programs to focus on issues of responsiveness, flexibility, and adaptability in the face of uncertainty. While much has been written about these subjects as they pertain to the American military generally, less has been said about these issues as they relate to procurement specifically. This dissertation is a foray into that relatively unexplored territory; the hope is that it can provide insights into how the DoD tried to respond to an unexpectedly long and trying conflict and what lessons might be learned for the future.

Second, the Iraq and Afghanistan Wars represent a special set of circumstances that allow scholars to examine bureaucratic behaviors in their most natural way (short of controlled experiments). Three circumstances were particularly important. First, the question of priorities and threats was resolved. With over 200,000 troops deployed and

\footnotetext{
9 An exhaustive history of early acquisition program shortcomings is contained in J. Ronald Fox, Defense Acquisition Reform, 1960-2009: An Elusive Goal, ed., Washington, D.C., Center for Military History, 2011.

${ }^{10}$ See the discussion on the McNamara and Packard reforms in McNaugher, ed.

11 Richard Danzig, Driving in the Dark: Ten Propositions About Prediction and National Security, Washington, D.C.: Center for a New American Security, October, 2011, http://www.cnas.org/files/documents/publications/CNAS_Prediction_Danzig.pdf (as of March 16, 2016).
} 
significant public discourse about the war affecting national elections, the wars in Iraq and Afghanistan were clearly priorities for the DoD. Second, the DoD was given a de facto blank check on its procurement expenditures. Congress' willingness to fund procurement needs through supplemental budgets meant that the DoD had a much easier time getting funding during than before these conflicts. Lastly, the introduction of multiple alternative policies for acquisition at the departmental level, by the military services, and other sub-organizations reduced procedural barriers to DoD investment choices. Put together, these strategic, budgetary, and procedural circumstances represent the most unconstrained expression of DoD's investment choices (particularly immediate investments) in many years.

Despite this environment, there remained administrative and bureaucratic behaviors that continued to emphasize long-term investments. The delay in procuring the MRAP vehicle due to long-term logistical and amphibious shipping compatibility issues is one example of this. That problem and other bureaucratic behaviors are unsurprising hindrances to shifting between immediate and long-term investments that we will term "bureaucratic inertia." Understanding this inertia and how it can be mitigated will be important to understand if the DoD is to increase its ability to adapt to an uncertain strategic environment.

Lastly, the DoD's increased emphasis on immediate investments resulted in responsive and effective outcomes. Responsiveness was expected - the DoD's rapid acquisition policies emphasized speed above other values such as maximized general utility and cost. Moreover, some programs (though not all) were also quite innovative and effective even when compared to conventional acquisition efforts. Programs such as the PRC-117G networking radio and the MQ-1 Predator demonstrated that the DoD's shift towards greater immediate investments could yield benefits beyond speed of action. The opportunity to examine the underlying factors and drivers in an in-depth manner through the use of case studies is one that cannot be ignored by any serious student of defense analyses.

\section{Research Questions and Hypotheses}

In implementing rapid acquisition projects, the DoD invested more of its resources in meeting immediate needs, rather than investing for long-term modernization, as the acquisitions process is designed to do. ${ }^{12}$ That tension between immediate and long-term

\footnotetext{
12 Rapid acquisition initiatives generated much enthusiasm amongst policymakers during the height of the wars in Iraq and Afghanistan, but enthusiasm has faded once it was clear that the United States was drawing down its forces in both countries. See the discussion about one such organization (JIEDDO) in
} 
investments highlights a set of implicit trade-offs. On one hand, immediate investments that might be good enough for a specific need today might not be useful in the future. On the other hand, long-term investments in grand defense projects may ultimately become unwieldy.

This inspired me to examine that tension more closely to see how it affected defense acquisition in the recent past and how any lessons learned from it might be applied to future endeavors. I will examine them through four research questions and offer preliminary hypotheses:

RQ1: How much flexibility does the DoD have (in policy and practice) to invest in both immediate and long-term needs across the services and for different budget activities?

H1: Substantial policy flexibility to shift between immediate and long-term investments exists. However, practical disincentives deter the DoD from making full use of that flexibility. Ambiguity and lack of coordination in existing policies also contribute to the disincentives to making full use of the existing flexibility.

RQ2: How did the balance between immediate and long-term investments in the Department of Defense across services and types of weapons change during the Iraq and Afghanistan wars?

H2: The majority of investments for the Navy and Air Force remained largely focused (over 90\%) on long-term objectives. Immediate investments due to the needs of the Iraq and Afghanistan wars remained relatively small (not more than $10 \%$ ).

RQ3: What factors affect the Department of Defense's consideration of immediate investments?

H3: Operationally, periods of surging technological innovation, operational concept changes, and threat uncertainty would be the most critical junctures during which to consider greater flexibility. Operationally, conflicts that are likely to lack a

Corbin Hiar, House offers budget boost to troubled Pentagon agency fighting roadside bombs: The Center for Public Integrity, May 19, 2014, http://www.publicintegrity.org/2011/07/14/5223/house-offers-budgetboost-troubled-pentagon-agency-fighting-roadside-bombs (as of Nov 16, 2014). 
definable end for the United States or involve the possibility of an asymmetric adversary would also be a time to consider greater flexibility. ${ }^{13}$

RQ4: What policy, organizational, and incentive structure changes should be considered if operational and organizational conditions warrant greater attention to immediate investments?

H4: New policies and organizations will not likely be necessary, although existing practices will require existing policies on investment flexibility or oversight to be consolidated and streamlined.

Personnel and organizational incentive structures will need to change to allow investment flexibility decisions to have the most effectiveness. Incentive structures, particularly as they pertain to Congressional oversight and expectations, contracting arrangements, and defense industrial base relationships, will need to be changed.

The nature of the four research questions will drive me to focus on the findings and their implications, rather than proving or disproving the hypotheses. The preliminary hypotheses presented here are only intended to aid me in conceptualizing the research design. These hypotheses will not be proven or disproven in the research that follows.

\section{Dissertation Organization}

Having laid out the motivation, potential policy impacts, and research questions in this introductory chapter, the remaining chapters will investigate each issue individually. Chapter One will examine the question of how flexible the DoD's acquisition policies were in regard to shifting between immediate and long-term investments. After establishing the size of this policy space for flexibility, Chapter Two will investigate how much of that policy space was actually used to shift between investment types by examining DoD investment choices over time, as expressed in DoD budget requests. Chapter Three will look more closely at six individual immediate investments to understand the most common characteristics of successful short-term investments and the problems they faced related to bureaucratic inertia. Lastly, Chapter Four will return to the

\footnotetext{
${ }^{13}$ Obviously, no one can predict the end of a conflict, but there are often periods when it becomes increasingly clear to policymakers that a conflict or intervention is becoming more involved. The Chinese entry to the Korean War is one example. Another was the late 2003-2004 time period during the Iraq War, when the possibility of a long-term insurgency was becoming more evident, even as the Bush administration tried to downplay such characterizations.
} 
themes of responsiveness and uncertainty. Those themes, along with the findings from the examination of policies, budgets, and programs will inform a set of policy recommendations and considerations in the conclusion. 


\section{Chapter One: Exploring Rapid Acquisition Policies}

This dissertation begins by examining the numerous rapid acquisition policies that were enacted and revised over the course of Operation Iraqi Freedom (OIF) and Operation Enduring Freedom (OEF). This research seeks to examine how the balance of procurement investments changed during OIF and OEF. Therefore, the rapid acquisition policies that frame these changes should be examined first. Subsequent chapters will examine how much the DoD made use of these policies and in what ways they did so.

We will examine the policy space by addressing my first research question:

RQ1: How much flexibility does the DoD have (in policy and practice) to invest in both immediate and long-term needs across the services and for different budget activities over time?

To which I hypothesized:

H1: Substantial policy flexibility to shift between immediate and long-term investments exists. However, practical disincentives deter the DoD from making the full use of that flexibility. Ambiguity and lack of coordination in existing policies also contribute to the disincentives to making full use of the existing flexibility.

This chapter will begin by developing a framework for assessing organizational flexibility. I will then apply that framework to the DoD's rapid acquisition policies. I conclude this chapter by examining the findings from that analysis and its implications for DoD flexibility as a whole.

\section{Defining Flexibility in Relation to Defense Acquisition}

To approach the research question, I developed an explicit definition and a way of measuring acquisition policy flexibility. This section begins with a review of existing research on organizational flexibility. I then describe how I aggregated the most salient metrics from that scholarship to build a framework for measuring acquisition policy flexibility. 
While the scholarship on organizational flexibility is very broad, there are fewer attempts to develop methods to measure it. A recent review of 10 flexibility evaluation methodologies by Shaarabh, et al. reveals that many of these measurement frameworks are based on subjective metrics such as customer satisfaction ratings, market trends, assessment of an organization's strategic culture, and so on. ${ }^{14}$

Quantitative measurement frameworks appear to be more relevant for our purposes. A number of these frameworks identify and weigh variables (e.g. the levels of hierarchy in an organization, the throughput of a production process, etc.) to compare organizations to each other. Since my research is focused on comparing one organization to itself over time, I can utilize some metrics directly, without weighting.

\section{Metrics for Measuring Investment Flexibility}

After reviewing 17 different models (10 reviewed by Shaarabh et al. and seven more reviewed separately), I adapted five common metrics to evaluate the degree to which DoD's acquisition policies provided for flexibility and developed one metric to form the basis for the measurement framework:

- Policy pathways for acquisition (metric developed for this research)

- Minimum speed of performance

- Maximum funding allowed

- Level of secured funding

- Senior leader attention required

- Number of approvals required

The first metric is the number of policy pathways possible. This metric helps characterize the opportunities available for acquisition flexibility. I presume that more pathways allow for a program to enter the procurement system in more ways. For instance, the Marine Corps' I Marine Expeditionary Unit (I MEF) requested that the Marine Corps invest in Mine Resistant Ambush Protected (MRAP) vehicles to protect troops that were being killed and wounded by Iraqi improvised explosive devices (IEDs). I MEF failed to gain approval from the Marines' rapid acquisition system (USMC Universal Urgent Needs Statement, or UUNS) for purchasing the MRAP. They turned to the joint process (Joint Urgent Operational Needs Statement, or JUONS) and were

\footnotetext{
${ }^{14}$ Gupta Rishi Murarka Shaarabh, Sharma SK, "A Review on Measurement of Agility," Industrial Engineering and Management, Vol. 3, no. 1, January 2014.
} 
successful there. ${ }^{15}$ This example provides evidence that a greater number of pathways available for investment can result in greater flexibility.

While this metric is not found in the literature, it is worth including because of the uniqueness of DoD procurement. For most commercial (and many government) organizations, only one (or a few) purchasing or procurement policies exist. DoD procurement is significantly more complex, and grew more complex during the wars in Iraq and Afghanistan, according to a 2009 Defense Science Board (DSB) report, which identified 25 different processes, organizations, and funding mechanisms to make immediate procurement investments, in addition to the conventional acquisition process. ${ }^{16}$ Many of these pathways did not exist prior to OIF and OEF. As evidenced in the MRAP example, it is important to capture this proliferation of pathways to procurement investment.

The minimum speed of performance refers to the maximum time allowed by policy for a given investment to be approved and executed. This metric was aggregated from two from Gong and Janssen's research on e-governance business process improvement. ${ }^{17}$ In that work, response time and case handling time were identified as metrics for measuring the handling of individual cases for the provision of notional public services. Although DoD acquisition presents a more complex set of agents than the e-governance example presented by Gong and Janssen, the general notion that the speed at which an organization performs its functions is important to measure. ${ }^{18}$ Theoretically, a faster speed of performance will enable an organization to complete existing work and move on to new priorities more easily, thereby indicating greater flexibility.

\footnotetext{
${ }^{15}$ This dissertation will draw extensive examples from a set of six case studies of successful rapid acquisition programs, including the MRAP. For details on the process of investing in the MRAP, see Appendix E: MRAP Case Study.

${ }^{16}$ See Figure 2 in Defense Science Board, Report of the Defense Science Board Task Force on the Fulfillment of Urgent Operational Needs, July 2009.

${ }^{17}$ Marjin Janssen Yiwei Gong, "Measuring process flexibility and agility," in Proceedings of the 4th International Conference on Theory and Practice of Electronic Governance (Beijing: ACM, 2010).

${ }^{18}$ In particular, DoD acquisition involves a principal (DoD) who sets objectives and its agents (contractors) who take actions not visible to the principal to carry them out. Additionally, the outputs of the agents and the outcomes desired by the principal may not be visible in a timeframe that allows for corrective action. The e-governance example used by Gong and Janssen involves the provision of services where there is no distinction between principals and agents and where outputs (the action of providing a service) and outcomes (how many people were provided with said service) is visible. For a more detailed examination of these performance attributes, see James Q. Wilson, Bureaucracy: What Government Agencies Do and Why They Do It, ed., New York, Basic 1989.
} 
The maximum funding allowed refers to the funding ceiling for each policy. ${ }^{19}$ This metric is adapted from a metric included in all of the evaluated frameworks. Those frameworks uniformly measured the size of the organization's budget. In this case, we assume that the amount of total funding is an exogenous variable, given Congressional tendency to appropriate more funds than the DoD requests. ${ }^{20}$ Additionally, we assume that the conventional acquisition process has no upper limit, although budget appropriations from Congress to the DoD can only be spent for their stated purpose and cannot be moved in most cases without permission.

In addition to the maximum funding allowed, measuring the amount of funding that is secured is also necessary for measuring the overall allocation of resources that can be applied to any given investment. As previously described, DoD funding works much differently than private organizations and even most government ones as well. While the maximum funding allowed is a telling measure of flexibility, the way the funding is allocated is just as important, since many of the rapid acquisition pathways only approve programs that can identify funding sources (i.e. by reprogramming funds each year). Thus, the level of maximum funding that is secured (through a dedicated line in the budget, for instance) is a separate, but necessary expression of the level resource allocation possible for any given investment.

Why do we not only use the level of secured funding? Although the level of secured funding represents a higher level of flexibility than unsecured funding, it is still important to express the total possible ceiling. That ceiling represents a lower level of flexibility because of the uncertainty of funding, but still represents the possibility of flexibility. For instance, many short-term investments that the DoD made in 2002-12 were made through processes that did not have secured funding associated with it.

Measuring the level of senior leader attention required for ensuring policy functioning presumes that a greater amount of attention required means a higher degree of possible bottlenecking and less flexibility in shifting between immediate and long-term investments. Yauch and Dove highlight the importance of measuring an organization's proficiency at change to understand its flexibility. ${ }^{21}$ Yauch in particular notes that

${ }^{19}$ For example, if one policy has a threshold of $\$ 10$ million dollars and another policy has a threshold of $\$ 20$ million, the aggregate funding ceiling will be expressed as $\$ 30$ million.

${ }^{20}$ Amy Belasco, The Cost of Iraq, Afghanistan, and Other Global War on Terror Operations Since 9/11, Washington, D.C.: Congressional Research Service RL33110, March 29, 2011.

${ }^{21}$ Charlene Yauch, "Measuring agility as a performance outcome," Journal of Manufacturing Technology, Vol. 22, no. 3, 2011. 
implementing change leading to "quality results without the need for constant attention" (emphasis added) is a telling indicator of organizational flexibility. ${ }^{22}$

In the DoD's case, this metric is highly relevant. The senior leadership intervention required to make several key immediate investments (most notably the MRAP and ISR assets) may indicate a lack of flexibility in making investments. In this framework, this metric can be expressed as the highest level of approval required for an investment to be made. This level can be as high as the Secretary of Defense or can go all the way down to individual program managers.

Lastly, measuring the total number of approvals required to make any given investment is a metric closely related to the senior leader one. It is reasonable to assume that a higher number of required approvals means that there are more stakeholders whose interests need to be aligned and thus a lower degree of flexibility. This metric was adapted from the Yauch and Dove frameworks as well as Agile software development approaches. ${ }^{23}$

\section{Making a Summative Assessment of Flexibility}

The approaches for summative assessments in the literature follow two general approaches. Summative assessments in the literature are not made if qualitative metrics are used. In those cases, holistic assessments are made. ${ }^{24}$ If quantitative metrics are used, as in the case of Gong and Janssen's work, the metrics are weighted, summed, and compared between organizations (e.g. between two market competitors). ${ }^{25}$ However, the subjective nature of weighting and conversion to comparable units are acknowledged by them to be methodological shortcomings of this approach.

All of the six metrics used for this assessment are quantitative and can be weighted and combined to produce a summative assessment. However, this is not ideal. Weighting the metrics would entail making subjective judgments about the relative importance of each metric. Those subjective judgments would be hidden under the imprimatur of quantitative rigor assumed by a single summative assessment. Combining the metrics without weighting is also inappropriate. The units of measurement for the chosen metrics

22

${ }^{23}$ Su Chang Pete Modigliani, Defense Agile Acquisition Guide: Tailoring DoD IT Acquisition Program Structures and Processes to Rapidly Deliver Capabilities: The MITRE Corporation, 14-0391, March, 2014.

${ }^{24}$ Murarka Shaarabh.

${ }^{25}$ Marjin Janssen Yiwei Gong, "Measuring process flexibility and agility," in Proceedings of the 4th International Conference on Theory and Practice of Electronic Governance (Beijing: ACM, 2010). 
are not directly comparable. Combining them would assume a subjective judgment that the metrics are equally important to one another and again hide that fact under the guise of quantitative rigor.

Therefore, I will use a hybrid summative assessment approach that makes its subjective nature explicit, while preserving some of the precision gained by collecting quantitative metrics. Since this research is interested in examining flexibility over time, I will examine the change in each metric over time. The unit of measurement will remain the same, since each metric will be compared to itself. I will then holistically assess the direction of those changes across all six metrics. This will ensure that the summative assessment will make best use of the quantitative nature of the individual metrics while explicitly acknowledging methodological shortcomings.

\section{Identifying Policies for Assessment}

To apply the metrics to defense acquisition policies, I first had to identify policies that were relevant to procurement investment flexibility. I began by using the DSB's 2009 study on the fulfillment of urgent needs. The DSB identified over 25 policies, organizations, and processes that are relevant to urgent needs. ${ }^{26}$ Since I am interested in policies, I focused on the seven rapid acquisition policies identified in that study - two joint policies and a policy for each service (the Army had two policies).

\section{Legislative Context}

Although I focus my analysis on the DoD's policies for procurement flexibility, it is also important to briefly discuss the legislative context under which these policies exist. This context is best understood as the way the $\mathrm{DoD}$, a department of the executive branch, interprets and implements statutes passed by Congress. ${ }^{27}$ For this research, I reviewed sections of the annual National Defense Authorization Act (NDAA) between 2002 and 2012 because they contain language that is relevant to the DoD's ability to shift between immediate and long-term investments.

Two sections in the 2003 and 2005 NDAA discuss short-term investments in the form of rapid acquisition. The 2003 NDAA directed the Secretary of Defense to enact procedures to enable joint rapid acquisition of items "urgently needed to react to an

\footnotetext{
${ }^{26}$ Defense Science Board, Report of the Defense Science Board Task Force on the Fulfillment of Urgent Operational Needs, July 2009,

${ }^{27}$ Georgetown University Law Center, "Overview of Administrative Law Sources," (Washington, D.C.: Georgetown University Law Center, 2014).
} 
enemy threat. ${ }^{, 28}$ It also specified that these procedures streamline communications between internal DoD stakeholders as they propose, prioritize, and procure rapidlyneeded items. The 2005 NDAA gave the Secretary of Defense the authority to waive the normal acquisition requirements to meet urgent needs. It also allowed him to move up to a total of $\$ 100$ million annually from any DoD budget activity to rapidly procure items, without prior Congressional approval. These authorities are collectively known as rapid acquisition authority (RAA) ${ }^{29}$

The collective implication here is that the $\mathrm{DoD}$ was given latitude at the statutory level to shift between immediate and long-term investments. The legislation highlights congressional intent to give more attention and weight to short-term investments. The language used implicitly empowers the DoD to consider the widest range of solutions of immediate procurement needs, including investments in new technologies not yet available to the government or commercially. Lastly, the legislation's specific authority granted to the DoD to reprogram significant amounts of funds within any part of its budget (even beyond procurement) to meet its immediate needs is significant. To put it into context, the amount that the DoD was allowed to reprogram without prior Congressional approval in 2005 was greater than the individual amounts that the DoD requested for the F-22 Raptor, C-17A, the Army Family of Heavy Tactical Vehicles (FHTV), and the V-22 Osprey in that year. ${ }^{30}$ Normally, prior congressional approval is required to reprogram $\$ 10$ million for an existing procurement program or $\$ 2$ million for a new program. ${ }^{31}$ The magnitude of the amount of reprogramming authority given to the Secretary of Defense showed how seriously Congress believed rapid acquisition and immediate investments to be.

\section{Assessment Results}

With this wide statutory latitude in mind, I next discuss the level of investment flexibility in the DoD policies reviewed according to the framework developed herein. Full details of the reviews, organized by component (e.g., joint, Army, Navy, etc.) can be found in Appendix A.

\footnotetext{
28 Bob Stump National Defense Authorization Act for Fiscal Year 2003. PL 107-314.

${ }^{29}$ Ronald W. Reagan National Defense Authorization Act for Fiscal Year 2005. PL 108-375.

${ }^{30}$ See Office of the Under Secretary of Defense (Comptroller), "Procurement Programs (P-1), Department of Defense Budget Fiscal Year 2005," (Washington, D.C.: 2004). Although these programs are worth more than the $\$ 100$ million reprogramming authority over their life of their procurement, it is still a useful yardstick to measure the magnitude of the authority given to DoD by Congress.

${ }^{31}$ Department of Defense, "DoD 8000.14-R DoD Financial Management Regulation," (2011).
} 


\section{Policy Pathways for Acquisition}

To assess the metric of the number of pathways to rapid acquisition, I collected all versions of the policies for the timeframe of interest (2002-12). I found the most current versions of the policies on official websites and older versions on the Defense Technical Information Center (DTIC). Finally, I contacted Air Force acquisition officials, who provided me with old versions of Air Force rapid acquisition policies. In total, I collected 23 different versions of the seven policies under investigation (see Figure 1.1).

Figure 1.1: DoD Rapid Acquisition Policies

\begin{tabular}{ll}
\hline Organization & \multicolumn{1}{c}{ Policy } \\
\hline Joint & DEPSECDEF Memo (Sept 3, 2004), Meeting the Immediate \\
& Warfighter Needs \\
- & OSD Memo (Sept 10, 2004), Meeting the Immediate Warfighter \\
& Needs \\
- & DEPSECDEF Memo (June 27, 2004), Joint Improvised \\
& Explosive Device (IED) Defeat \\
- & DoDD 2000.19 (June 27, 2004), Joint Improvised Explosive \\
& Device (IED) Defeat \\
- & CJCSI 3470.01 (July 15, 2005), Rapid Validation and \\
& Resourcing of Joint Urgent Operational Needs (JUONS) in the \\
& Year of Execution \\
- & DoDD 2000.19E (Feb 14, 2006), Joint Improvised Explosive \\
& Device (IED) Defeat \\
- & DoDD 5000.71 (Aug 24, 2012), Rapid Fulfillment of Combatant \\
& Commander Urgent Operational Needs \\
- & AR 71-9 (Apr 30, 1997), Material Requirements \\
- & Rapid Equipping Force Streamlined Acquisition Process \\
& Presentation (Oct 27, 2005) \\
- & AR 71-9 (Dec 28, 2009), Warfighting Capabilities Determination \\
- & SECNAVINST 5000.2B (Dec 6, 1996) Implementation of \\
& Mandatory Procedures For Major and Non-Major Defense \\
& Acquisition Programs and Major and Non-Major Information \\
& Technology Acquisition Programs \\
- & SECNAVINST 5000.C (Nov 19, 2004), Implementation and \\
& Operation of The Defense Acquisition System and The Joint \\
& Capabilities Integration and Development System \\
Army &
\end{tabular}




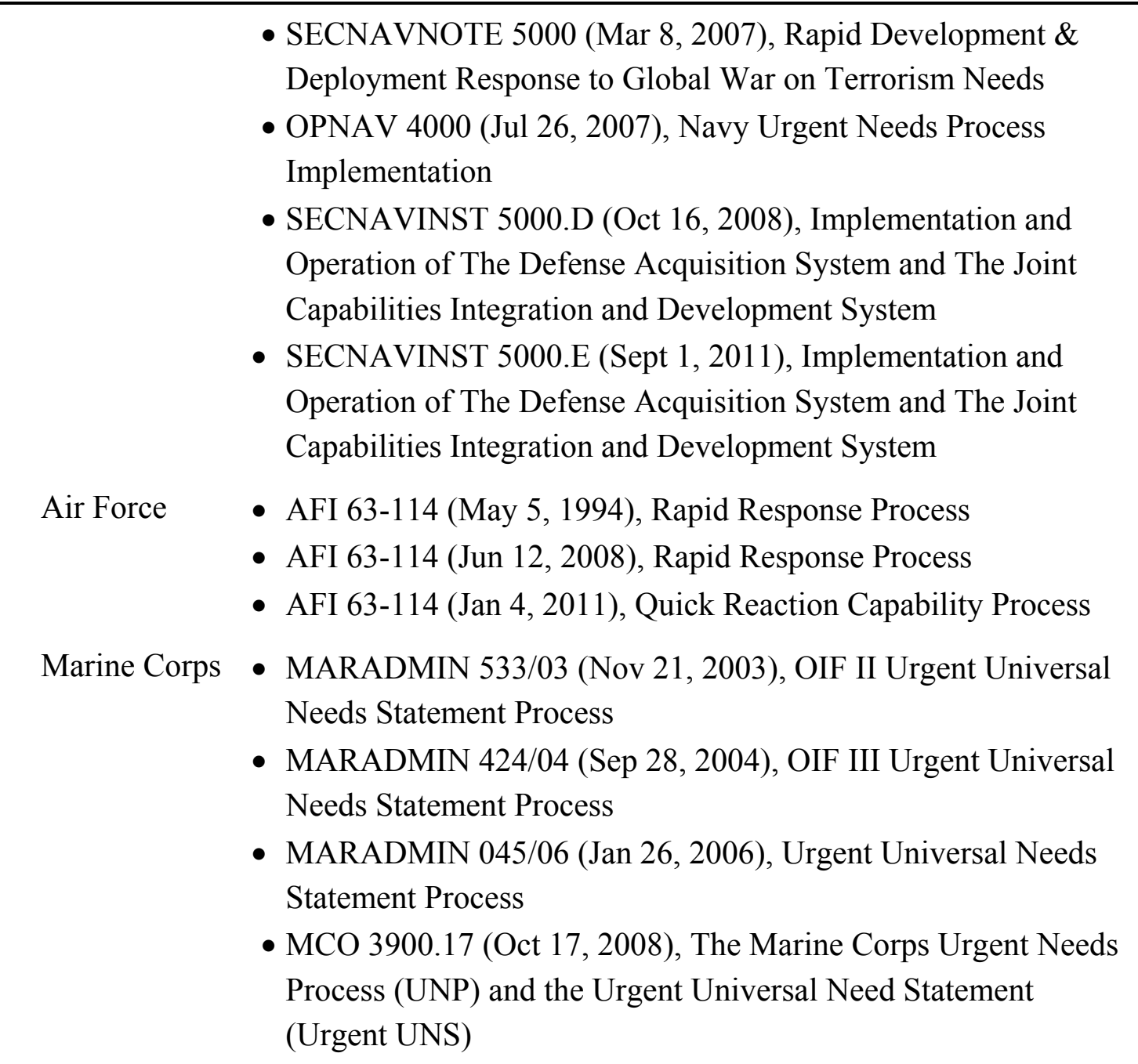

Between 2002 and 2012, the number of pathways to rapid acquisition increased considerably. Three of the four services had a policy to address immediate needs in place prior to 2002. The Marine Corps instituted a rapid acquisition policy in 2003. A joint policy and a second Army policy (the Rapid Equipping Force) were added in 2005.

These policies were revised over time, becoming increasingly more specific. Policies in 2002 and prior were uniformly vague and not specific about roles, authorities, and specific processes for identifying, validating, prioritizing, and implementing immediate needs. It appears that as OIF and OEF progressed and the need for rapid acquisition to address capability gaps increased, these policies were put to more frequent use. That frequent use revealed gaps, ambiguities, and areas for refinement, resulting in the numerous revisions depicted in Figure 1.1. For example, the 1994 version of the Air Force Rapid Response Process (RRP) provide no guidance on the commencement of rapid acquisition programs that cannot be tied to existing programs, requiring 
Congressional notification. The 2008 version of the policy established provisions including the notification of the Chief of Staff of the Air Force (CSAF) in certain cases and provides guidance to program officers on which programs require Congressional notification. ${ }^{32}$ With the exception of the Army's Operational Needs Statement (ONS) process, each service revised its rapid acquisition policies between three to five times from 2002 to $2012 .{ }^{33}$ Revisions generally made timelines, responsibilities, and processes clearer.

No joint policies for immediate needs existed, possibly because unforeseen capability needs were assumed to be too small to require a joint approach. This is implied in the language of the four service policies at the beginning of the timeframe, which all assume that unforeseen capability needs would be small. For example, the Air Force's policy in place in 2002 (and written in 1994) states that rapid acquisition proposals should first seek funding within the major command (MAJCOM, or the 3-star and 4-star commands that are Air Force equivalents to geographic and functional combatant commands) before requesting Headquarters Air Force assistance in identifying other sources for possible funding. ${ }^{34}$ Similar language exists in Army and Navy policies at that time. This implies that policymakers assumed that rapid acquisition needs would be very small and would not likely require joint coordination. It was not until 2004 that the first joint rapid acquisition policies were developed (presumably as a result of the 2003 NDAA). It appears that these joint policies drew from the lessons of their more mature counterparts in the individual services, since the first version of the joint policy was far more specific than the pre-2002 service policies.

\section{Minimum Speed of Performance}

Most policies required the agencies responsible for approving rapid acquisition needs to validate or turn down a request within two weeks of submission. This requirement was generally present prior to 2002 and remained true through 2012 . The exception to this is the Marine Corps UUNS policy, which never specified a time for response.

Although validation is only the first step towards making an actual, immediate investment, stipulating a response deadline is important. Validation is a critical step in the

\footnotetext{
32 Department of the Air Force, "Air Force Instruction 63-114: Rapid Response Process," (1994), _ "Air Force Instruction 63-114: Rapid Response Process," (2008).

${ }^{33}$ The Army only revised its ONS policy once during the timeframe in question in 2009. This may be because the focus of Army rapid acquisition was on the Rapid Equipping Force (a separate policy that came formally into being in 2005) and was intimately involved in the IED Task Force, which eventually became the Joint IED Defeat Organization (JIEDDO), one of the two joint policies examined herein.

${ }^{34}$ Department of the Air Force, "Air Force Instruction 63-114: Rapid Response Process," (1994).
} 
conventional and rapid acquisition process that commits the procuring organization to finding a solution to the request. In essence, action by the service or joint rapid acquisition authority is assured after validation. For rapid acquisition, a fast validation decision (either validating or turning down the request) is almost as important as the overall speed of performance of the system generally, because it commits the organization to a solution.

There is more variation in the overall speed of performance, from the receipt of the request to fielding and sustainment. This ranges from 60 days (Marine Corps UUNS process) to 270 days (Navy RDD process) for the full process. Curiously, timeframes for earlier policies sometimes required a shorter performance speed than later iterations of the same policy; some policies also did away with specific performance speeds outside of validation altogether. For example, the Army ONS policy in 1997 stated that an initial course of action would be developed within 120 days of validation. ${ }^{35}$ When the policy was updated in 2009, it stated that an initial response was due in 14 days, but that the ultimate solution would depend on the complexity of need. ${ }^{36}$

These shifting performance speeds may indicate an inconsistent level of flexibility across the DoD in making immediate investments. However, it is more likely that the DoD's understanding of what constituted an immediate investment matured and grew more nuanced over time. Prior to 2002, all rapid acquisition policies focused on technologically-mature solutions that could be quickly procured, once a rapid acquisition requirement was validated. As the wars in Iraq and Afghanistan went on, more capability gaps were identified. Some of these (such as tactical electronic defensive attack or tactical biometric identity validation) required new technologies and consequently more time. The uniformly fast validation deadlines and varying system-wide performance speeds may be a reflection of that need to develop new technologies.

\section{Maximum Funding Allowed}

There was very little consistency in the collected policies about the maximum funding level allowed. Three policies (Army REF, Navy RDD, and JIEDDO) had their own budget lines in policy. ${ }^{37}$ The 2005 version of the joint policy noted that it applied to ACAT II or equivalent programs, meaning that the maximum funding should be $\$ 835$ million (in 2012 constant dollars). However, the next iteration of the policy in 2012

35 Department of Army, "Army Regulation 71-9: Materiel Requirements," (1997). 36 , "Army Regulation 71-9: Warfighting Capabilities Determination," (2009).

37 Although the Navy RDD policy specifies that it would have its own budget, a review of the FY2002-12 budget requests does not show any line for this program. 
omitted any mention of the ACAT II ceiling. The remaining policies did not mention maximum funding at all.

\section{Level of Secured Funding}

Only three policies (Army REF, Navy RDD, and JIEDDO) mentioned dedicated funding sources in the DoD budget. However, no funding line was found for the Navy RDD program in FY02-12. Additionally, the joint policy had a budget line in the FY0810 budget request, but was repeatedly denied by Congress and was dropped in the FY11 budget. $^{38}$

The amount of secured funding for these policies varied widely. Figure 1.2 depicts REF, JIEDDO, and joint budget requests from FY02-12, comparing it to the M-1126 Stryker procurement request for the same period. The Stryker is an ACAT I program and is depicted to provide context for the relative size of the other three funding levels. Figure 1.2 shows that the joint and REF budgets are not very significant in comparison to the Stryker budget. However, the JIEDDO budget is roughly comparable to the Stryker budget, exceeding it in 2009, 2011, and 2012. ${ }^{39}$

The remaining policies do not have dedicated budgets, implying that funding for these policies depends on transferring funds from other budget line items (a practice known as reprogramming). This required those responsible for managing rapid acquisition programs to seek out funding sources for reprogramming and enlist enough stakeholder support to overcome any objections from the losing program and its supporters to reprogram the funds. Reprogramming is not a simple process and requires significant effort on the part of rapid acquisition program officers to see it through to completion.

Over time, each policy provided more guidance on how to seek out funds for reprogramming. For example, the Army ONS and Air Force policies in 2002 vaguely discouraged requesters who did not have their own budgets to reprogram. By 2005 though, most policies used neutral language about reprogramming, and by 2012, some policies provided suggestions for areas to look for funding (e.g., the Joint IED Defeat Fund, supplemental budgets, etc.). Nevertheless, reprogramming is a complicated procedure that requires an internal consensus to be reached within the $\mathrm{DoD}$ (or an

${ }^{38}$ Shawn McKay Isaac R. Porche III, Megan McKernan, Robert W. Button, Bob Murphy, Kate Giglio, Elliot Axelband, Rapid Acquisition and Fielding for Information Assurance and Cyber Security in the Navy, ed., Santa Monica, RAND Corporation, 2012.

39 The JIEDDO budget includes four separate budget line items: Attack the Network, Defeat the Device, Train the Force, and Operations. 
individual military service) to shift funds from an existing program to a rapid acquisition one.

Figure 1.2.: Secured Funding Levels (FY12 \$m)

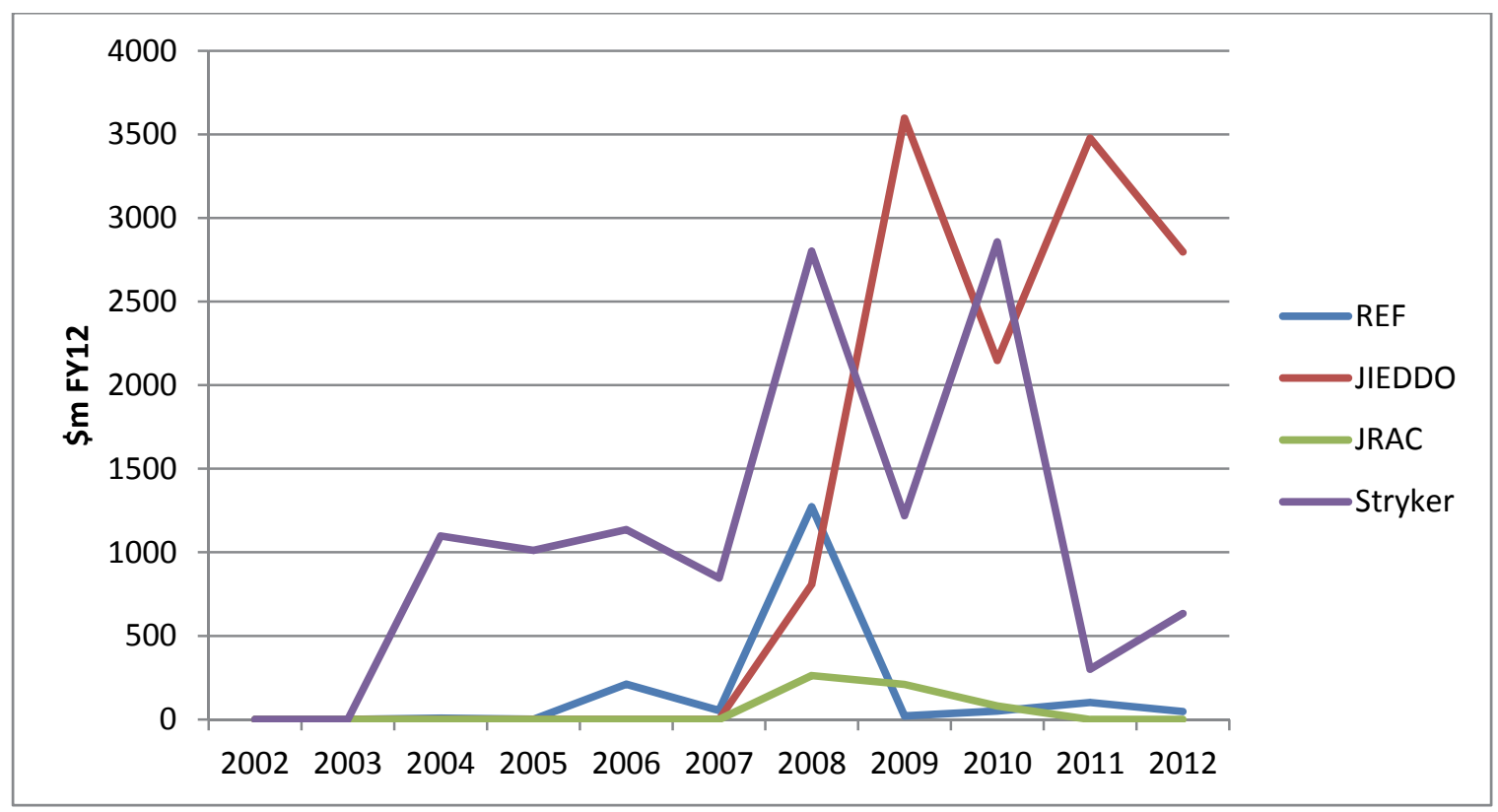

Source: Author analysis of DoD procurement documents

When considering all factors, the level of secured funding for the DoD's immediate investments is not significant and only concentrated in its IED defeat efforts. Although there are many investments that can be linked to IED defeat, that restriction is still one that does not contribute to the DoD's ability to shift between immediate and long-term investments.

\section{Senior Leader Attention Required}

In regard to senior leader attention, the services divide into two distinct camps. The Army ONS and Marine Corps UUNS policies empower O-9 (lieutenant general, or "three star" general officers) level capability development entities to approve or turn down urgent needs requests. Army REF policy further delegates this authority to the O-6 (colonel) level. The Navy and Air Force require higher authorities to be involved in the approval process. The Navy requires the civilian Assistant Secretary of the Navy for Research, Development, and Acquisition, or ASN(RD\&A), to approve requests. The Air Force requires approval by its Rapid Response Policy Council chaired by an O-9 or civilian equivalent. Additionally, it requires the Chief of Staff (the highest-ranking uniformed officer in the Air Force) to be informed of approvals and requires him to 
confirm disapprovals. For all the services, these policies for required senior leader attention have remained constant over time. ${ }^{40}$

The joint process also requires a high level of senior leader attention. The original 2005 policy required two Undersecretaries of Defense (Comptroller and Acquisition, Technology, and Logistics) to approve joint urgent needs. This was elevated in 2012 with the addition of the Senior Integration Group (SIG) for oversight. The SIG is chaired by the Deputy Secretary of Defense, the second-highest civilian in the Department of Defense.

It appears that there is a consistent trend in requiring high (O-9) and very high (senior service and DoD leaders) to be part of the process for shifting in between immediate and long-term investments. Yauch and Dove would argue that this indicates a low level of institutional flexibility.

\section{Number of Approvals Required}

The number of approvals required varied widely across the policies and over time. For some policies (Army REF and ONS, Marine Corps UUNS), two to four sets of approvals are required and requests can be originated at a relatively low level (O-6 for ONS and UUNS, any soldier for Army REF). Joint, Navy, and Air Force processes require eight to twelve approval steps. Furthermore, the number of approval steps shifted over time. The Air Force policy grew from seven to twelve steps between 1994 and 2008. The Army ONS process went from two steps to three.

The operational contexts of the Navy and Air Force explain why the numbers of approvals are higher for those processes. Highly technical and complex systems are an integral part of each service. New equipment made through rapid acquisition processes will require greater integration with these systems, necessitating more stakeholders (such as test and evaluation organizations) to participate, leading to more steps in the processes. This also explains the growth in the number of steps in the Air Force process.

The joint process also requires more approvals, because of the wide-ranging nature of DoD-wide rapid acquisition programs. The joint process fulfills the rapid acquisition needs of multiple services, requiring more stakeholders in the process. These do not just include the services that train and equip forces; it requires input from the combatant

\footnotetext{
${ }^{40}$ Specifically, the titles and organizations change, but the levels of authority represented by those various individuals, offices, and organizations do not.
} 
commanders as well. The higher number of stakeholders means that there are more approvals that need to be made.

The growth in the number of steps in the Army process from two to three is due to the loose definitions for each step in the 1997 policy. The second step of the 1997 process states that the Office of the Deputy Chief of Staff for Operations (ODCSOPS) will staff the ONS request "within [Headquarters Department of the Army]" but does not specify how that staffing process in HQDA will proceed. ${ }^{41}$ The 2009 revision added a third step that gives more details to that staffing process.

Lastly, investigation of the approvals required showed that the level at which rapid acquisition requests can be submitted varies. The JUONS process requires requests to originate from the $\mathrm{O}-10$ combatant commander. Other policies either imply or state that any servicemember can initiate a request, but that a senior leader is required to endorse the request. Figure 1.3 describes the current paths to initiation:

Figure 1.3: Rapid Acquisition Initiating Authorities

\begin{tabular}{ccc}
\hline Process & Initiator & Endorsements Required \\
\hline JUONS & Combatant Commander & None \\
Army ONS & Any (implied) & O-6 in chain of command \\
Army REF & Any & None \\
Navy UON & Any (implied) & Flag officer in chain of \\
command \\
Marine Corps UUNS & Any & COMMARFOR (O-9) \\
Air Force QRC & Any (implied) & Needs to be submitted by \\
& & COMAFFOR (O-9)
\end{tabular}

\section{Summative Assessment}

To complete this assessment of the DoD's policy flexibility to make immediate and long-term investments, I will make a two-part summative assessment. First, I will assess

${ }^{41}$ Department of Army, "Army Regulation 71-9: Materiel Requirements," (1997). 
the changes in each metric individually over time, to determine if each individual metric provided for more flexibility, less, or remained the same. I will then make a holistic assessment of the policies based on the overall direction of the changes in the individual metrics.

Assessing the six metrics over time shows that flexibility improved unevenly over time. Half of the metrics (pathways to rapid acquisition, maximum funding allowed, and level of secured funding) increased, indicating increased flexibility. Two metrics (minimum performance speed and number of approvals required) increased, indicating decreased flexibility according to the framework definitions. The last metric (senior leader attention required) remained unchanged. Figure 1.4 summarizes these findings.

Figure 1.4: Flexibility Metric Changes Over Time (2002-12)

\begin{tabular}{|c|c|c|}
\hline Metric & Change & Assessment \\
\hline $\begin{array}{l}\text { Policy pathways to rapid } \\
\text { acquisition }\end{array}$ & $\begin{array}{l}\text { Increased from } 3 \text { pathways } \\
\text { to } 7\end{array}$ & Increased flexibility \\
\hline $\begin{array}{l}\text { Minimum speed of } \\
\text { performance }\end{array}$ & $\begin{array}{l}\text { Increased from } 60-270 \text { days } \\
\text { for completion to undefined } \\
\text { timeline }\end{array}$ & Decreased flexibility \\
\hline Maximum funding allowed & $\begin{array}{l}\text { Increased from suggested } \\
\text { limit of } \$ 835 \mathrm{~m} \text { to no defined } \\
\text { limit }\end{array}$ & Increased flexibility \\
\hline Level of secured funding & $\begin{array}{l}\text { Increased from no secured } \\
\text { funding to three policies } \\
\text { with total of } \$ 5 \text { bn funding in } \\
\text { FY08-10. Fell to } \$ 3.5 \text { bn in } \\
\text { by FY12. }\end{array}$ & Increased flexibility \\
\hline $\begin{array}{l}\text { Senior leader attention } \\
\text { required }\end{array}$ & No change over time & No change in flexibility \\
\hline $\begin{array}{l}\text { Number of approvals } \\
\text { required }\end{array}$ & $\begin{array}{l}\text { Air Force increases from } 7 \\
\text { to } 12 \text { steps, Army increases } \\
\text { from } 2 \text { to } 3 \text { steps. }\end{array}$ & Decreased flexibility \\
\hline
\end{tabular}


Based on these findings, I conclude that DoD policy provides for flexibility in specific situations. Increasing flexibility in three metrics (pathways to rapid acquisition, maximum funding allowed, and level of secured funding) show that the DoD increased the policy space for rapid acquisition and removed any policy caps on the maximum amount of funding allowed and appropriated to rapid acquisition programs. This is clear evidence of increasing flexibility.

The metrics that point to decreased flexibility or remain unchanged should not be considered simply as impediments to flexibility in shifting between immediate and longterm investments. Rather, they should be considered as checks and balances to the three metrics that showed increasing flexibility. Consistently high senior leader attention ensures that rapid acquisition ideas are brought to the attention of the top of the organization. Instead of an indication of inflexibility (as Yauch and Dove would argue), it actually highlights the importance of rapid acquisition to DoD leadership at the highest levels.

The increased minimum performance speed and slight increase in the number of approvals necessary also point toward sensible checks and balances to the increased funding and pathways to acquisition. These increases can be strictly interpreted as impediments to a faster, more agile rapid acquisition enterprise. They can also be interpreted as sensible accommodations to the wide variety of unforeseen needs that rapid acquisition processes were attempting to address. Some of those needs could not be fulfilled through existing and technologically-mature solutions. Some capability solutions required significant development and testing. Therefore, increases in these metrics is not the hallmark of a slower, less agile organization, rather an indication that the DoD was admirably open to considering a wider range of solutions for rapid acquisition requests.

\section{Conclusion}

Do the DoD's policies provide flexibility in shifting between immediate and longterm procurement investments? Using the metrics culled from organizational management literature, we find that:

- The DoD increased the pathways to rapid acquisition.

- The policies emphasized speed in validating urgent needs, but remained otherwise ambiguous about the speed at which each pathway performed overall

- Some funding for rapid acquisition was allocated. For other cases, policies for shifting funds implied the need for program officers to identify funding sources and gain buy-in for reprogramming for all pathways except REF and JIEDDO. 
- All pathways except REF required senior (O-9 or civilian equivalent and above) leaders to be actively involved in approving or turning down urgent needs.

- Steps to approval varied by service, based on assumptions by policymakers about how technologically complex most requests would be.

- All pathways except REF required O-6 or higher entry to the system.

Overall, I found that $\mathrm{DoD}$ increased the flexibility for shifting between long-term and immediate investments while balancing the need for senior leader attention and an increasingly wide conception of what rapid acquisition could be utilized for. In the next chapter, I will examine the extent to which this policy flexibility was used. 


\section{Chapter Two: Immediate Investments in the DoD Procurement Budget}

Chapter One established that DoD rapid acquisition policies clarified procedural ambiguities and helped stakeholders to communicate better in order to create an environment more favorable to immediate investments. To evaluate the efficacy of those policy changes, I will examine the DoD procurement budget for evidence of increased spending on immediate investments.

In addition to the first research question, the second research question and hypotheses will guide this analyses:

RQ2: How did the balance change between immediate and long-term investments in the Defense Department, across services and types of weapons, during the wars in Iraq and Afghanistan?

This chapter will begin by discussing the utility of examining the budget for evidence of increased investment in immediate procurement needs. I will then define long-term and immediate investments by examining existing definitions and proposing new ones that capture the nuance and variety of the DoD's investments. Lastly, I will examine the DoD's procurement budget for FY02-12 for evidence of increased immediate investments by categorizing budget line items using the proposed definition.

\section{Using Budgets to Measure the Effect of Policy Changes}

There are three reasons to use budgets to examine the effect of policy changes. First, budgets reveal the true preferences of any organization. In his seminal work on the federal budget process, Wildavsky noted that budgets represent an organization's internal consensus of the relative merits of its priorities. ${ }^{42}$ In his words, budgets "lie at the heart of the political process." 43 Although American public institutions (and especially the DoD) regularly develop and publish strategies, white papers, and other documents that describe organizational priorities, the budget reveals true preferences by showing where the money to actualize those stated priorities goes.

\footnotetext{
42 Aaron Wildavsky, The New Politics of the Budgetary Process. Second ed., New York, Harper Collins, 1992.

43 , ed.
} 
This is particularly relevant as we examine budgets for evidence of the DoD's ability to shift between immediate and long-term investments. Chapter One demonstrated that the DoD created more opportunities for making immediate investments by establishing and refining a set of seven rapid acquisition policies. Examining budgets provides a way to make precise, quantitative assessments of the efficacy of those policy changes.

Second, the nature of defense budgeting and its emphasis on long-term investments mean that deviations from this preference are indicative of the shifts that I seek to detect. Wildavsky observed that budgets are constructed incrementally. He argues that budgets represent an internal consensus on priorities for government organizations. That consensus may take great effort to achieve. Consequently, policymakers prefer to make only incremental changes to the budget during any given year, all other factors being equal. Larger shifts will disrupt the established consensus. Therefore, any changes (or new immediate investments to the budget) that do appear would be a clear sign of a shift between long-term and immediate investments.

This is especially true of the DoD, which emphasizes long-term priorities and investments more than other departments of the federal government. The DoD plans its budgets in five-year increments. In addition to the annual budget requests that it submits to Congress, it uses the Planning, Programming, Budgeting, and Execution (PPBE) system to make preliminary five-year plans (Future Years Defense Plans, or FYDPs) for its budgets. These FYDPs provide stability and predictability in resource expenditure. Changes to the FYDP can occur from year to year, but these are usually marginal. Any deviations from this norm would indicate external influence on the budget process, such as budget cuts imposed by Congress, or emerging threats that require the DoD to make immediate investments.

Lastly, the expensive weapons that make up significant portions of the defense budget tend to have long expected service lives, ranging from 20 to even 50 years. These weapons are either high-risk ventures that require long lead times for RDT\&E and production (such as aircraft like the F-35 Joint Strike Fighter) or are meant to be purchased on a large scale (such as the Army's fleets of light, medium, and heavy trucks). Schick observed that this tendency to make long-term investments is true even as the speed of technological innovation and obsolescence has quickened. ${ }^{44}$ In any case, the tendency for the DoD to make long-term investments means that evidence of immediate

${ }^{44}$ Allen Schick, The Federal Budget: Politics, Policy, Process, ed., Washington DC, Brookings, 2007. 
investments in the budget will be significant to our understanding of the DoD's ability to balance the need for those investments and long-term ones.

For these reasons, examining the DoD procurement budget is a powerful way to identify shifts between long-term and immediate investments. As previously established, budgets provide one of the most reliable measure of a government organization's priorities. Furthermore, the nature of defense budgeting and its known emphasis on longterm investments conveniently gives us a particularly sensitive measure of shifts between investment priorities.

It would be ideal to examine the efficacy of changes in rapid acquisition policy directly, through documentation that accompanies those changes. Unfortunately, complete and reliable documentation of rapid acquisition efforts does not exist. ${ }^{45}$ The GAO and the Joint Rapid Acquisition Cell (JRAC) have both observed that rapid acquisition authorities did not do an adequate job of documenting their efforts, making it difficult to estimate what investments were made. ${ }^{46}$ The DoD budget offers a complete record of investment activity available, although it will require some effort to develop a framework to identify and categorize the data. This effort will be discussed in the next section.

\section{Methodology}

In this section, I begin by discussing why existing definitions of immediate investments are not sufficient for this research. I will then present a definitional framework to analyze DoD budget data. Lastly, I describe the steps taken to prepare and sort my data set.

\section{Defining Immediate and Long-Term Investments}

Two definitions for immediate and long-term investments exist in the DoD. The DoD Financial Management Regulation (FMR) defines immediate investments (or expenses, as they are referred to) as "costs incurred to operate and maintain the organization, such as personnel services, supplies, and utilities." The FMR goes on to define long-term investments (known simply as investments in the FMR) as "costs that result in the acquisition of, or an addition to, end items. These costs benefit future periods and

\footnotetext{
45 I did obtain a complete record of Marine Corps urgent needs requests embedded in their OEF retrograde plans. However, these records only show items that were in theater at the time that retrograde began in 2012.

${ }^{46}$ Government Accountability Office and Joint Rapid Acquisition Cell, Jan 142014.
} 
generally are of a long-term character such as real property and personal property."47 The FMR then aligns budget accounts (personnel, operations and maintenance, etc.) with expense, investment, or mixed characterizations.

A second definition for immediate investments can be inferred from the DoD rapid acquisition policies. These policies uniformly define immediate investments in terms of the consequences of not fulfilling a given request. For instance, the joint policy uses the term "urgent and compelling" to separate immediate investments from long-term ones. It defines urgent and compelling as a need that "[m]ust be addressed immediately in order to prevent either mission failure or combat-related loss of life." ${ }^{48}$ Similarly, the Marine Corps process states that an urgent need is characterized by adverse consequences, noting that "[f]ailure to deliver the capability requested by the Urgent UNS is likely to result in the inability of units to accomplish their missions or risks increased probability of casualties and loss of life." 49 The emphasis on the negative consequences of not fulfilling urgent needs is a consistent aspect of the DoD's implicit definition of an immediate investment.

While these definitions provide insight into the DoD's concept of immediate versus long-term investments, they are not precise enough to use for the purposes of this research. The FMR definition of an immediate investment focuses on the day-to-day running of the organization, but that does not necessarily include the cost of the OIF and OEF campaigns. The inferred definition of an immediate investment drawn from rapid acquisition policy is too broad. That definition can include almost any investment. Because the analysis of the budget will entail categorizing budget line items using these definitions, a mutually exclusive set of definitions is needed.

Since current definitions are too vague, a new set of definitions needed to be developed. I began by considering a sample of 15 acquisition programs and attempted to group them into distinct categories. ${ }^{50}$ I then defined those categories, resulting in six distinct types of investments of varying levels of immediacy (Figure 2.1).

\footnotetext{
47 Department of Defense.

48 Department of Defense, "CJCSI 3470.01 "RAPID VALIDATION AND RESOURCING OF JOINT URGENT OPERATIONAL NEEDS (JUONS) IN THE YEAR OF EXECUTION"," (2005).

49 United States Marine Corps, "MCO 3900.17: THE MARINE CORPS URGENT NEEDS PROCESS (UNP) AND THE URGENT UNIVERSAL NEED STATEMENT (URGENT UNS)," (2008).

${ }^{50}$ Those fifteen acquisition programs were: F-35 Joint Strike Fighter, M777 Lightweight Howitzer, Stryker Combat Vehicle, Command Post of the Future (CPOF), PRC-117G tactical radio, Chameleon RCIED jammer, M-32 Multiple Grenade Launcher, Theater Battle Management Core Systems (TBMCS), MQ-1B Predator, Mine Resistant Ambush Protected (MRAP) vehicle, MC-12 Liberty, Family of Medium Tactical Vehicles (FMTV), M1114 HMMWV, RQ-7 Shadow, and the M72 Light Anti-tank Weapon (LAW). These
} 
Figure 2.1: Six Categories of Acquisitions

\begin{tabular}{|l|l|l|l|l|l|l|}
\hline & $\begin{array}{l}\text { Long-Term } \\
\text { Acquisition }\end{array}$ & $\begin{array}{l}\text { Long-Term } \\
\text { (Expedited) }\end{array}$ & $\begin{array}{l}\text { Long-Term } \\
\text { (Recapitalization) }\end{array}$ & $\begin{array}{l}\text { Alternative } \\
\text { Acquisition }\end{array}$ & $\begin{array}{l}\text { Missed } \\
\text { Opportunity }\end{array}$ & $\begin{array}{l}\text { New } \\
\text { Opportunity }\end{array}$ \\
\hline Definition & $\begin{array}{l}\text { Accepted } \\
\text { capability need } \\
\text { procured } \\
\text { through normal } \\
\text { acquisition } \\
\text { practices. War } \\
\text { has no effect } \\
\text { on activity }\end{array}$ & $\begin{array}{l}\text { War drives an } \\
\text { accelerated or } \\
\text { increased } \\
\text { conventional } \\
\text { acquisition of } \\
\text { an accepted } \\
\text { capability need. }\end{array}$ & $\begin{array}{l}\text { War consumes } \\
\text { long-term } \\
\text { acquisitions. } \\
\text { Exact } \\
\text { replacements } \\
\text { are made. }\end{array}$ & $\begin{array}{l}\text { War drives rapid } \\
\text { acquisition of } \\
\text { an accepted } \\
\text { capability need } \\
\text { that is being } \\
\text { pursued } \\
\text { concurrently }\end{array}$ & $\begin{array}{l}\text { War drives rapid } \\
\text { acquisition of } \\
\text { previously } \\
\text { rejected } \\
\text { concept, } \\
\text { capability, or } \\
\text { level of need. }\end{array}$ & $\begin{array}{l}\text { War drives rapid } \\
\text { acquisition of a } \\
\text { new capability } \\
\text { not previously } \\
\text { considered }\end{array}$ \\
\hline Example & F-35 & Stryker & $\begin{array}{l}\text { Ammunition } \\
\text { replenishment }\end{array}$ & PRC-117G & MRAP & CREW \\
\hline
\end{tabular}

The six investment categories highlight the fact that the DoD is never fully at peace and is not often fully at war. Many previous studies of the DoD as a bureaucratic organization examined the DoD during peacetime and at war, noting that they were significantly different organizations. ${ }^{51}$ This binary distinction, however, is not relevant to the DoD during the period of 2001-2012 in which we are interested. Even though the DoD was conducting large-scale combat operations in Iraq and Afghanistan (i.e., the DoD was at war), it was still conducting much of its organizational functions as it would in peacetime. ${ }^{52}$ The need for six categories to examine DoD investments is a necessary consequence of the DoD's wide range of activities.

The first three categories define three types of long-term investments. Long-term acquisitions are investments that are made through the DoD's deliberate planning, budgeting, and acquisition processes. An example of this is the F-35 Joint Strike Fighter. Within long-term acquisitions, two subsets exist. Expedited acquisitions also have many characteristics of long-term investments, since they describe investments that were made with deliberation but spent more quickly than originally planned. An example of this is the Stryker combat vehicle, which was fielded faster than originally planned in order to outfit newly-reorganized Army brigade combat teams (BCTs) which were established earlier than planned in order to meet the manpower demands of OIF. ${ }^{53}$ Recapitalization

programs were chosen through individual research and consultation with DoD acquisition subject matter experts at the RAND Corporation.

${ }^{51}$ In particular, see Stephen Peter Rosen, Winning the Next War: Innovation and the Modern Military, ed., Ithaca, NY, Cornell University Press, 1991, James Q. Wilson, Bureaucracy: What Government Agencies Do and Why They Do It, ed., New York, Basic 1989.

52 This point is made frustratingly clear by former Secretary of Defense Robert Gates, who bemoaned that while individual troops and units were at war, the Pentagon (as a bureaucracy) was not. See Gates, ed.

${ }^{53}$ Department of Defense, "DEPARTMENT OF DEFENSE FY 2005 SUPPLEMENTAL REQUEST FOR OPERATION IRAQI FREEDOM (OIF), OPERATION ENDURING FREEDOM (OEF), AND OPERATION UNIFIED ASSISTANCE " (2006). 
acquisitions (or "recap" acquisitions) replace items that were expended in operations, such as ammunition and destroyed weapons systems. Collectively, these three types of acquisitions represent the DoD's long-term procurement investments.

The next three types of investments make up the definition of immediate investments. Alternative acquisitions fulfill capability needs that have already been expressed and agreed upon. The investment is an alternative means of achieving a capability need that the conventional defense acquisition system has not achieved quickly enough to meet an emerging need. An example of this pathway is the PRC-117G tactical radio, which gave the Army and Marine Corps communication capabilities that the long-term investment in JTRS could not deliver. ${ }^{54}$

Finally, the last two categories (missed and new opportunities) exhibit the least amount of longevity. Missed opportunities address a capability need that was previously deemed unnecessary, is unlikely to be needed at the level initially desired, or is otherwise rejected by the defense planning and budgeting process. This pathway is related to the planning and budgeting decisions that policymakers make based on likely threat scenarios. An example of a program in this pathway is the MRAP program. In 1999, the potential need for a mine-resistant specialty vehicle was identified by the Marine Corps, which saw an example of the MRAP in use in South Africa. This need was seen as one that was unlikely to be realized and was rejected until it was revisited by the field commanders in $2005 .^{55}$ Note that this pathway includes cases where defense policymakers did not anticipate the level of need for a capability (e.g., the unforeseen underestimation of the need for UAVs).

New opportunities represent capability needs that are rapidly acquired and were not been previously considered for acquisition through the conventional defense acquisition system. Again, the threat-based decision making process of policymakers is relevant to this scenario. Additionally, there may also be capability needs that simply cannot be foreseen until the onset of the next conflict. One example of this pathway to rapid acquisition is the Warlock CREW program to provide electronic jamming to counter remotely-detonated IEDs and similar iterations of it (e.g., Chameleon, Thor, etc.). ${ }^{56}$

Alternative, missed opportunity, and new opportunity investments are difficult to distinguish from one another in budget data, because their accompanying justification

\footnotetext{
${ }^{54}$ For details on this program, see Appendix B: PRC-117G Case Study

${ }^{55}$ For details, see Appendix E: MRAP Case Study

${ }^{56}$ For details, see Appendix F: CREW Case Study
} 
documents do not consistently include enough background information to make a determination. Therefore, they will be grouped as "AMN" investments in this chapter. The case study analysis in Chapter Three will provide enough background information to categorize a select number of investments for more detailed analysis.

\section{Applying the Framework to Data}

Using this framework of immediate and long-term investments, we can now apply it to a set of data. In this research, that data will include budget data to examine the DoD's overall balance of long-term and immediate investments. We will also apply this taxonomy to examine a sample of weapons systems in greater detail.

\section{Sample Timeframe}

These data will be examined for fiscal years (FY) 2002-12. During this ten-year period, the United States fought two protracted campaigns in Iraq and Afghanistan. During those two wars, the DoD was given the tremendous flexibility to shift between long-term and immediate investments. DoD budgets increased and were given equally tremendous leeway to meet immediate needs by Congress through supplemental budget requests and new reprogramming authorities. The DoD enacted policies that allowed immediate investments to be made, in the form of joint and service urgent needs processes. Lastly, the unconventional adversaries in both the Iraqi and Afghan theaters provided motivating factors for investing in immediate needs that were unforeseen. These factors make FY2002-12 the years in which shifts in the balance between long-term and immediate investments would be most apparent.

We chose not to examine FY2013 and 2014 procurement budgets for this research. Although the conflicts in Afghanistan were ongoing during those years, the restrictions of the 2011 Budget Control Act (BCA) set caps on the DoD's base budget from FY12 onward. ${ }^{57}$ This research includes the FY12 budget request because it was finalized before the onset of the BCA. Although OCO spending was not affected by BCA caps, we exclude post-BCA budget requests in order to concentrate on the actions and choices made by the DoD internally and to eliminate any possibility that the BCA caps did affect DoD budget choices.

\section{Information sources}

Budget data was exclusively drawn from DoD budget requests available on the Undersecretary of Defense's (Comptroller's) website. This data comes in two forms: base

${ }^{57}$ Budget Control Act of 2011. PL 112-25. 
and supplemental. Base budget data is part of the DoD's normal budgeting process and contains data broken down by component (one of the military services or a DoD agency), activity (aircraft, for instance), sub-activity (fighter aircraft, for instance), and individual line item. All information is presented in spreadsheets in current-year dollars (i.e. not adjusted for inflation).

Supplemental budget requests are not part of the regular budgeting process. These requests are for funds to meet emerging needs outside of the normal annual budget process. Traditionally, these funds would be requested only during the first year of military operations, natural disasters, or other emerging needs. These requests were submitted separately to Congress with less justification material and are customarily decided on quickly. Subsequent needs were traditionally included in the normal budget process, as was the case in the Korean and Vietnam Wars.

During the time period of interest however, the president submitted supplemental funding requests for each year of OIF/OEF. From FY2009 onward, the president also submitted these requests alongside the DoD's base budget request. For those years, supplemental requests were submitted with the same level of detail and justification as the base request and are presented in uniform spreadsheets. For years prior to FY2009, varying levels of detail are given. In some years (notably, FY2008), multiple supplemental requests were made. These requests are presented in narrative format.

\section{Favoring Request over Execution Data}

If the goal of this research is to characterize the balance between long-term and immediate defense investments, DoD budget execution (i.e. how the money is spent) data would be the most direct means to do so. However, this research uses DoD budget request data instead. This is because request data contains justification data that links budget amounts to rationales for spending. While execution data more closely represents what the DoD actually invested, it does not contain complete information on why it was spent. While execution data can be linked to the DoD request and its justification, that link would not account for factors that affected the execution of those funds that are not contained in the original justification.

Additionally, the object of this research is to understand the DoD's internal ability to balance between long-term and immediate investments. The introduction of external factors and stakeholders would distort my observations of the DoD in that regard. The lack of a logical link between request justification and execution and the possible distortion of the DoD's ability to balance investments may lead to inaccurate, overstated, 
or underestimated findings. To avoid such a possibility, this study strictly uses request data and justifications.

\section{Data Preparation and Methods of Analysis}

To prepare data for analysis, the raw procurement data downloaded from the OUSD $(C)$ website was merged and cleaned. First, I combined active and reserve procurement data for each year into one file. Next, I combined each year into one data file, ensuring that the data headers were aligned across years (the DoD changed header data three times during the sample time period). Lastly, I applied generic budget subactivity labels to each line item, to make budget sub-activities across services and DoD components comparable. For instance, the 20 different types of tactical ammunition (e.g. small arms ammunition, fuzesfuses, bombs, and missiles) were combined into a single ammunition sub-activity in order to capture sub-activity spending across the entire DoD.

Once the data was prepared, two methods were used to sort each budget line item into one of six acquisition categories. Supplemental budget line items were inspected individually. Each line item and its justification were examined to see which acquisition category it fit into. In cases where an individual line item contained sub-items that each fit into different categories, the whole line item was sorted into the category that contained the largest amount. While cases where the plurality of investments and the largest amount correspond to different investment types are possible, this was not observed.

For base budget items, a different approach was used. It is safe to assume that most line items in the base budget are long-term investments. Given that assumption and the large number of base budget items (up to 1,489 unique line items), only items that contained any one of seven keywords in their justification documents were examined. ${ }^{58}$ Line items that did not contain one of those keywords were categorized as long-term investments.

\section{Results}

In this section, I will examine the results of the budget analysis. First, I will examine DoD budget priorities by investment type (e.g. long-term expedited, expedited recap, and AMN). I will then examine DoD budget priorities by service and budget sub-activity.

\footnotetext{
58 Those keywords were: Iraq*, Afghan*, OIF, OEF, 9/11, contingency, and operation. The asterisks denote root words used in the search string.
} 
Generally, the policy flexibility that was observed in Chapter One was matched by a diversification in investments. Between FY04 and FY08, the DoD increased the proportion of its procurement budget devoted to AMN investments. Figure 2.2 shows this diversification by plotting investment types as a percentage of the entire procurement budget (represented in the vertical axis) over time (represented in the horizontal axis). This diversification declined after FY08 (after the large investment in MRAPs discussed below) and continued to taper off after FY09. This decline is probably not related to the OIF drawdown and OEF troop surge, rather it reflects the fact that immediate investment needs were greatest when troops in OIF and OEF first engaged the enemy and needed to address the capability gaps that their enemy was exploiting. This need tapered off over time, as shown in Figure 2.2.

Figure 2.2: Percent of Long-Term and Immediate Investments to Total Procurement Request

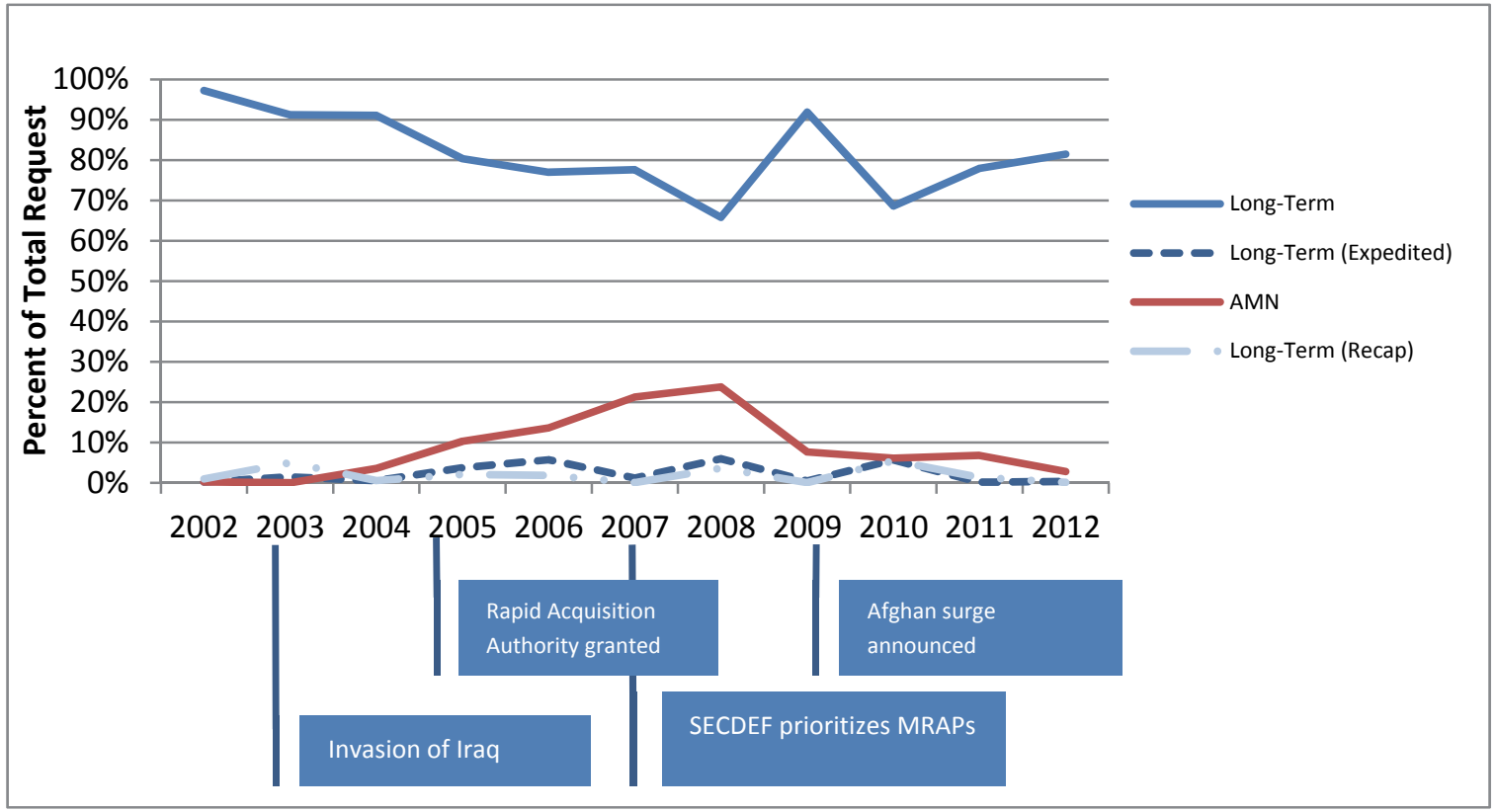

Source: Author analysis of DoD budget justification documents

AMN investments reached a high point in FY08, when they made up 24\% of all procurement spending. Interestingly, expedited and recap investments never comprised more than $6 \%$ of the total procurement budget. This may indicate that the DoD judged that existing modernization plans could not be expedited to meet the demands of OIF/OEF. Rather, immediate investments that were not part of the PPBE process would be needed. 


\section{Analysis of Army and Marine Corps Immediate Investments}

The analysis of investment types across the DoD in Figure 2.2 obscures different balances of immediate and long-term investments within the services. Figure 2.3 depicts AMN investment as a percentage of all procurement investment for each service, over time. In Figure 2.3, we see that Army and Marine Corps AMN investments exceeded our hypothesized estimate for several years during our time period of interest. The Army's AMN investments exceeded the higher bound of our hypothesis $(25 \%)$ of their entire procurement budget in FY06 and FY08. The Marine Corps exceeded 25\% FY05-07. In fact, AMN investments made up the majority of the Marine Corps' total budget for two years: FY05 and FY07.

Figure 2.3: Army and Marine Corps Percent of AMN Investment to Procurement Total

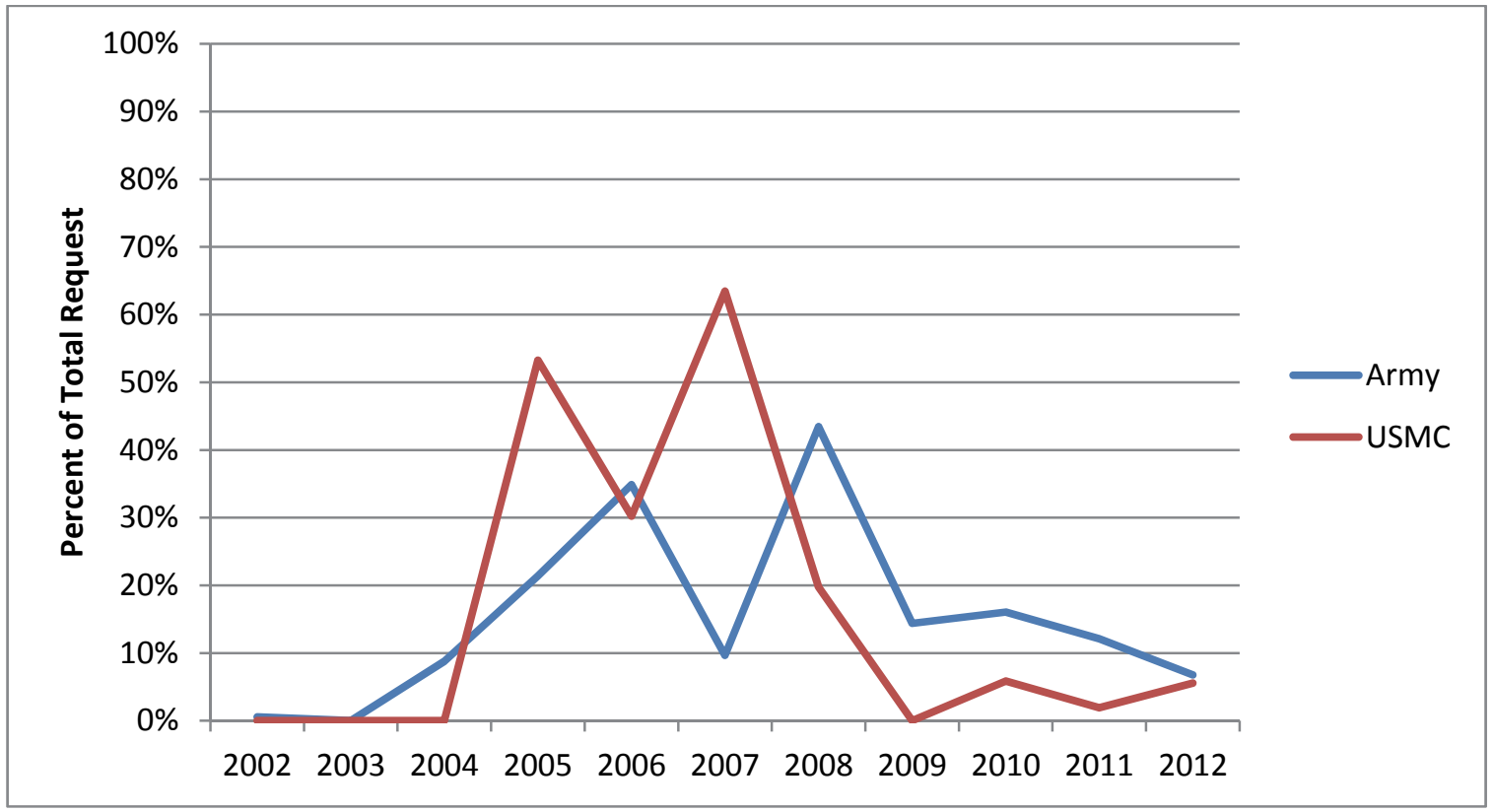

Source: Author analysis of DoD budget justification documents

Examining the Army's AMN investments shows that two budget activities-ground combat systems and communications and electronics - make up the vast majority (77\%) of AMN investments for the examined time period. Figure 2.4 shows the Army's total \$54.94bn AMN investment between FY2002-12 by budget sub-activity. ${ }^{59}$

${ }^{59}$ The BSAs are generalized, since the BSAs in the raw procurement data are named slightly differently depending on the service. 
Figure 2.4: Army FY02-12 AMN Investments (\$FY12 Bn) ${ }^{60}$

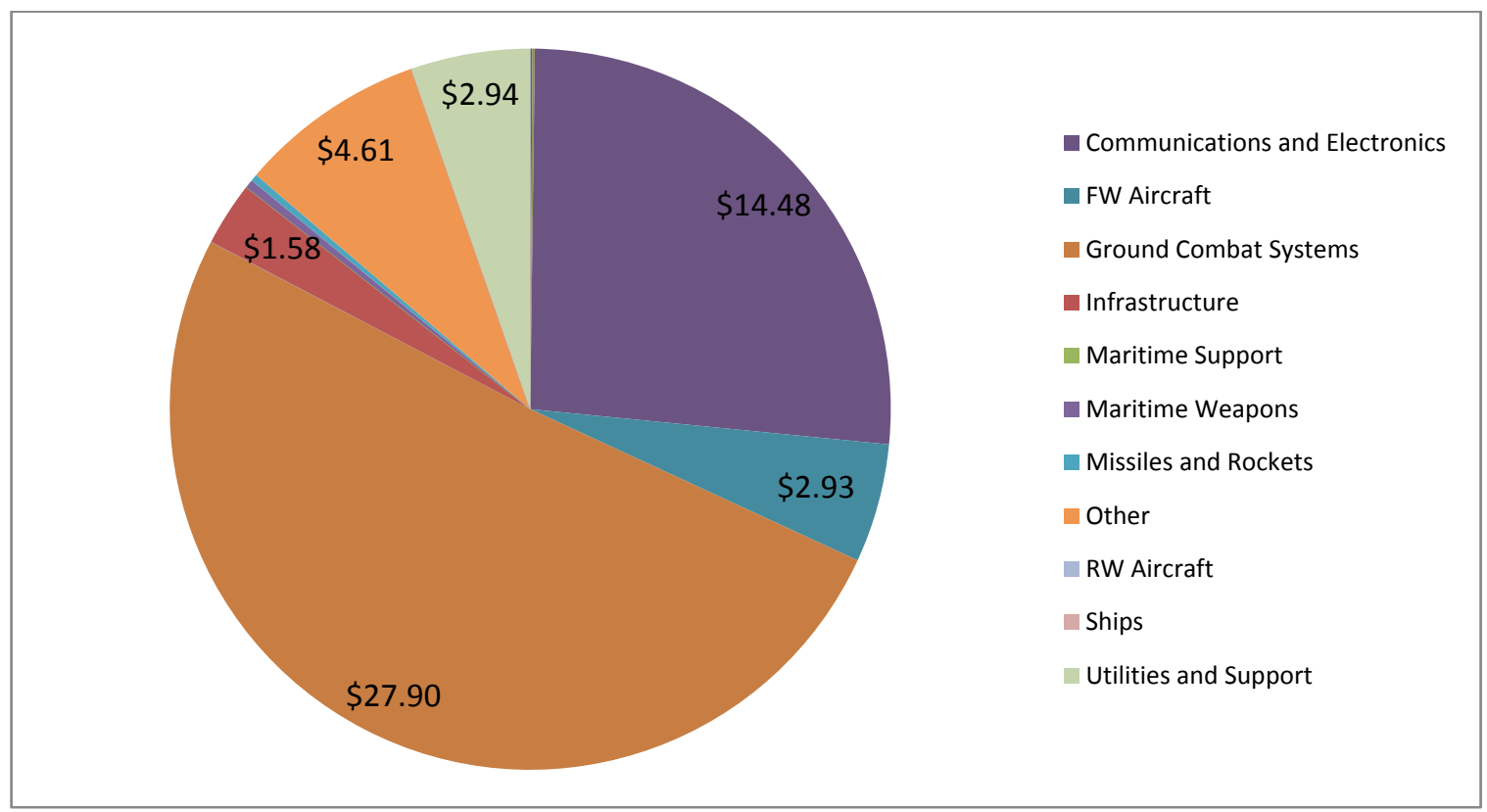

Source: Author analysis of DoD budget justification documents

The majority of Army AMN investments (51\%, or \$27.9bn) was spent on ground combat systems, with most of that total (\$17.21bn) being spent in FY08 on MRAPs (\$10.8bn), medium trucks (\$3bn), and High Mobility Multi Wheeled Vehicles (HMMVWs) (\$1.4bn). This breakdown indicates that the FY08 MRAP investment was highly significant on its own, making up 31\% of all Army AMN investments during the time period.

Over the time period in question, the Army made more consistent AMN investments in electronics and communications equipment. This is particularly true after FY04, when it spent between $\$ 2-4$ bn every year until FY11. The individual investments were diverse - everything from location-finding equipment, to intelligence analysis systems, to specialized SIGINT equipment. However, tactical radios (both VHF/UHF and HF) were a consistent AMN investment from FY03-11. This was a consequence of both the increased need for tactical radios in vehicles during motorized patrols and convoys, and the inability of the JTRS program of record to deliver long-term solutions to meet that

${ }^{60}$ Does not include $\$ 0.51 \mathrm{bn}$ invested in ammunition, aviation support, classified programs, ground support, maritime weapons, and missiles and rockets during FY02-12. 
need. ${ }^{61}$ Additionally, the Army began to consistently invest in counter-remote controlled IED electronic warfare (CREW) systems after FY07. ${ }^{62}$

The Marine Corps faced the same operational situation as the Army did in OIF/OEF, but their \$8.37bn AMN investments between FY2002-12 reflected slightly different shortfalls to correct and opportunities to take advantage of.

Figure 2.5: Marine Corps FY02-12 AMN Investments

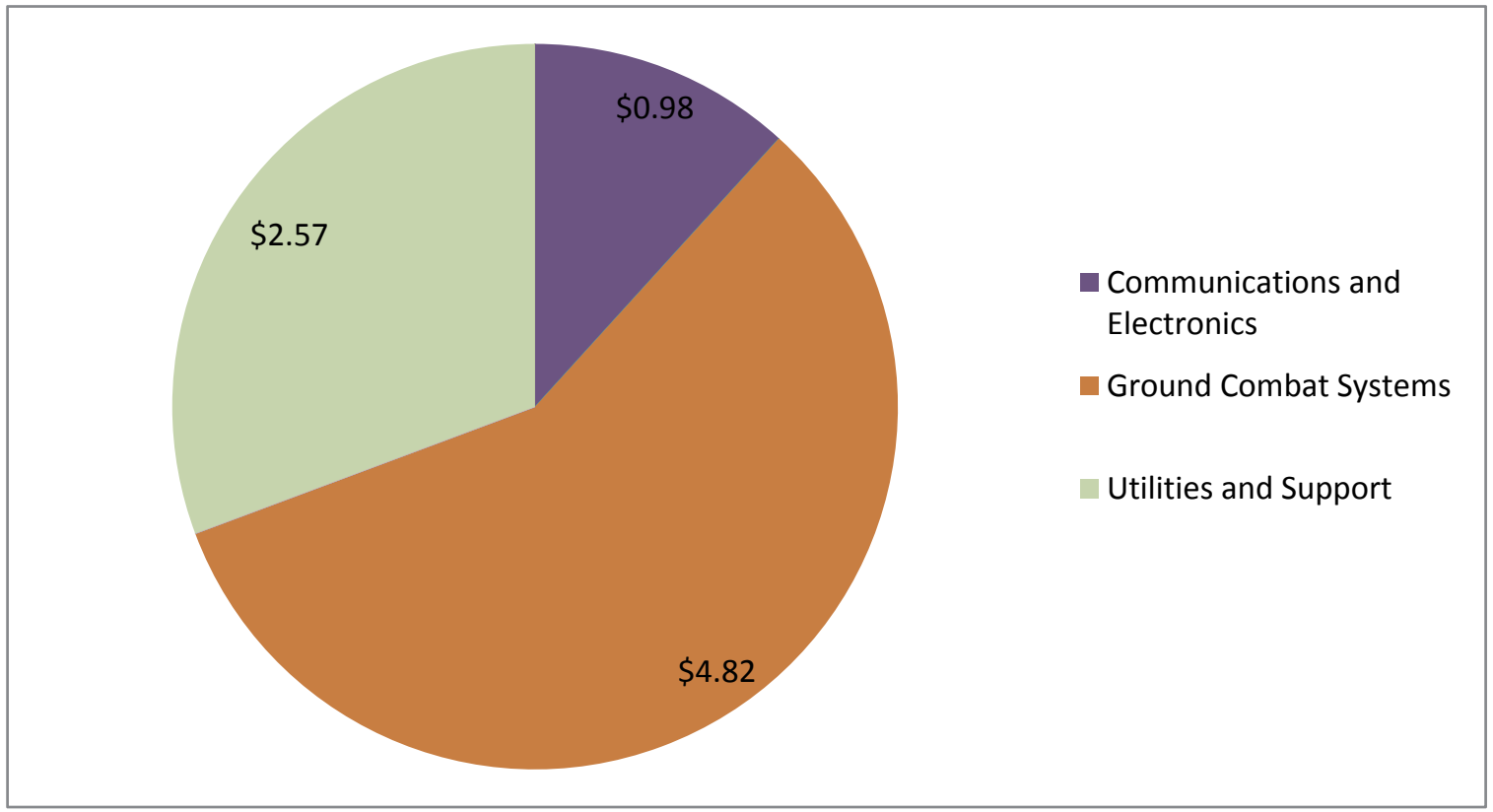

Source: Author analysis of DoD budget justification documents

Figure 2.5 depicts Marine Corps AMN investments by budget sub-activity over time. Since $66 \%$ of the Marine Corps' total AMN investments in that period were made in FY05 and FY07 (the two spikes depicted in Marine Corps investments in Figure 2.3), I begin my analysis there. In FY05, the Marine Corps' top ten procurement priorities (\$2.71bn, which made up 54\% of the entire Marine Corps procurement budget) were dominated by AMN investments with seven of those top ten priorities categorized as AMN investments. The Marine Corps made AMN investments that year in night vision equipment, upgrades to Light Armored Vehicles (LAVs), tactical radios, vehicle armor kits, medium trucks, unit operations centers, and HMMVWs. The first two items were due to the increase in vehicle convoys and patrols in Iraq. The Marine Corps had not foreseen the need to equip all units (not just combat arms units) with the proper

61 See Appendix B: PRC-117G Case Study

62 This additional investment must be caveated by the fact that joint funding for CREW systems by JIEDDO was administratively accounted for under the Army's budget. JIEDDO originated from an Army counter-IED task force. 
communications and night vision gear to enable those missions. ${ }^{63}$ Investments in vehicles and additional armor also touch on the increasing demand for motorized patrols and convoys.

In FY07, the Marine Corps procurement budget was dominated by a single AMN investment. A \$2.8bn AMN investment in MRAPs made up $63 \%$ of the entire Marine Corps' procurement budget that year. This is similar to the how the MRAP dominated the Army's AMN investments as well.

Generally, Marine Corps AMN investments prioritized a narrower set of investments compared to the Army. Figure 2.5 shows that the Marine Corps prioritized ground combat systems (dominated by MRAPs), while also investing in communications and electronics and utilities and support (this is dominated by combat engineering and EOD equipment). Figure 2.4 shows that the Army had a more diverse set of investments.

Note though, that the Marine Corps only spent a total of $\$ 8.38 \mathrm{bn}$ on AMN investments during the entire time period, while the Army spent \$54.94bn. Part of the reason why the Marine Corps spent less on AMN investments is because it was a smaller service. ${ }^{64}$ However, the Marine Corps was also probably benefitting from the investments made by the Army (e.g., JIEDDO's efforts in jamming remote IED detonators and other SIGINT and electronic warfare investments) that either ended up being fielded to the Marine Corps, or produced results (e.g., intelligence products) from which the Marine Corps benefitted. It may also have benefited from DoD-wide investments that had the same effect.

\section{Analysis of DoD-wide AMN Investments}

DoD-wide AMN investments made under joint auspices also made up a significant portion of all AMN investments, totaling \$25.77bn between FY02-12 (compared to $\$ 54.94$ bn for the Army and $\$ 8.38$ bn by the Marine Corps). Figure 2.6 depicts that spending over time. These DoD-wide investments include funding for US Special Operations Command (USSOCOM) forces, as well as DoD agencies and procurementrelated costs associated with increased Army and Marine Corps end strengths.

\footnotetext{
${ }^{63}$ Marine Corps Center for Lessons Learned (MCCLL), CONVOY OPERATIONS IN STABILITY AND SUPPORT OPERATIONS (SASO): A summary of collected lessons, observations, interviews, after action reports, and relevant documents from OEF, OIF-1, OIF-II, OIF-04-06, June 5, 2005.

${ }^{64}$ Between FY2002-12, Marine Corps procurement budget was 13\% of the Army's procurement budget on average.
} 
Figure 2.6: DoD-Wide Percent of AMN Investment to Procurement Total

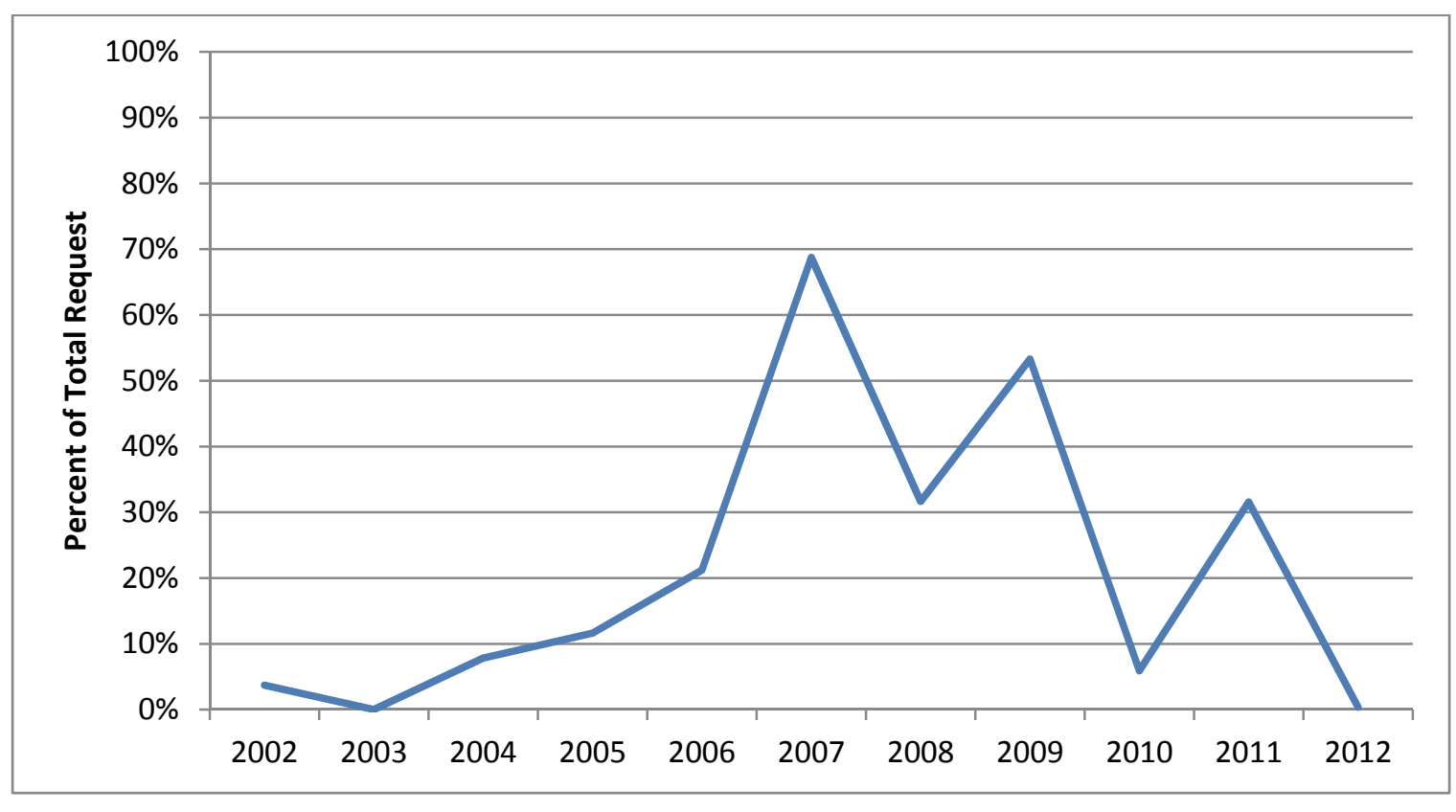

Source: Author analysis of DoD budget justification documents

Although the DoD relied on special operations forces (SOF) extensively during OIF/OEF, SOCOM did not make up a large percentage of AMN investments. During FY02-12, only \$1.44bn of DoD-wide AMN investments totaling \$25.77bn was designated for SOCOM. This may be due to SOCOM's existing long-term investments in specialized equipment that made it less necessary to turn to immediate investments. It also has greater flexibility in its procurement practices, mitigating the need to turn to AMM investments. In any case, SOCOM only made small AMN investments relative to its size and impact on OIF/OEF.

Instead, DoD-wide investment focused on supplementing Army and Marine Corps needs. Figure 2.7 breaks down their FY02-12 investments by budget sub-activity. Fifty percent of that investment occurred in FY07, when the \$12.9bn procurement cost of Army and Marine Corps end strength increases (e.g., increased procurement spending to equip the higher number of troops in each service) were paid for at the DoD level. $\$ 1.7 \mathrm{bn}$ was also spent on MRAPs. In other years, communications and miscellaneous investments and improvements to command and control infrastructure made up the majority of investments. These investments totaled $\$ 5.64$ bn. 
Figure 2.7: DoD-wide FY02-12 AMN Investments ${ }^{65}$

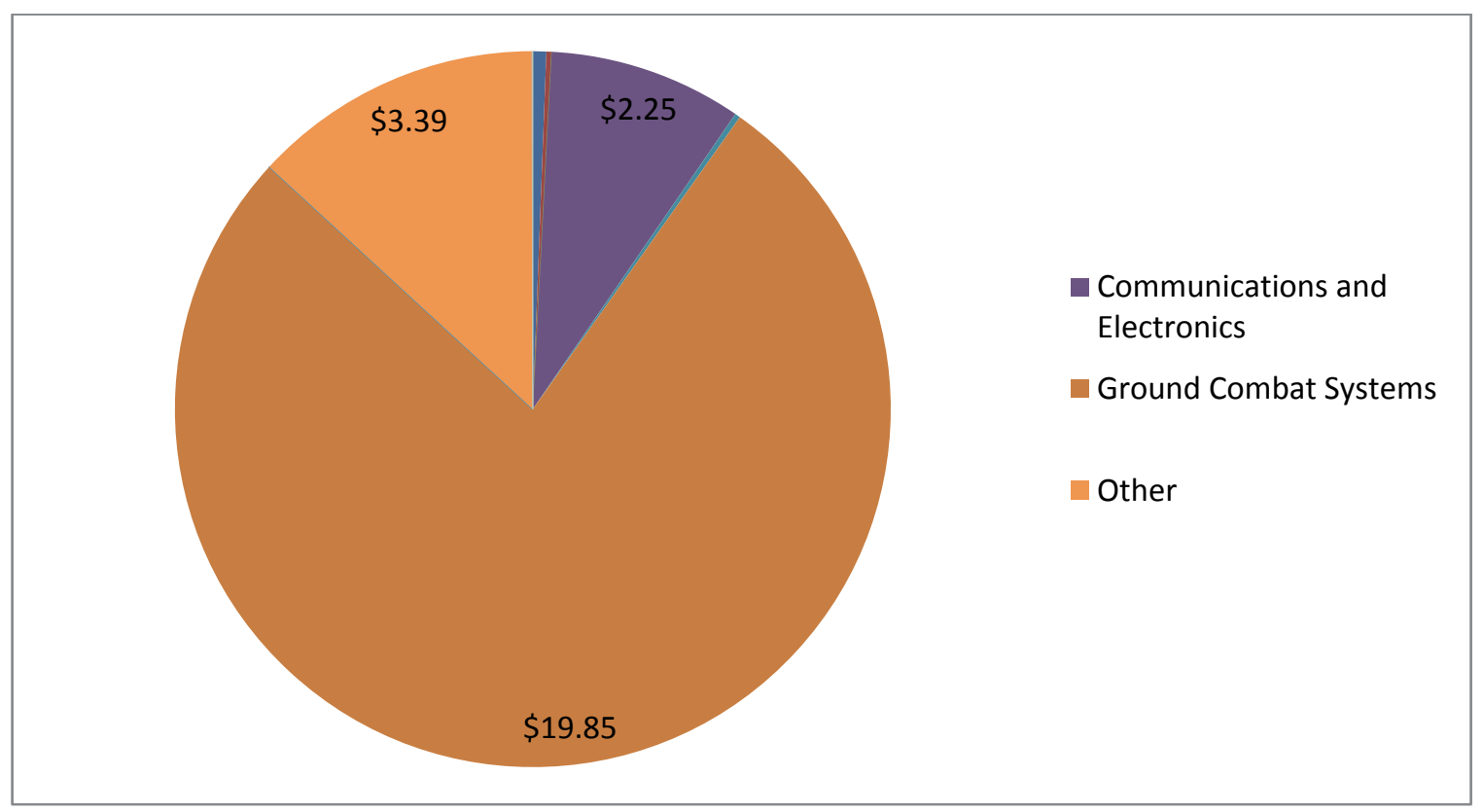

Source: Author analysis of DoD budget justification documents

DoD-wide AMN investments can be generally characterized as supplements to Army and Marine Corps needs, particularly for the unforeseen end-strength increases necessary to generate the forces necessary to conduct OIF and OEF. The remainder of DoD-wide investments was made towards improving global command and control (including the infrastructure required to house it in CONUS and overseas).

\section{Analysis of Navy and Air Force AMN Investments}

Navy and Air Force AMN investments made up a much smaller share of their total procurement budgets than those of the Army and Marine Corps. Figure 2.8 shows that the Air Force never requested more than $4 \%$ of its budget on AMN investments. The Navy never requested more than 5\%, except for FY08 when it requested $10 \%$ for AMN investments. Note that the y-axis scale on Figure 2.8 (from $0-12 \%$ ) is different than all others in this chapter (those scales go from $0-100 \%$ ).

${ }^{65}$ Does not include $\$ 0.29 \mathrm{bn}$ spent on aviation support, fixed-wing aircraft, and utilities equipment during the same time period. 
Figure 2.8: Navy and Air Force Percent of AMN Investment to Procurement Total

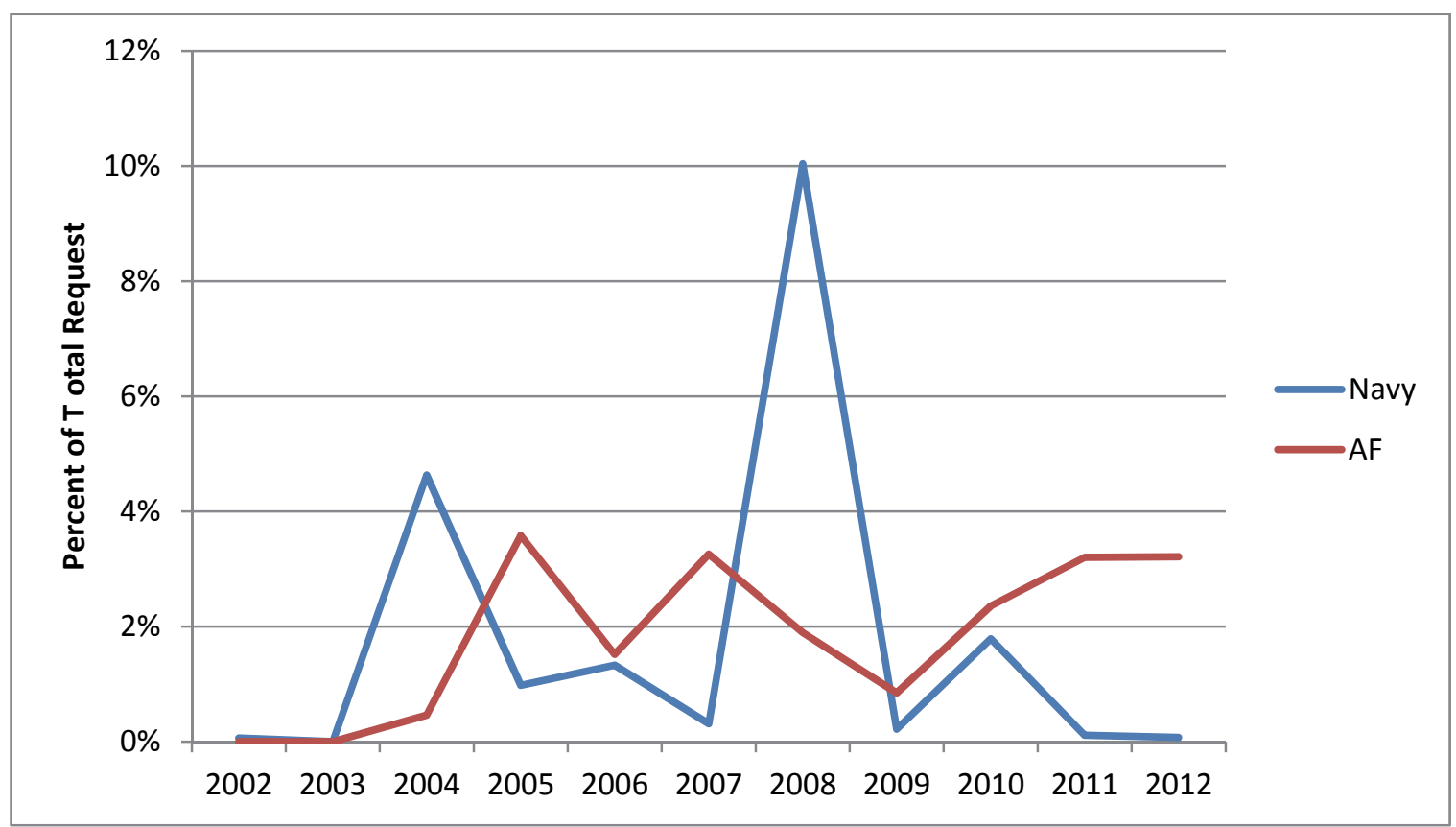

Source: Author analysis of DoD budget justification documents

According to Navy budget justification documents, AMN investments (totally \$71.8bn between FY2002-12) were part of the effort to mitigate the effect of IEDs during OIF. Outside of a large investment in aircraft in FY08 (discussed below), the Navy requested anywhere from $\$ 0.4$ to $\$ 1.5 \mathrm{bn}$ per year in $\mathrm{AMN}$ investments. These investments were evenly spread across a variety of budget sub-activities related to counter-IED efforts, as well as aviation support equipment to keep up with increased operational demand. Figure 2.9 shows the variety of the Navy's FY2002-12 AMN investments. 
Figure 2.9: Navy FY02-12 AMN Investments

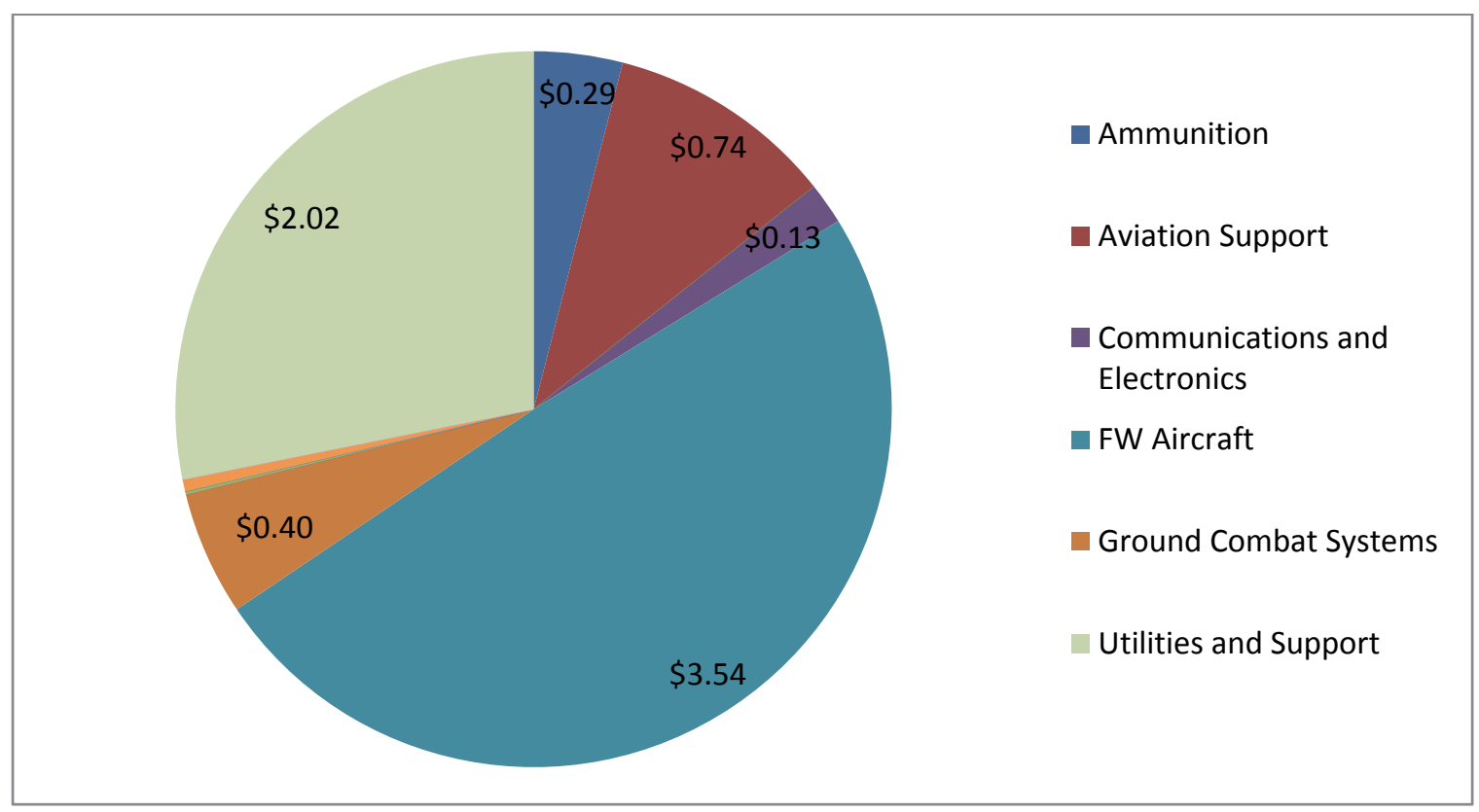

Source: Author analysis of DoD budget justification documents

The Navy's FY08 AMN investment is an outlier due to a one-time aircraft investment. That year, $10 \%$ of the Navy's procurement budget was devoted to AMN investments, with $44 \%$ of that year's AMN investments going toward five additional EA$18 \mathrm{G}$ electronic warfare aircraft to meet the increased OIF demand. These aircraft replaced older EA-6B aircraft that were part of the intense effort to detect and jam IEDs. Other AMN investments that year included three additional P-3 anti-submarine aircraft, explosive ordinance disposal equipment, and aviation support equipment. 
Figure 2.10: Air Force FY02-12 AMN Investments

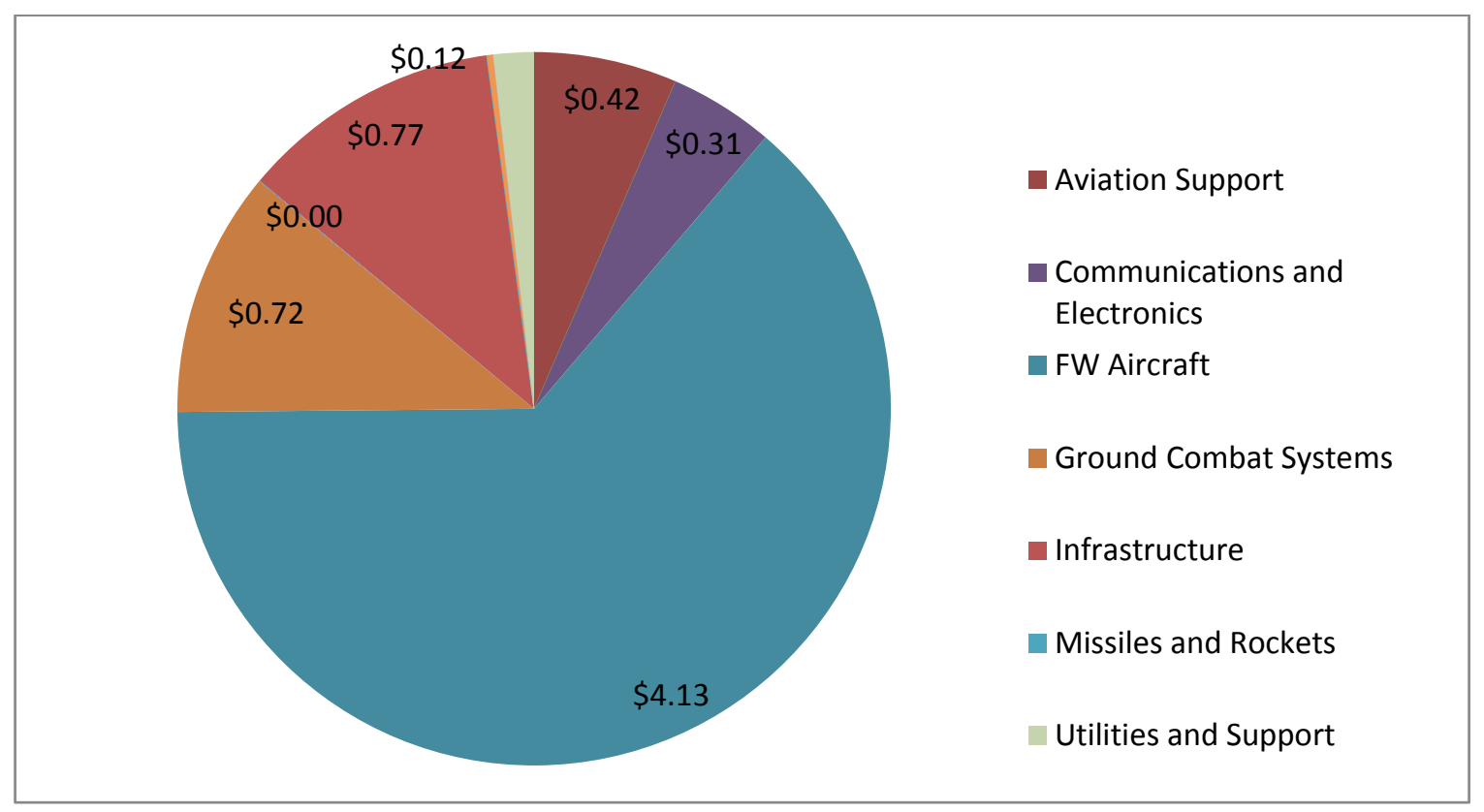

Source: Author analysis of DoD budget justification documents

Like the Navy, Air Force AMN investments were small compared to its total budget and focused on supporting counter-IED efforts. Figure 2.10 depicts these investments by budget sub-activity between FY2002-12. For the Air Force more so than the Navy, this included investments in intelligence, surveillance, and reconnaissance (ISR) assets. In particular, additional investments in MQ-1B Predator and MQ-9 Reaper aircraft and its supporting equipment made up 58\% of all Air Force AMN investments between FY02 and FY12. Other investments included a mixture of aviation support equipment to support increased operational tempo, additional missiles and other ordnance to meet demands in OIF/OEF, and some ground combat systems to outfit Air Force units that were on the ground in-theater.

\section{The Link between Immediate Investments and Rapid Acquisition}

The linkage between AMN investment and changes in rapid acquisition policy must be carefully considered. Examining rapid acquisition documents would have been a more direct way of characterizing the effect of DoD rapid acquisition policy changes, but this was not possible because of incomplete or inaccessible rapid acquisition records.

To investigate the linkage between changes in rapid acquisition policy and AMN investment activity, I examined available evidence and circumstantial factors and find that it is very likely that there is such a linkage for at least a substantial portion of AMN investments. Figure 2.11 depicts how the entirety of the DoD's \$102.76bn in AMN 
investments between FY2002-12 is linked (or not linked) to changes in DoD rapid acquisition policy.

Figure 2.11: AMN Investment Linkages to DoD Rapid Acquisition Policy Changes

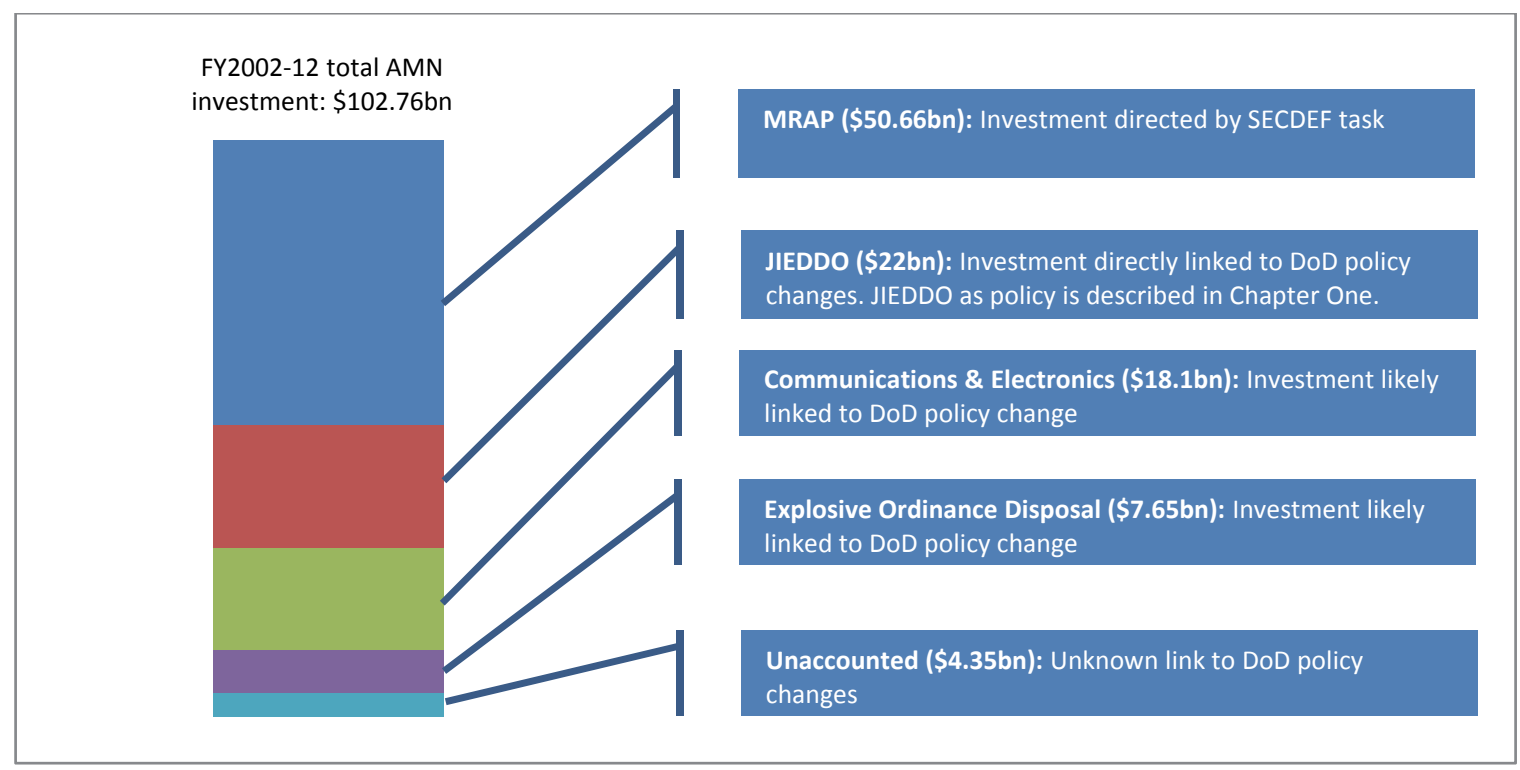

Source: Author analysis of DoD budget justification documents and USMC OEF Retrograde Playbook

First, the linkage between AMN investment and policy changes in the case of the largest investment, the MRAP, is clear. MRAP funding requests comprised of almost $51 \%$ of all AMN investments across all services in FY02-12. As described further in Chapter Three and Appendix E, the MRAP did not take advantage of any particular rapid acquisition policy. Rather, a task force convened at the behest of the Secretary of Defense had to intervene to make the MRAP investment possible.

If MRAP investments were not due to changes in rapid acquisition policy, they can be separated from other AMN investments that may be linked to policy changes. Figure 2.12 shows how the percentage of these remaining AMN investments to the total procurement budget request was still significant. Non-MRAP investments still rose from FY04 to FY06 from 3\% to 14\% of the total DoD procurement request. That percentage dipped slightly in FY07 as the MRAP dominated AMN investments, before rising again in FY08 to $15 \%$, and then falling steadily to $3 \%$ by FY12. The balance of investments still shifted, even when the MRAP investment is considered separately. 
Figure 2.12: Percent of Long-Term and Immediate Investments (MRAP and Non-MRAP) to Total Procurement Request

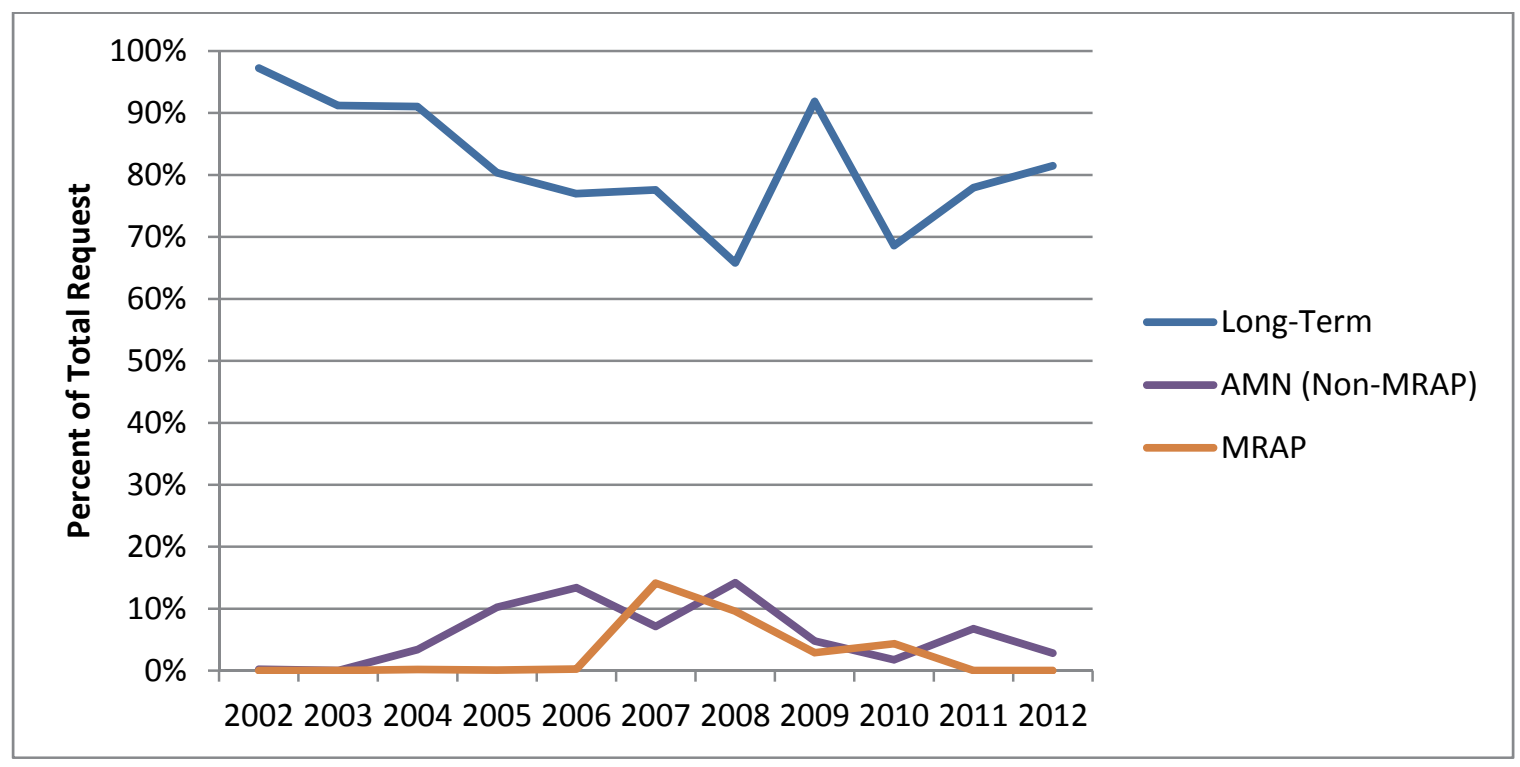

Source: Author analysis of DoD budget justification documents

Of the remaining \$52.1bn of non-MRAP AMN investments made between FY02-12, all but $\$ 4.35$ bn were either definitely or likely linked to changes in policy. $\$ 22 \mathrm{bn}$ was made by JIEDDO, which is described as a rapid acquisition process in Chapter One. These investments are verifiably linked to a DoD policy change.

However, the circumstances suggest that the link between AMN investment activity and rapid acquisition policy changes is likely for $\$ 25.75 \mathrm{bn}$ in $\mathrm{AMN}$ investments. The \$18.1bn spent on communications and electronics between FY02-12 includes a number of tactical radio, biometrics, and networking systems that were known to have been introduced into the procurement system via the rapid acquisition processes. ${ }^{66}$ The $\$ 7.65 \mathrm{bn}$ requested for EOD equipment includes robots and other equipment that were specified as rapid acquisition initiatives in supplemental justifications. These were verified by cross-referencing these investments to available Marine Corps records on urgent needs requests. Although this only establishes a link between AMN investment activities and rapid acquisition policies, it is unlikely that the Marine Corps was making AMN investments through its urgent needs process while the Army was pursuing the same need as a long-term investment. ${ }^{67}$

${ }^{66}$ For details, see Appendix B: PRC-117G Case Study and Appendix G: ABIS Case Study

${ }^{67}$ This was asked of a former I Marine Expeditionary Force G-9, who was responsible for managing a large number of Marine Corps urgent needs. He indicated that while I MEF did not coordinate with Army units to make joint requests often, they were generally aware of each other's efforts and did not think that this possibility was likely. See I MEF Interview, Nov 92015. 
There are also other means by which rapid acquisition needs could be funded, outside of the budget data examined. Our findings in Chapter Three indicate that reprogramming was an important aspect of several rapid acquisition programs. Chapter One indicates that this was standard practice for most rapid acquisition policies. Since reprogramming requests were not part of this analysis, this is a notable weakness in the analysis.

Discussions with individuals familiar with rapid acquisition processes though, indicate that while reprogramming is important to start funding a rapid acquisition initiative, budget requests do play a role in rapid acquisition. The timing of supplemental budget requests before 2009 gave program officers a chance to reconcile this by inserting their rapid acquisition funding needs into a supplemental request. Those actions made their efforts visible to this analysis. ${ }^{68}$ Additionally, maintaining and procuring more equipment allowed program officers a chance to insert those requests into the budgeting process (either in the base or supplemental budget), again making their investments visible to this analysis.

Although MRAP investments were not linked to changes in DoD rapid acquisition policy (instead, it was a policy decision made by the Secretary of Defense), a significant portion of them were either linked, or likely to be linked, to policy changes. I conclude that $21 \%$ of non-MRAP AMN investments, made to fund JIEDDO, were definitely linked to such changes. Another $25 \%$ of total AMN investments were likely to have been linked to policy changes. If additional rapid acquisition program documents can be located in the future, this would be an interesting area to explore and verify.

\section{Conclusion}

This examination of the budget has shown that the DoD, in addition to the Army, Marine Corps, and the DoD top-level organization, increased its immediate investments as a percentage of the entire procurement budget over time.

This analysis also characterized that the DoD's unforeseen needs were largely in OIF/OEF. Counter-IED efforts to detect and prevent IED attacks and mitigate their effects were very prominent, even for services that were not primarily involved in ground combat missions. Communications and electronics investments were also prominent. ${ }^{69}$

68 $132015 b$.

69 This is surprising, given the DoD's emphasis on networking and situational awareness throughout the 1990s. However, the demand for more radios (apart from modernized ones) may have driven that —even 
Finally, investments related to Army and Marine Corps end strength increases (to procure equipment for these additional troops) were also notable.

Lastly, this analysis indicates that the DoD took advantage of changes in rapid acquisition policies for up to $46 \%$ of all AMN investments. These investments were large enough to alter the balance of immediate and long-term investments, even when a slight majority (51\%) of AMN investments cannot be linked to changes in rapid acquisition policy. I conclude then, that the DoD as a whole responded appreciably to the changes in rapid acquisition policy.

combat support and combat service support units needed extensive communications equipment to carry out their missions in OIF/OEF. That may not have been foreseen. 


\section{Chapter Three: Rapid Acquisition in Practice}

In Chapter One, I described how the DoD established and refined policies to increase its ability to shift between immediate and long-term investments. In Chapter Two, I showed how those policy changes were linked to changes in the balance between immediate and long-term investment priorities in the budget.

In this chapter, I will examine how those changes were made by examining individual cases of alternative, missed opportunity, and new opportunity investments. The research question in the introduction asked:

RQ3: What factors affect the Department of Defense's consideration of immediate investments?

I will begin with a general discussion on the case study methodology used for of this portion of the study. I will then discuss the five factors that I am interested in exploring through the cases and case selection criteria. Next, I will present the six cases for the study and data collection and synthesis methods. Finally, I will analyze the six selected cases across the five factors and describe my findings in regard to each factor and across factors.

\section{Study Design}

A case study methodology was chosen for this study for three reasons. First, I expected to find nuances in the way the DoD (as an organization) approached its need to make immediate investments. This would necessitate deep examination, which case studies are amenable to. Secondly, I expected those nuances to be highly contextual, based on multiple factors, such as service sponsor, operational needs, and the type of investment being made (i.e. a command and control system versus a combat vehicle, for example). Lastly, I expected that the data that could be collected about AMN investments would be of inconsistent quality due to the lack of complete documentation (discussed in Chapter Two). This meant that there would not be enough data to use other quantitative methods, such as an econometric analysis of a large number of AMN investments. For these reasons, a case study methodology is used. ${ }^{70}$

${ }^{70}$ The research design of our case studies is heavily informed by Robert Yin's work in case study research. Rather than quote his case study handbook repeatedly throughout this section, I acknowledge his influence throughout the case study research design here at the outset. 
The methodological goal of the case study approach for this research is to inductively articulate an explanatory theory about the factors that affect the DoD's consideration of immediate investments. To achieve that goal, multiple cases are used for this research. The multiple case design establishes and confirms the validity of a theory by iteratively comparing data and tentative theories for one case. This is repeated for more cases, in the same way that multiple experiments are conducted to confirm a scientific theory. ${ }^{71}$ This inductive and iterative process of building theories from case studies is called replication logic.

\section{Units of Analyses}

For this research, two hierarchical units of analyses are presented. This embedded multiple-case design (see Figure 3.1) allows us to observe both the decisions and outcomes of similar programs, as well as program-level variation to produce richer analysis and more tailored policy recommendations. ${ }^{72}$

At the top level, the units of analyses are the three immediate types of investment. These pathways correspond to the three most immediate types of investment described in Chapter Two: alternative, missed opportunity, and new opportunity. The unit of analysis embedded within the investment types is a single AMN investment.

\footnotetext{
${ }^{71}$ Kathleen M. Eisenhardt, "Building Theories from Case Study Research," The Academy of Management Review, Vol. 14, no. 4, October, 1989.

${ }^{72}$ After some exploratory analysis of possible cases, we sensed that there were striking similarities between some programs, caused by shared contexts. This led to the realization that what we were actually observing were the three types of investments described in Chapter Two, which can be broadly interpreted as contexts.
} 
Figure 3.1: Embedded Multiple Case Study Framework
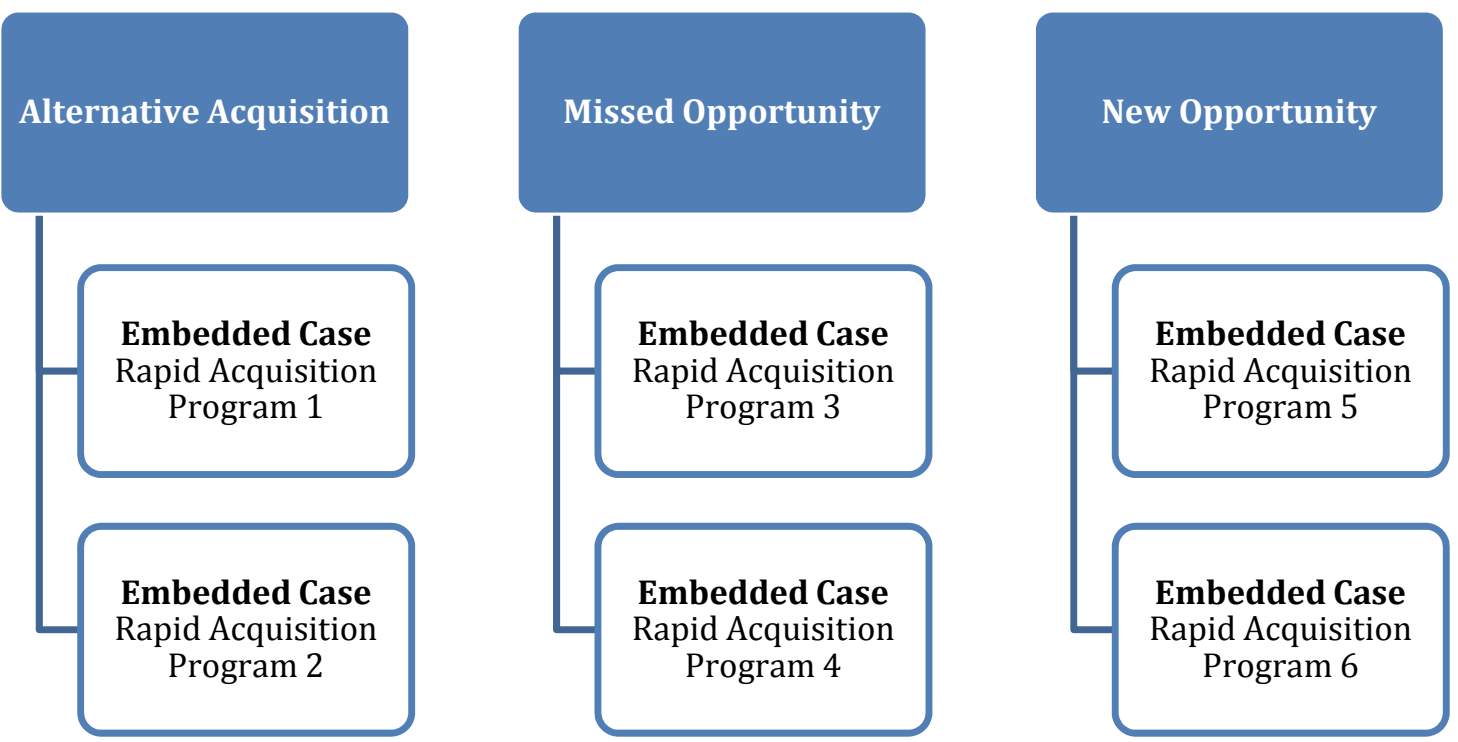

\section{Top Level Cases: Immediate Investment Types}

Top-level cases are the pathways by which defense procurement programs come to be included in rapid acquisition initiatives. These correspond to the three most immediate types of investment described in Chapter Two.

\section{Embedded Cases: Single AMN Investment}

Within the three pathways to rapid acquisition are the individual AMN investments. These form our second, embedded unit of analysis. As described in Chapter Two, these come in three forms. Alternative acquisition fulfils a capability need that has already been expressed and agreed upon. Missed opportunities address a capability need that was previously deemed unnecessary. New opportunities represent capability needs that are rapidly acquired and had not been previously considered.

\section{Case Study Selection Considerations}

Having established the structure of the case study design, I now turn to the process of selecting cases. Top-level cases will consist of the three immediate investment types: alternative, missed opportunity, and new opportunity. The budget data analysis described in Chapter Two found no immediate investments that fell outside of these three investment types. Since this means that the entire population of immediate investments is represented, no selection is needed. 
Selecting embedded cases to populate the framework requires more consideration. The first priority of embedded case selection for this research is to achieve the most variation across the factors of interest (described below). The second priority is to select cases where data is available and accessible. Given the incompleteness of rapid acquisition documentation, this is a non-trivial consideration. The use of six cases was the most reasonable choice, based on these priorities and the desire to achieve the replication logic approach used in this research.

There are four factors that I am interested in exploring for the embedded cases (Figure 3.2). I am interested in examining cases across sponsors such as the Army, Navy, Air Force, and Marine Corps. This factor is important to consider because the various sponsors are the components that comprise the $\mathrm{DoD}$ as a whole. They have different organizational cultures and procedures that may affect how they make immediate investments, so comparing and contrasting cases may yield insights.

Figure 3.2: Embedded Case Factors of Interest

\begin{tabular}{ll}
\hline \multicolumn{1}{c}{ Criteria } & \multicolumn{1}{c}{ Examples } \\
\hline Sponsor & $\begin{array}{l}\text { Army, Navy, Air Force, } \\
\text { Marine, Joint }\end{array}$ \\
& $\begin{array}{l}\text { Threat-driven, technology } \\
\text { capture-driven }\end{array}$ \\
Investment Driver & C4ISR, vehicle, aircraft \\
System Type & High $(>\$ 1 \mathrm{bn})$ \\
Procurement Cost & Medium $(\geq \$ 500 \mathrm{~m} ;<\$ 1 \mathrm{bn})$ \\
Level & Low $(<\$ 500 \mathrm{~m})$
\end{tabular}

I am also interested in examining the external investment driver(s) and how they might influence DoD immediate investments. One driver, the need to respond to an enemy threat, is likely to be a constant. However, the example of the PRC-117G described in the introduction may mean that another factor, the propensity for the DoD to capture non-defense technologies for their work, is worth exploring.

System type and cost level are also important factors that deserve attention. Presumably, the DoD considers different factors when considering one type of system versus another (e.g., a command and control system versus a tactical vehicle). The 
systems' expected cost levels may also influence the DoD's willingness to make that immediate investment.

\section{A Note on Investment Drivers}

The concept of investment drivers is novel, but it is known under different names and theories. It is worth clarifying this concept at the outset. This factor considers the DoD's willingness to make immediate investments in equipment that is already developed (referred to by the DoD as commercial off-the-shelf, or COTS) versus the DoD's willingness to invest in something to capture the benefits of technological advances happening outside of the military research and development ecosphere. This would imply that the DoD, even as it invests in something that is needed immediately, is also interested in seeing some longer-term benefits as well. Interest in this factor is motivated by the unintentional innovation of the PRC-117G described in the introduction.

There are multiple competing theories about the nature of defense investment and the way in which changes to the timing of the investment status quo can occur. Rosen argues that only peacetime innovation that takes advantage of technological capture forces is best. Technological capture in peacetime allows ideas to be fully tested. ${ }^{73}$ This was also the assumption of scholars who proposed the Revolution in Military Affairs (RMA) in the 1990s like Michael O'Hanlon and Eliot Cohen. Their writings showed that they implicitly believed that advances in computer technology could drive changes in defense investments and warfighting doctrine. ${ }^{74}$ A 1969 National Science Foundation study empirically tested this theory and found that technological capture was the main driver in five major civilian innovations. ${ }^{75}$

A competing theory is that threat-driven investment is the motivator of changes. A 1967 DoD study on defense innovation that examined 50 military innovations that resulted in investment found that demand (or threat) driven investment was far more important than technological capture factors. ${ }^{76}$ More practically, Schneider argued that DoD RDT\&E and procurement investments during the 1970s were unsurprisingly

\footnotetext{
73 Stephen Peter Rosen, Winning the Next War: Innovation and the Modern Military, ed., Ithaca, NY, Cornell University Press, 1991.

74 See a summary of Michael O’Hanlon's work in Scott Stephenson, "The Revolution in Military Affairs: 12 Observations on an Out-of-Fashion Idea," Military Review, May-June, 2010. See also Elliot A. Cohen, "Change and Transformation in Military Affairs," Journal of Strategic Studies, Vol. 27, no. 3, Sept, 2004.

${ }^{75}$ For a description of this study, known as the Technology in Retrospect and Critical Events in Science (TRACES) study, see Richard Smith, "The Roots Of Innovation," British Medical Journal (Clinical Research Edition), Vol. 295, no. 6609, November 21, 1987.

${ }^{76}$ Office of the Director of Defense Research and Engineering, Project HINDSIGHT Final Report, Washington D.C.: Department of Defense, October, 1969.
} 
motivated in large part by the Soviet threat. ${ }^{77}$ As a rule, only crises and threats are significant enough to move a large organization like the DoD away from the existing status quo.

Still other theories postulate that both drivers must be present for the investment status quo to change. Zmud, Baker and Freeland, and Utterback all argued that changes in institutional investment only occur when new technology and needs (or threats) occur at roughly the same time, providing mutually-reinforcing reasons for institutions to change its investment patterns. ${ }^{78}$ In any case, examining these drivers can reveal much about the DoD's investment choices. The lack of settled theory on the drivers of investment means that this analysis will contribute to that scholarship.

\section{Cases Selected for Analysis}

After reviewing previous research on rapid acquisition, consulting with subject matter experts (both DoD and external) and conducting exploratory analysis on candidate cases, I selected a set of six cases that best met the case study considerations described above. Note that the cases needed to be selected as a set in order to achieve variation across the factors of interest (depicted in Figure 3.2). Figure 3.3 below gives preliminary descriptions of each factor for the six cases, drawn from exploratory analysis.

Figure 3.3: Cases Selected for Analysis

\begin{tabular}{|c|c|c|c|c|c|}
\hline Case & $\begin{array}{l}\text { Investment } \\
\text { Type }\end{array}$ & Sponsor & System Type & $\begin{array}{c}\text { Theorized } \\
\text { Investment Driver }\end{array}$ & $\begin{array}{l}\text { Cost } \\
\text { (ACAT } \\
\text { Equivalent) }{ }^{79}\end{array}$ \\
\hline $\begin{array}{l}\text { PRC- } \\
117 G\end{array}$ & Alternative & $\begin{array}{l}\text { Harris Corp., } \\
\text { Army, USMC }\end{array}$ & C4ISR & Tech capture & $\begin{array}{l}\text { ACAT III } \\
(\$ 600 \mathrm{~m})\end{array}$ \\
\hline \multicolumn{6}{|c|}{$\begin{array}{l}{ }^{77} \text { Francis P. Hoeber William Schneider Jr., Norman Polar, Arms, Men, and Military Budgets: Issues for } \\
\text { Fiscal Year 1981, ed., New York, Transaction, } 1980 .\end{array}$} \\
\hline \multicolumn{6}{|c|}{$\begin{array}{l}\text { Knowledge Work," Management Science, Vol. 30, no. 6, June, 1984., James R. Freeland Norman R. Baker, } \\
\text { "Information and Innovation in Research Organizations," in ORSA National Meeting (Detroit, MI: 1970)., } \\
\text { and William J. Abernathy James M. Utterback, "A Dynamic Model of Process and Product Innovation," } \\
\text { The International Journal of Management Science, Vol. 3, no. 6, } 1975 .\end{array}$} \\
\hline
\end{tabular}




\begin{tabular}{llllll}
\hline Palantir & Alternative & $\begin{array}{l}\text { Palantir, } \\
\text { Army, USMC }\end{array}$ & C4ISR & Tech capture & $\begin{array}{l}\text { ACAT III } \\
(\$ 35 \mathrm{~m})\end{array}$ \\
MRAP & $\begin{array}{l}\text { Missed } \\
\text { Opportunity }\end{array}$ & Army, USMC & $\begin{array}{l}\text { Tactical } \\
\text { Vehicle }\end{array}$ & Threat & $\begin{array}{l}\text { ACAT I } \\
(\$ 50 \mathrm{bn})\end{array}$ \\
\multirow{2}{*}{ MQ-1 } & $\begin{array}{l}\text { Missed } \\
\text { Opportunity }\end{array}$ & Air Force & Aircraft & Tech capture & ACAT I \\
& & & & $(\$ 4 \mathrm{bn})$ \\
CREW & New & Army, Navy, & EW/C4ISR & Threat & ACAT I \\
& Opportunity & USMC & & & $(\$ 5.2 \mathrm{bn})$ \\
ABIS & New & Army & C4ISR & Threat & ACAT I \\
& Opportunity & & & $(\$ 3.04 \mathrm{bn})$
\end{tabular}

The cases described below are expanded on significantly in Appendices B-G, which include specific sources and citations. Discussion of cases in this chapter will cite the case study reports in Appendices B-G.

\section{Alternative Investment Cases}

The PRC-117G is a tactical radio used by air, naval, and ground forces to communicate using voice and data transmissions across the VHF and UHF frequency spectrums. The PRC-117G has some notable technological advantages over existing DoD tactical radios. It is capable of forming ad hoc networks that allow users to access network resources the Secure Internet Protocol Router Network (SIPRnet) while in the field. It is also smaller and lighter than previous tactical radios. The PRC-117G was developed privately by Harris Corporation and procured by the Army and Marine Corps through rapid acquisition processes to meet the increased demand for tactical radios caused by increased OIF and OEF operational tempo and the delayed development of the Joint Tactical Radio System (JTRS) program of record. See Appendix B: PRC-117G Case Study for details.

Palantir intelligence analysis software is used by analysts across the intelligence community (IC) to analyze raw intelligence data collected across a variety of sources. Palantir software integrates information from multiple intelligence databases to help intelligence analysts investigate linkages, sort through data, and organize intelligence information. Palantir was privately developed by Palantir Technologies and was procured as a joint urgent operational need (JUON) for forces deployed to OEF. It is used to varying degrees by military members of the IC as an alternative to the Distributed Common Ground Sensor (DCGS) family of intelligence analysis programs, which are programs of record. See Appendix C: Palantir Case Study for details. 


\section{Missed Opportunity Investments}

The Mine Resistant Ambush Protected (MRAP) vehicle is a family of armored trucks featuring v-shaped hulls that are specifically designed to deflect blasts from improvised explosive devices. MRAPs were developed in South Africa in the 1970s and observed by US forces during peacekeeping operations in Somalia during the early 1990s. At that time, the MRAP was considered to be of limited utility to the US military. Increasing insurgent IED attacks made the DoD reconsider this position, and they were eventually procured in large numbers for all four services after contentious debate about their utility by the DoD, Congress, and the media. See Appendix D: MRAP Case Study for details.

The MQ-1 Predator is a medium-altitude, long-endurance unmanned aerial vehicle primarily used by the US Air Force for aerial surveillance and some precision strike missions. The Predator was developed in the late 1990s as part of a small DoD concept development program called the Advanced Concept Technology Demonstrator (ACTD) program, which focused on user needs and earlier operational testing than normal acquisition programs. It saw extensive use during OIF and OEF, which resulted in institutional strain within the Air Force as it sought to reconcile the increased demand for the Predator and its desire to prioritize manned aircraft programs. See Appendix E: Predator Case Study for details.

\section{New Opportunity Investments}

Counter Remote Improvised Explosive Device Electronic Warfare (CREW) is a family of electronic jammers that disrupt the detonation of remote controlled improvised explosive devices (RCIEDs). CREW is normally mounted in vehicles and backpacks to provide protection from RCIEDs during patrols. CREW systems were developed in response to the increase of RCIED attacks during OIF and OEF and required significant field experimentation and iteration to perfect their operation. Integrating CREW into Army and Marine Corps operations was particularly difficult, as both services did not possess electronic warfare expertise (in the case of the Marine Corps, this expertise was only resident in its aviation units). CREW systems were developed and procured by JIEDDO. See Appendix F: CREW Case Study for details.

The Automated Biometrics Identification System is a database system used by the DoD to manage biometric data. It serves two functions. First, it manages biometric information collected by troops in the field. Second, it helps troops and intelligence analysts identify individuals using that stored biometric data. ABIS was procured through rapid acquisition processes to meet the need by troops in OIF and OEF for a reliable 
method of identifying civilians and insurgents during the counterinsurgency campaigns in both theaters. See Appendix G: ABIS Case Study for details.

\section{Case Selection Methodological Tradeoffs}

Some tradeoffs between variation and data availability were made. Navy and Air Force-sponsored cases are not well-represented. C4ISR systems are over-represented. Given the budget data analyzed in Chapter Two, I conclude that this is due to the nature of the wars in Iraq and Afghanistan and the immediate investments needed to fill a given capability gap. Navy and Air Force AMN investments were a fraction of the Army and Marine Corps' investments. C4ISR systems represented a significant fraction of AMN investments across all four services and DoD-wide investments. Therefore, I conclude that the embedded case selection is a fair reflection the overall distribution of AMN investments during FY02-2012. Consequently, program costs for the selected cases were clustered around high cost levels for missed and new opportunities and low costs for alternative investments.

In spite of these tradeoffs, the analysis and comparison of the six case reports can still yield useful findings. Comparing Army and Marine Corps programs can highlight service-specific factors in shifting investment balances. High and low cost levels still provide the variation needed to make comparisons between investment types. ${ }^{80}$ The one concerning factor that cannot be mitigated is the overrepresentation of C4ISR systems. This means that we will not be able to analyze system type-specific factors in how the DoD shifts its procurement investments. The resulting theories from this research may not be generalizable to other kinds of immediate investments that the DoD may pursue in the future.

Why were cases of failed programs not selected? There are two reasons. First, this research is focused on examining the way DoD shifts its investments. While there were undoubtedly some immediate investments that were made in failed programs, these would presumably be overshadowed by the procurement spending in successful programs. Secondly, data sources on failed programs are more sparse. In the interest of ensuring a consistently high quality of data feeding into this analysis, I chose to work only with successful cases.

\footnotetext{
${ }^{80}$ Missing medium-cost programs is preferable to missing high or low cost programs, since high and lowcost programs form the extreme cases that I seek to use for this analysis.
} 


\section{Data Collection and Synthesis}

For all cases, data collection began with open source literature. This data included official sources like Selected Acquisition Reports (SARs), GAO, CBO, and CRS reports on systems and classes of system, DoD operational test data summaries, Congressional testimony, and other reports, studies, and analyses produced by DoD on these systems. It also included material that was accessed with assistance from archivists at the Army War College, Marine Corps Historical Division, and the Joint Staff Library.

These were supplemented with non-official public sources. These included information from Janes' defense database, think tank reports, trade publications (e.g., Defense News, Military Times, etc.), general news publications, and books (in the case of the Predator). A draft case report was written using this open source information.

These draft case reports were used as a basis for interviews and correspondence with subject matter experts who were either involved in the DoD's management of the program, participated in its development, or were part of the contractor teams that developed and produced the weapons systems represented. The goal of the interviews and correspondence was to verify the accuracy of the draft case report and seek additional information not available in open sources. These individuals were contacted primarily through referrals by RAND Corporation researchers and cold calls via email and LinkedIn messages. Interviews were conducted in person when possible and via telephone when necessary. Email follow-ups were also used. Figure 3.4 shows the breakdown of interviews and correspondence. Figure 3.5 shows the organizations that were contacted. ${ }^{81}$

Figure 3.4: Case Interview Responses

\begin{tabular}{lccc}
\hline \multicolumn{1}{c}{ Case } & $\begin{array}{c}\text { Individuals } \\
\text { Contacted }\end{array}$ & $\begin{array}{c}\text { Interviews } \\
\text { Conducted }\end{array}$ & $\begin{array}{c}\text { Correspondence } \\
\text { Response Only }\end{array}$ \\
\hline PRC-117G & 18 & 8 & 2 \\
Palantir & 5 & 1 & 0 \\
MRAP & 8 & 3 & 1 \\
Predator & 6 & 2 & 1 \\
CREW & 14 & 6 & 1
\end{tabular}

${ }^{81}$ Information about interviews and organizations is separated into Figures 3.4 and 3.5 to protect the identities of the individuals interviewed. 
Figure 3.5: Organizations Contacted

\begin{abstract}
Case
Organizations Contacted

PRC-117G I MEF G-6, Harris Corporation, HQDA G-8, Joint Tactical Networking Center (JTNC), Marine Corps Information Operations Center (MCIOC), RAND Corporation

Palantir Palantir Technologies Inc., RAND Corporation

MRAP HQDA (G-8), HQMC(CD\&I), HQMC (I\&L), Marine Forces Central Command (MARCENT), Marine Corps Systems Command (SYSCOM)

Predator General Atomics Aeronautical Systems (GA-ASI), RAND Corporation, University of Iowa, USAF MQ-1 Predator Program Office

CREW HQDA (G-3/5/7), , Johns Hopkins Applied Physics Laboratory, Marine Corps Systems Command (SYSCOM), RAND Corporation, SRC Inc.

ABIS DoD Biometrics Program Management Office, independent contractor, RAND Corporation

The draft case studies were then updated with new information from the interviews, as well as with gray literature provided by interviewees. Gray literature, which includes reports, presentations, and correspondence not available to the public, provided an invaluable point of view of the internal discussions and debates of the program personnel that would not otherwise be documented or mentioned in public.

The result of this data collection is the final case report. Each case report is divided into four sections. The first section describes the investment. The second section examines the extent to which the DoD was driven to invest in the weapon to address the threat at hand, or to capture technological advances. The third section discusses implementation obstacles and their mitigations. The last section examines the outcome of the program.
\end{abstract}

\title{
Analysis and Results
}

To answer the research question, I examined the DoD's ability and willingness to shift from long-term investments to immediate ones by comparing case reports across four factors previously identified: 
- Investment type

- Investment driver

- Service sponsor (Army and Marine Corps only)

- Cost level (high and low only)

The analysis focused on how each of the factors influenced the individuals and organizations within the DoD across the six cases. This analytical process is depicted in Figure 3.6.

Figure 3.6: Within-Case Analysis

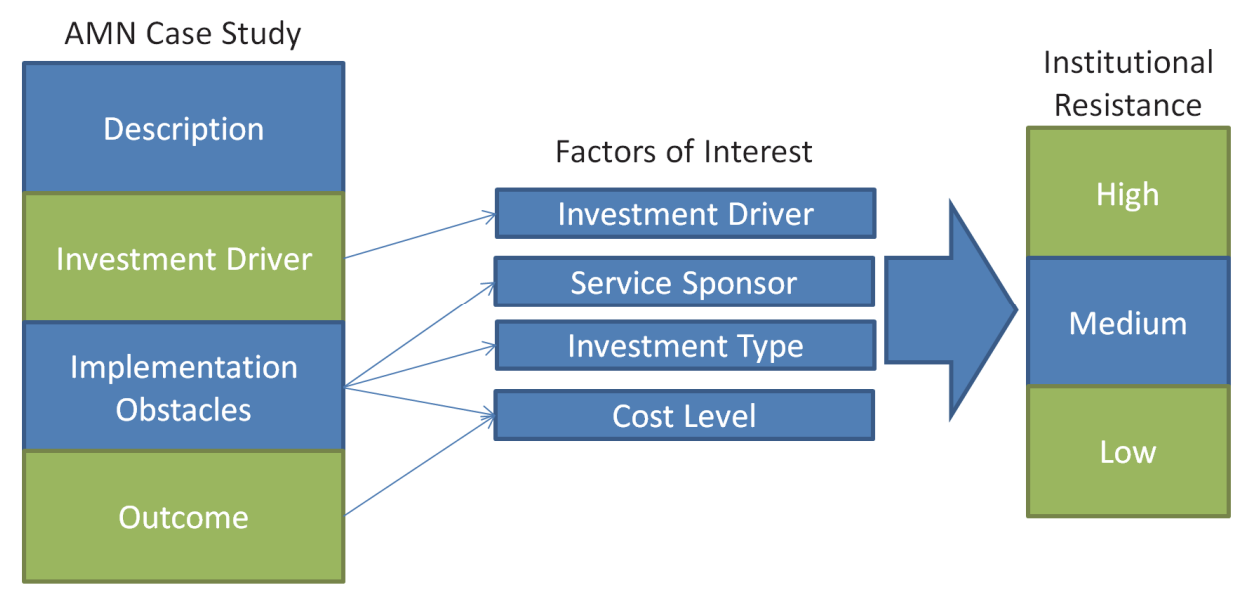

Data for each factor will be drawn from the case study. The factors of interest will be characterized by how each factor contributed to any resistance to the decision to invest, or the implementation of the investment. I will assess any resistance found in those three factors as one of three types: low, medium, and high. Low resistance to an investment means that no evidence could be found to indicate that any DoD stakeholder group objected to the investment. Medium resistance indicates DoD resistance that was settled internally. High resistance indicates resistance to the investment or its implementation that required intervention by actors outside the DoD.

The goal of these comparisons is to determine how the four factors affect the DoD's ability to make immediate investments. In this section, I will first examine investment drivers. The first comparison (investment type) examines the top level cases of our framework. The following three comparisons (investment driver, service sponsor, and cost level) focused on the embedded cases. Lastly, I examined institutional resistance across factors in the conclusion of this chapter. 
The following analyses draw data entirely from the case studies. Facts reported below can be referenced in the case study reports in Appendices B-G.

\section{Case Comparison: Investment Type}

Of the three types of immediate investments, only the new opportunities examined encountered low resistance. Resistance to alternative acquisitions cases was mixed and depended on the status of the corresponding program of record. Lastly, the two missed opportunity cases examined faced medium to high resistance. Figure 3.6 provides a summary of these results. The following sections describe each finding in detail.

Figure 3.6: Investment Types and Institutional Resistance

\begin{tabular}{ccc}
\hline Case & Investment Type & $\begin{array}{c}\text { Institutional } \\
\text { Resistance }\end{array}$ \\
\hline PRC-117G & Alternative & Low \\
Palantir & Alternative & Mixed \\
Predator & Missed Opportunity & Medium \\
MRAP & Missed Opportunity & High \\
CREW & New Opportunity & Low \\
ABIS & New Opportunity & Low
\end{tabular}

\section{New Opportunities}

No resistance to investment in CREW and ABIS was found. In both cases, DoD stakeholders (JIEDDO and the DoD Biometrics Program Office) were also willing to accept partial solutions. JIEDDO developed and acquired 16 different CREW systems from FY2002-12. Early systems had numerous limitations - one early system could only jam one specific type of trigger while others did not produce enough jamming power. Still other systems jammed friendly radios, impeding command and control. This was also true for ABIS - reaction time for the entire system was slow, with some matches taking 15 days to be communicated to the originating unit. Nevertheless, these partial solutions were deemed to be acceptable enough to be fielded to troops in Iraq and Afghanistan.

These problems represent normal technological growing pains. However, the DoD was willing to accept partial solutions because there were no better alternatives to the 
problems that these investments addressed. The DoD possessed electronic warfare capabilities, but these were strategic assets like the Air Force EC-130H Compass Call and Navy EA-6B Prowler that were both too powerful for tactical applications and so few in number that they could not possibly provide coverage for the thousands of daily patrols conducted in Iraq and Afghanistan.

Similarly, forces in the field were willing to accept ABIS even though it was slow and unwieldy because the alternative to biometric identification (ID cards) were too prone to manipulation. Biometrics was far more reliable, even if it was slower. Because no better alternative existed and little thought was given prior to 2002 to studying these needs, the DoD was willing to shift investment toward these capabilities without much consternation.

\section{Alternative Investments}

Resistance to investment in the PRC-117G and Palantir was mixed, depending on the status of the program of record. This resistance was encountered despite the fact that both programs were the product of similar circumstances. Both were developed privately by companies that paid very close attention to the needs of the operators (intelligence analysts in the case of Palantir, communicators in the case of the PRC-117G). These companies forged close relationships with those operators during the development process and took advantage of new policy flexibility to get their products in the hands of operators more quickly. According to interviews with General Atomics Aeronautical Systems and a former Palantir official, the companies that developed these alternative investments were extremely confident that their products would be so effective that the DoD would eventually decide to invest deeply in them, as opposed to the programs of record to which they were alternatives.

This was clearly the case for the PRC-117G. Despite this encroachment on the DoD's JTRS program, the Army and Marine Corps accepted the PRC-117G without resistance. Not only did the DoD Information Systems Agency (DISA) allow the PRC-117G to be deployed in Afghanistan to carry classified network traffic, the DoD eventually reconfigured its program of record to be an open source venue that allowed contractors access to standardized waveforms and allowed them to demonstrate their radios in headto-head competitions.

For Palantir, the Army and Marine Corps' reactions to its grassroots adoption was much more uneven. There was no resistance to adoption by the Marine Corps. The Marines were amenable to adopting Palantir because its own DCGS-MC program of record was only in its initial development stages. Buying Palantir licenses was an 
acceptable alternative to not having any comparable capability on the horizon. The fact that Palantir was also embraced by non-military members of the intelligence community also contributed to the Marines' acceptance of Palantir.

The adoption of Palantir faced high resistance in the Army, however. The Headquarters Department of the Army G-2 (HQDA G-2) allowed some units to use Palantir for a period of time but eventually decided that its DCGS-A program of record was sufficiently developed for its purposes and subsequently forbade its use. Some Army intelligence analysts disagreed with this assessment, which eventually embroiled Palantir and the Army in a public dispute about the relative merits of DCGS-A and Palantir. In any case, Palantir was not widely adopted by the Army, although some units still work using Palantir.

The Army and Marine Corps' reactions to the PRC-117G and Palantir depended on how close the respective services wwere to actualizing the program of record. In the case of the PRC-117G, both the Army and Marine Corps recognized that its JTRS program of record was unlikely to produce a working solution in the time allowed. The same was true for the Marines' adoption of Palantir. However, the Army's negative reaction to Palantir may be attributed to the fact that DCGS-A appeared to have the potential to work out its development problems. Additionally, the Army did not believe that Palantir was actually a better analysis platform.

\section{Missed Opportunities}

Both the MRAP and Predator faced resistance to their implementation. The MRAP encountered high resistance within the Army and Marine Corps when the investment was first proposed in 2005. Both services initially marginalized field commanders' requests for MRAPs, believing them to be imprudent investments despite the fact that the MRAP was known to be better at protecting troops from IED attacks. The services believed that existing efforts to retrofit HMMVWs with armor was a better use of resources and sufficiently effective against IEDs. They further believed that the MRAP would be a burden to them in the future - the vehicle required high maintenance, had poor handling characteristics, and was very heavy. Overcoming the services' resistance required intervention by the Secretary of Defense and Congress as well as pressure from the media.

The Air Force raised medium resistance to an increased demand for the Predator during OIF. The aircraft was already in the Air Force's inventory before 2002, albeit in unarmed form (the MQ-1A). The fact that it was already developed made the issue of whether or not the aircraft should be pursued irrelevant. However, once the demand for 
the Predator's intelligence, surveillance, and reconnaissance (ISR) capabilities increased beyond what the Air Force had envisioned prior to 2002, organizational and operational friction increased. Between 2006 and 2014, more than 25 urgent needs requests were submitted to the JRAC and Air Force to increase the number of ISR combat air patrols. Rather than embrace the ISR mission though, the Air Force was initially reluctant to invest in the manpower and training resources to generate the combat air patrols demanded by CENTCOM. According to a former Predator program officer, this hesitancy was due to the Air Force's reluctance to allow a remotely-piloted platform to perform missions that were once considered the sole domain of manned aircraft.

When the Air Force did begin to address the demand for UAS, haste required it ignore some of the Predator's shortcomings as they attempted to scale up operations. Aircraft and control units were not standardized, with over 12 different control configurations in use at one point. Documentation and maintenance procedures were not fully understood, requiring a higher than normal level of contractor support. According to two former Predator program officers and GA-ASI personnel, the increased production of the Predator was also hindered by the program office's capability to keep up with some of the oversight requirements demanded of the program once it grew to the point where it became an ACAT I program.

Generally, these shortcomings were not tolerated by Army, Marine Corps, and Air Force stakeholders to the same degree as those in the two new opportunity investment cases. There was much more consternation by DoD stakeholders about requirement validation and program execution than there was for new opportunities.

This dismay regarding operational issues may be because missed opportunities involve re-examining previous decisions about a capability. Army combat engineers unsuccessfully advocated for an MRAP-like vehicle throughout the 1990s after observing South African versions during peacekeeping operations in Somalia. The Air Force considered the Predator to be a minor experimental aircraft unrelated to its core mission. Investing in missed opportunities involved overturning previous decisions and upsetting existing consensus. This would presumably be a challenge to any large organization.

To overcome high resistance, senior leader intervention was required in both cases. For both the MRAP and the Predator, the Secretary of Defense needed to exert direct pressure to force the DoD to make the investment in a missed opportunity. In the case of the MRAP, Congress weighed in decisively as well. These interventions were required to settle the debate about whether or not an investment was warranted (in the case of the MRAP) and how responsibilities for executing the investment should be delineated (in 
both cases). Senior leader attention also clearly signaled to the entire DoD that the program was backed by the leadership as an unambiguous priority, which focused the entire organization's attention on the investment under scrutiny.

\section{Case Comparison: Investment Drivers}

Analysis of the six cases found no evidence of a link between investment driver and institutional resistance to the decision to invest or the implementation of the investment. Figure 3.4 depicts the results of this within-case comparison.

Figure 3.7: Investment Drivers and Institutional Resistance

\begin{tabular}{ccc}
\hline Case & Investment Driver & $\begin{array}{c}\text { Institutional } \\
\text { Resistance }\end{array}$ \\
\hline PRC-117G & Simultaneous & Low \\
Palantir & Simultaneous & Mixed \\
Predator & Sequential & Medium \\
MRAP & Threat & High \\
CREW & Threat & Low \\
ABIS & Threat & Low
\end{tabular}

No linkages could be found between investment driver and institutional resistance for any of the cases. The low resistance of stakeholders to the PRC-117G and mixed resistance to Palantir is rooted in the relative technological maturity of the programs of record to which they were alternatives. The medium resistance to the Predator and high resistance to the MRAP were due to the disruption caused by the need to reconsider the decisions by their relative stakeholders to not invest in each program. The low institutional resistance to CREW and ABIS stems from their status as new opportunities that were preferable to the status quo. Given these mixed results, no linkages between institutional resistance and investment type could be found.

There is evidence that the DoD stakeholders involved in these six cases did not have a propensity for either driver. Figure 3.7 shows that all cases were driven at least in part by threat. This is natural, since the time period of interest was during a period of conflict for the United States. However, there is no consistency observed otherwise. Some cases (PRC-117G and Palantir) were driven by both the threat and the potential to capture technological advancements at the same time. The Predator was driven by alternating 
drivers in sequence over a longer period of time. The MRAP, CREW, and biometrics were all purely driven by the threat at hand, with little regard to additional technological capture. No clear pattern is evident.

This lack of a pattern matches the loosening of requirements in rapid acquisition policy observed in Chapter One. All rapid acquisition policies in 2002 explicitly stated that potential solutions must be technologically mature. As the wars progressed, those explicit statements disappeared from the policies, just as strict minimum performance standards did (e.g., a rapid acquisition program must be completed within two years). As mentioned in Chapter One, this may be due to the DoD's increased understanding that some capability gaps required development to be effective. The outcomes of that policy deletion can be seen in the six cases examined through the lack of a clear tendency towards one driver or another.

The lack of an observed bias indicates institutional flexibility in these six cases. DoD stakeholders were not biased towards pursuing investments that were purely threat-driven or purely technology capture-driven. If DoD stakeholders merely pursued the former, it would mean that the they were only willing to invest in capabilities that were already fully developed, limiting the DoD's prospects for fully addressing an unforeseen capability gap. If stakeholders only pursued the latter, they may have been needlessly pursuing bespoke solutions when off-the-shelf ones already existed. Having no bias towards either indicates an organization that is able to appreciate the full span of possible solutions without being beholden to one or the other. This flexibility is exhibited across the six cases examined.

Lastly, the lack of observed bias in the six cases does not seem to substantiate any one of the three theories about investment drivers described in this chapter. Rather, the evidence presented herein indicates that investment drivers are highly contextual and not amenable to a single parsimonious theory. The unsettled literature on investment drivers further reinforces this possibility.

\section{Case Comparison: Sponsors}

It is difficult to resist a comparison of the military services' relative abilities to react to and shift their investment priorities. Such comparisons usually are made to provide some insight into issues of service culture and practices. This research does not contain enough collected data from all services to make a similar comparison for the four services. 
However, a limited comparison of the actions taken by the Army and Marine Corps for four of the cases (PRC-117G, Palantir, MRAP, and CREW) can be made. In all four cases, the Army and Marine Corps' investments in these programs occurred at the same time. Additionally, two of the cases are of the same investment type (alternative investments). These constant elements will aid in uncovering any service-specific behaviors and preferences in immediate investments. Neither service behaved in a significantly different way than the other in the implementation of the four cases examined, with one exception. Figure 3.8 depicts the results of the service sponsor analysis.

Figure 3.8: Institutional Resistance by Service Sponsor

\begin{tabular}{ccc}
\hline Case & $\begin{array}{c}\text { Army Institutional } \\
\text { Resistance }\end{array}$ & $\begin{array}{c}\text { Marine Corps } \\
\text { Institutional Resistance }\end{array}$ \\
\hline PRC-117G & Low & Low \\
Palantir & High & Low \\
MRAP & High & High \\
CREW & Low & Low
\end{tabular}

\section{Low Resistance: PRC-117G and CREW}

No evidence of institutional resistance to the implementation of the PRC-117G and CREW was found during data gathering for these cases. It appears that both services were amenable to the PRC-117G and CREW systems because they both had demands for those capabilities that were either being developed too slowly for their current needs (in the case of the PRC-117G) or had not been considered by the conventional acquisition system at all (in the case of CREW).

Although both services were equally amenable to the PRC-117G and CREW, there were slight differences in how each of these investments were implemented by the services. The Marine Corps took greater advantage of the PRC-117G's networking capability. According to Harris Corporation representatives, the Marine Corps was quick to see the utility of the PRC-117G's ability to act as a wireless network node, in addition to its multi-band capabilities. Army units that procured the PRC-117G (the $82^{\text {nd }}$ Airborne Division and the $10^{\text {th }}$ Mountain Division) were more attracted to the radio's small size and did not take advantage of the radio's networking capabilities as much as the Marines did. Both services were willing to shift their investments to procure the PRC-117G. The 
Marines were more amenable to the PRC-117G and the full span of its capabilities, however.

In the case of CREW, the Army and Marine Corps differed in how long they were willing to wait for new iterations of CREW systems to be developed and fielded. The Army appears to be more willing to wait longer for more complete solutions, opting to pursue the development of the more technically-complicated (but potentially more effective) Duke system, rather than choose a commercially-developed jammer. The Duke system was a reactive jammer that listened for detonation signals and intercepted them. This allowed it to use less power because it was precisely targeted at detonation signals, rather than constantly broadcasting a jamming signal. It was also easier to integrate with other electronic systems, because it was not constantly broadcasting a signal that could also jam radios and command and control systems.

In the CREW case, the Marine Corps Systems Command decided to procure General Dynamics' Chameleon RCIED jammer, rather than wait for the Army to develop Duke. Chameleon was an active jammer that used a more "brute force" approach to RCIED jamming compared to the Duke. Chameleon was designed to constantly broadcast a jamming signal. This required more power and required mission planners to use other means to deconflict Chameleon's jamming signal with radios and other command and control systems.

\section{High Resistance: MRAP}

The Army and Marine Corps uniformly showed high resistance to the MRAP. Both services initially viewed the MRAP as too specialized for general use and lacking enough utility over existing armored vehicles (e.g., up-armored HMMVWs and trucks) to be a worthwhile investment. Both services were preparing to invest in the HMMVW's replacement, a vehicle program called the Joint Lightweight Tactical Vehicle (JLTV). The JLTV was supposed to incorporate some of the capabilities of the MRAP without the disadvantages in size, weight, and limited general utility. Ultimately, it took senior leaders outside of the services (the Secretary of Defense and Congress) to overcome this resistance to the MRAP. Both services behaved similarly in exhibiting high resistance to the MRAP.

\section{Mixed Resistance: Palantir}

The one system that the Army and Marine Corps exhibited different levels of institutional resistance to was Palantir. The Marine Corps showed low resistance to this intelligence analysis software. It initially took advantage of the software licenses procured through a JUONS submitted by the Deputy Chief of Staff for Intelligence of US 
Forces Afghanistan in 2010. It also renewed its licenses through its service-level UUNS process afterwards, indicating that it wanted to continue to invest in Palantir.

The Army initially took advantage of the Palantir licenses procured through the 2010 JUONS but eventually decided to continue the implementation of its DCGS-A program of record. There is evidence that showed that Army intelligence analysts did not agree with this change and sought to continue using Palantir. Eventually, this disagreement was made public, and the Army was forced to defend its decision to Congress.

The key factor in the differing responses by the Army and Marine Corps to Palantir was that the Army was closer to developing its program of record system, DCGS-A, than the Marine Corps was. The Marine Corps had begun to develop its own program of record, DCGS-MC, but was much further behind in the process than the Army was. The evidence appears to show that the Army felt that it was close enough to implementing DCGS-A that it felt that the disadvantages of Palantir (it was a proprietary system with fewer functions than DCGS-A) outweighed the benefits in terms of usability.

\section{Case Comparison: Cost Levels}

Cost levels were not observed to be a factor connected to institutional resistance in five of six examined investment cases. The two low cost programs examined faced low resistance (PRC-117G) and mixed resistance (high resistance to Palantir from the Army, low resistance from the Marine Corps). The institutional resistance to high cost programs also varied, from low resistance (CREW and ABIS) to medium resistance (Predator) to high resistance (MRAP). No pattern was found in these cases, as shown in Figure 3.9.

Figure 3.9: Institutional Resistance by Cost Level

\begin{tabular}{ccc}
\hline Case & Cost Level & $\begin{array}{c}\text { Institutional } \\
\text { Resistance }\end{array}$ \\
\hline PRC-117G & Low & Low \\
Palantir & Low & Mixed \\
Predator & High & Medium \\
MRAP & High & High \\
CREW & High & Low \\
ABIS & High & Low
\end{tabular}


For all cases except the MRAP, no mention of cost as a negative decision factor was found at all. In fact, for the PRC-117G and Palantir (both of which are alternative investments), their low costs compared to the struggling programs of record to which they were alternatives was a major positive factor in those investment decisions. Total program costs for the PRC-117G were approximately $\$ 600$ million, compared to the JTRS GMR program, which was $\$ 6$ billion (at the time of its cancellation in 2011), or ten times as much. The DoD spent \$35 million on Palantir licenses, compared to the $\$ 11.2$ billion spent on all versions and increments of DCGS up to 2012. In particular, congressional interest in DCGS-A and Palantir centered around how much more affordable the alternative investment was compared to the struggling program of record.

For three of the four high cost programs (Predator, CREW, and ABIS), cost also did not appear to be a decisive factor in investment or implementation decisions. Rather, cost appears to be a lagging indicator of efforts to mitigate implementation obstacles and responses to increased operational demand.

For new opportunities (CREW and ABIS), this apparent lack of concern for costs may have been because the DoD understood that the urgency and technology development required for both of these systems demanded a tolerance for high costs. Although RDT\&E costs are not captured in procurement budgets in the case of ABIS, the demand for a biometrics capability was such that the DoD acquired relatively underdeveloped systems to meet the demand while more technology development took place (at which time the DoD would procure more systems). For CREW, RDT\&E costs were accounted for in the Joint IED Defeat Fund (JIEDF) in the procurement budget. In both cases though, the lack of evidence pointing to cost levels as an investment decision factor may be due to the implicit understanding that the cost of new opportunity investments would be expensive.

In only one case (MRAP) did cost levels appear to be a factor mentioned in the case study. The MRAP's costs were not originally a decision factor, but only because the originator of the request for the vehicle (I MEF) suppressed their full demand for the vehicle, requesting only 1,169. After further senior level scrutiny, the requirement was increased to 15,912 vehicles, which included an Army request. As the requirement was increased, opposition to the MRAP grew. The MRAP's opponents pointed out that its costs were high compared to its limited utility as a general-purpose vehicle, the concurrent effort to up-armor existing HMMVWs, and the MRAP's impact on the Joint Light Tactical Vehicle (JLTV) program. Quite simply, the MRAP did not appear to be worth the cost in the eyes of some Army and Marine Corps leaders. It took senior DoD leadership, Congressional, and press scrutiny to overcome the services' cost objections. 
The same might have been true for the Predator, had it not been for two factors. First, the lack of cost as a decision factor for investment may be due to the fact that the program was relatively small compared to other Air Force procurement priorities. For instance, the Predator and its successor (the MQ-9 Reaper) cost one-fifth of the Air Force's F-22 Raptor procurement (Figure 3.5). The Predator was simply not expensive compared to other Air Force programs.

Figure 3.7: MQ-1, MQ-9, and F-22 Cumulative Program Costs

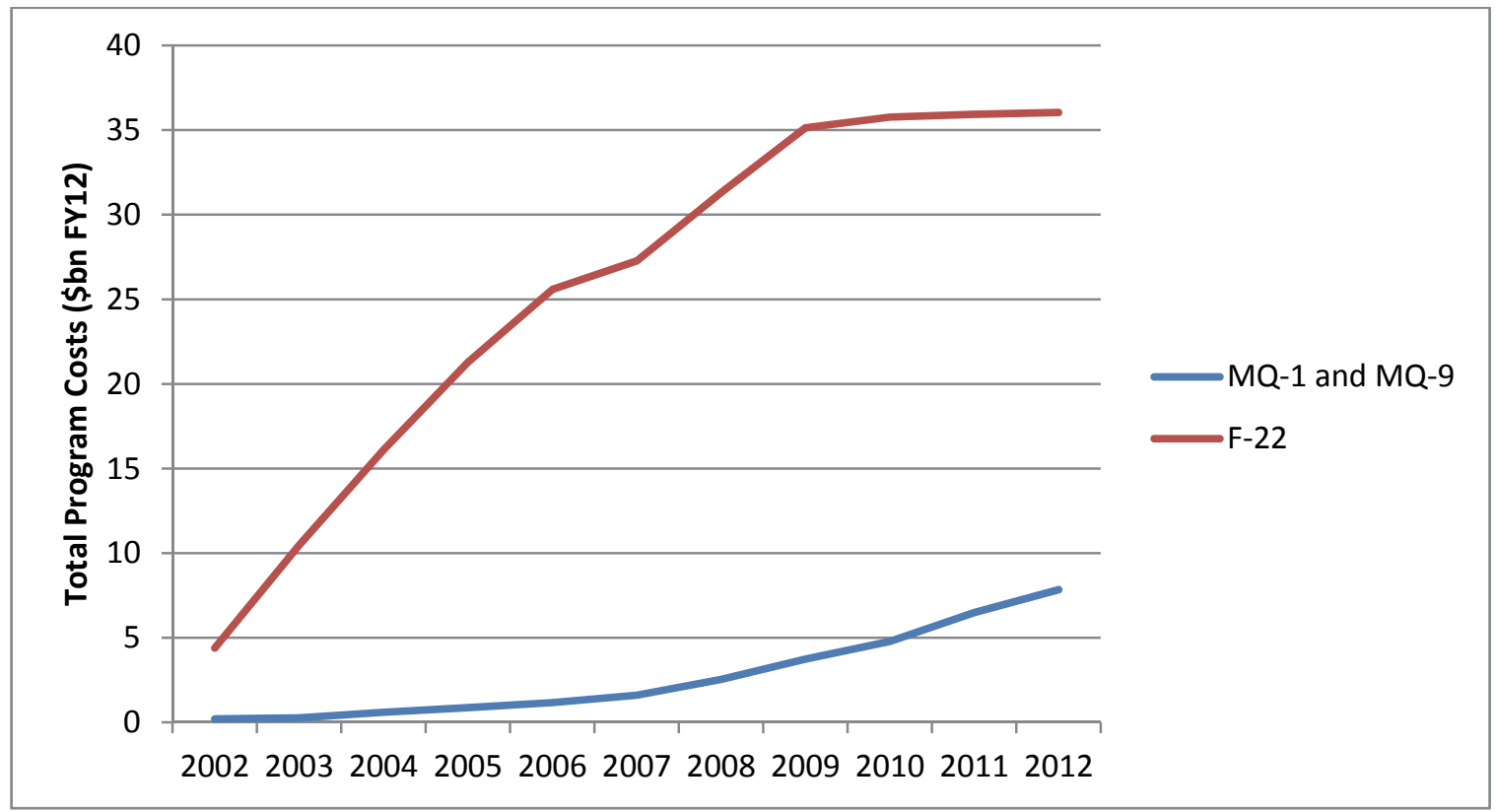

Source: Author analysis of DoD budget justification documents

The other factor that might have dampened the resistance to increased Predator demand may have been that the sum of the demand could be met by rearranging existing resources. In fact, senior leaders focused on the lack of trained aircrews and underutilized Predators outside of CENTCOM as issues that required their attention, not increased funding for airframes. Increased procurement was also needed, but this was not the most contentious point.

I conclude that cost level was not a factor in the DoD's decision to make immediate investments during $\mathrm{OIF} / \mathrm{OEF}$, at least compared to other factors (e.g., investment driver or type). In five of the six cases, costs were not found to be a decision factor in the DoD's investment decision. However, costs were a factor in the MRAP. This is not a small caveat - the MRAP was by far the largest of the six cases examined in this research. It 
was even significantly larger than the other four high-cost programs examined (see Figure 3.6). There may be some cost level higher than $\$ 5.2$ billion (which was the cumulative cost of the next highest program after MRAP) where cost is a factor, but we cannot conclude that from the cases or data available.

Figure 3.8: Cumulative Program Costs (High Cost Cases)

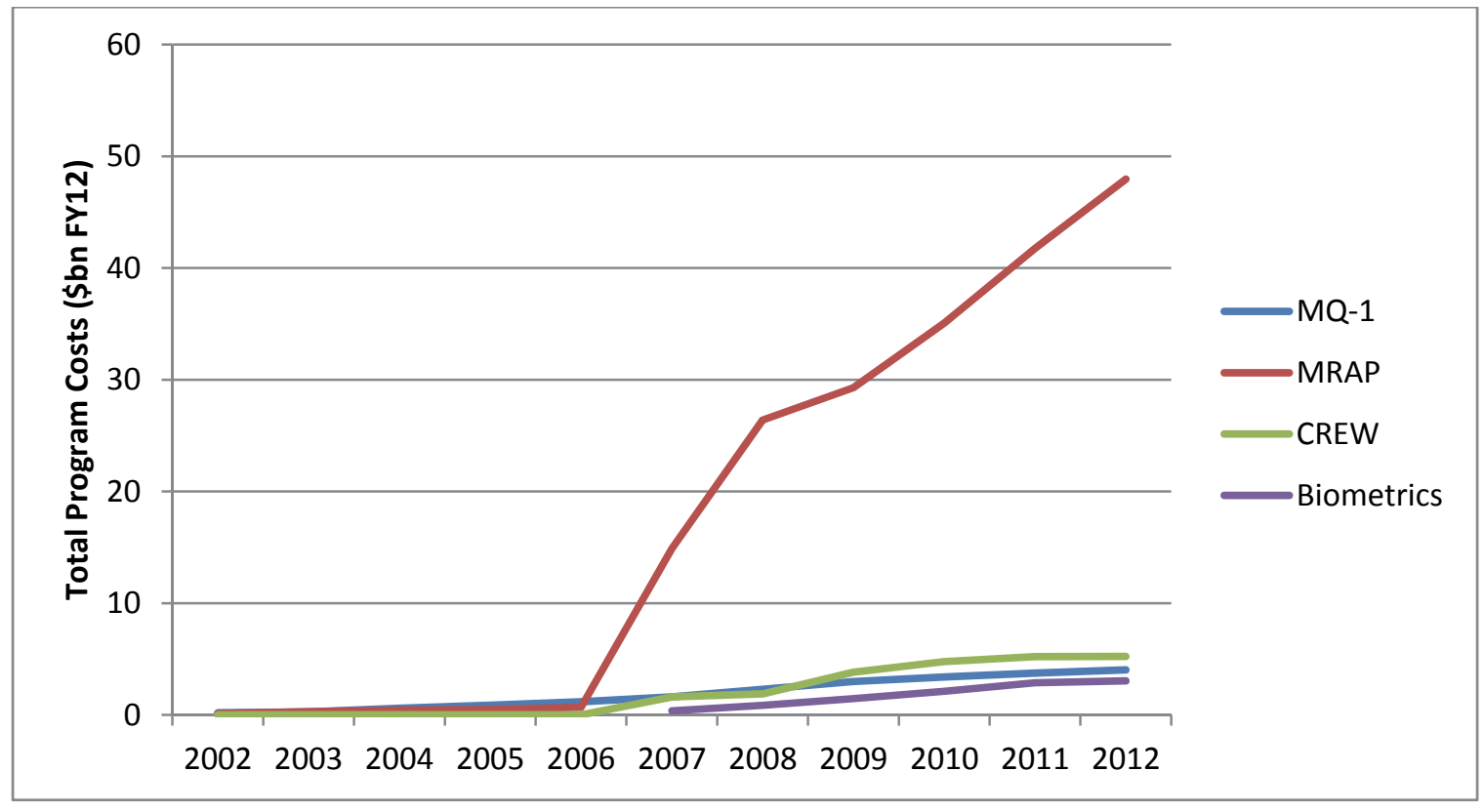

Source: Author analysis of DoD budget justification documents, GAO

\section{Cross-Factor Comparisons}

Having examined the individual impact of investment type, drivers, sponsors, and cost levels, I now examine institutional resistance to the six investment cases across factors. Figure 3.9 summarizes this analysis.

Figure 3.9: Institutional Resistance Across Factors

\begin{tabular}{ccccccc}
\hline Case & $\begin{array}{c}\text { Institutional Investment } \\
\text { Resistance }\end{array}$ & $\begin{array}{c}\text { Investment } \\
\text { Type }\end{array}$ & $\begin{array}{c}\text { Sponsor } \\
\text { Desiver } \\
\text { (Army) }\end{array}$ & $\begin{array}{c}\text { Sponsor } \\
\text { Resistance } \\
\text { (USMC) }\end{array}$ & $\begin{array}{c}\text { Cost } \\
\text { Level }\end{array}$ \\
\hline PRC- & Low & Alternative & Simultaneous & Low & Low & Low \\
$117 \mathrm{G}$ & & & & & Low & Low \\
Palantir & Mixed & Alternative & Simultaneous & High & & High \\
Predator & Medium & Missed & Sequential & & &
\end{tabular}




\begin{tabular}{lllllll}
\hline MRAP & High & Missed & Threat & High & High & High \\
CREW & Low & New & Threat & Low & Low & High \\
ABIS & Low & New & Threat & Low & Low & High
\end{tabular}

\section{Analysis of High and Medium Institutional Resistance Programs}

Palantir, the Predator, and the MRAP were observed to have encountered high or medium institutional resistance by their relative stakeholders (the Army showed high resistance to Palantir, while the Marine Corps did not). The common theme in these three cases is that the DoD's institutional stakeholders resisted these investments because they required a substantial reconsideration of previous acquisition decisions. Both the MRAP and the Predator were missed opportunity investments where the conventional DoD acquisition process rejected the need for the capability (in the case of the MRAP) or settled on a lower level of investment than was ultimately needed (in the case of the Predator). The same theme is present in the Army's high resistance to Palantir, despite it being an alternative investment. Adopting Palantir would have required the Army to disregard the progress and sunk costs in the DCGS-A program, which was difficult to do because the Army judged that DCGS-A was close to achieving its goals.

\section{Analysis of Low Institutional Resistance Programs}

This theme of requiring a substantial reconsideration of previous acquisition decisions is not present in the four instances of low institutional resistance. For the two new opportunity investments (CREW and ABIS), no previous acquisition decisions were made. Similarly for Palantir, the Marine Corps in 2010 had not started to invest significant resources in developing DCGS-MC, even though it was already established as a program of record.

The PRC-117G case requires more careful analysis. PRC-117G is an alternative to the JTRS program of record, which was well established, unlike the DCGS-MC program. It was 13 years old by the time the PRC-117G was developed and over $\$ 6$ bn had already been spent on it. However, JTRS was widely recognized to be unable to field a tactical radio in time to meet operational needs. The Defense Information Systems Agency (DISA) acknowledged this when it issued a general waiver to the services in 2005 to allow them to procure legacy radio systems to meet operational needs. Therefore, the PRC-117G case conforms to the theme described above because DISA and the services recognized that no reconsideration of a previous acquisition decision was necessary. The condition of the JTRS program made such reconsideration a moot point. 


\section{Conclusion}

In this chapter, I have described how investment types, drivers, the sponsoring service, and cost levels affected DoD stakeholders' acceptance or resistance to six immediate investments. Analysis of the cases showed that:

- The cases that showed evidence of the most institutional resistance to implementation were the MRAP and Predator, which were both missed opportunity investments.

- DoD stakeholders in the six cases were driven by both the need to react to the enemy threat and the desire to capture technological advances. These stakeholders were not biased toward one driver or the other, but capitalized on both in ways that best fit the context for each case.

- Analysis of four cases showed that the service sponsor (the Army and Marine Corps in this research) was not a significant factor in the acceptance of or resistance to an immediate investment.

- Cost levels did not contribute to the acceptance or resistance of five of the six cases. For the MRAP, high cost was a factor that contributed to institutional resistance to its implementation.

Analysis across these factors revealed that the institutional resistance to the six immediate investments examined was attributable to the difficulty of a DoD stakeholder in substantially reconsidering previous acquisition decisions. This theory holds true for the two missed opportunity investments examined, as well as for one alternative investment case where the program of record was close to achieving its goals. Analysis of cases that showed low institutional resistance also confirms this theory.

This theory is the manifestation of bureaucratic inertia. OIF and OEF created conditions that were very amenable to increased immediate investments. Policies were changing to accommodate more immediate investments, as shown in Chapter One. DoD procurement funding was increased through the growth of supplemental funds. The conflicts in Iraq and Afghanistan allowed the DoD to focus on a clear adversary, rather than planning for a hypothetical one. This theory of institutional resistance, attributable to the need to reconsider previous acquisition decisions, represents the bureaucratic behavior that persists in these organizations in spite of these conditions. This behavior can be best described as bureaucratic inertia. 


\section{Chapter Four: Recommendations and Conclusions}

Rapid acquisition played a significant role in the Iraq and Afghanistan Wars. The way the United States fought these wars depended almost as much on the rapidly-acquired tools of war as the skill, imagination, and bravery of the men and women who wielded them. Although the strategic outcomes of the Iraq and Afghanistan Wars have been disheartening to date, the imprint of rapid acquisition efforts on the wars is unmistakable.

With that in mind, I turn to our final research question, which seeks to take what we have learned about rapid acquisition and build on it for the future.

RQ4: What policy, organizational, and incentive structure changes should be considered if operational and organizational conditions warrant greater consideration for immediate investments?

To better understand how policy and practices need to be changed, I begin this chapter by reviewing the findings from the previous three chapters. I then discuss some areas for further research that were outside the scope of this dissertation. Next, I propose three policy recommendations to marginally improve rapid acquisition policies across the DoD. Lastly, I argue that the findings imply that the DoD's rapid acquisition enterprise should not be modified beyond such marginal improvements.

\section{Review of Findings}

The previous three chapters examined changes in rapid acquisition policy (Chapter One), how those changes affected the DoD's procurement budget (Chapter Two), and how those changes affected the implementation of six rapid acquisition programs (Chapter 3). These findings are summarized in Figure 4.1:

Figure 4.1: Summarized Findings

\begin{tabular}{cll}
\hline Chapter & \multicolumn{1}{c}{ Finding } \\
\hline One & $\bullet$ & The DoD increased the pathways to rapid acquisition. \\
& $\bullet$ & The policies emphasized speed in validating urgent needs but \\
& remained otherwise ambiguous about the speed at which each \\
& pathway performed at overall
\end{tabular}


- Some funding for rapid acquisition was allocated. For other cases, policies for shifting funds implied the need for program officers to identify funding sources and gain buy-in for reprogramming for all pathways except REF and JIEDDO.

- All pathways except REF required senior (O-9 or civilian equivalent and above) leaders to be actively involved in approving or turning down urgent needs.

- All pathways except REF required O-6 or higher entry to the system.

Two - DoD increased its immediate investments as a share of total procurement budget requests during the course of OIF/OEF.

- $46 \%$ of immediate investments between FY02-12 are either identifiably or likely linked to changes in DoD rapid acquisition policies.

- $51 \%$ of immediate investments between FY02-12 were MRAP investments linked to senior leader intervention outside of rapid acquisition policy.

Three - The cases that showed evidence of the most institutional resistance to implementation were the MRAP and Predator, both of which were missed opportunity investments.

- DoD stakeholders in the six cases were driven by both the need to react to the enemy threat and the desire to capture technological advances. These stakeholders were not biased toward one driver or the other, but capitalized on both in ways that best fit the context for each case.

- Analysis of four cases showed that the service sponsor (Army and Marine Corps in this research) was not a significant factor in the acceptance of or resistance to an immediate investment.

- Cost levels did not contribute to the acceptance of or resistance to five of the six cases. For the MRAP, its high cost was a factor that contributed to institutional resistance to its implementation.

\section{Areas for Further Research}

The process of investigating my research questions has uncovered more questions and areas for further research that are outside of the scope of this work. In this case, three specific areas deserve attention and scrutiny. 
First, a more detailed analysis of the relevant DoD budgets is warranted. Although the effort described in Chapter Two represents one of the fullest accountings of DoD immediate investment spending to-date, even more fidelity can be gained by examining budget items down to the program element (PE) level, which required more resources and manpower than was reasonable for this research. My examination indicated that there were a number of immediate investment activities occurring at the PE level. A more detailed examination can refine the estimate on immediate investment spending even further.

Second, RQ3 should be examined from the perspective of rapid acquisition organizations. I emphasized depth by examining individual rapid acquisition programs as a case study unit of analysis. A complementary analysis can emphasize breadth by examining the organizations that are responsible for rapid acquisition processes (e.g., JRAC, the Army REF, Air Force Rapid Capabilities Office, etc.). It will be interesting to see if the same findings observed in this research are confirmed in an analysis based on organizations as a unit of analysis.

Third, this research can benefit from an examination of failed rapid acquisition program cases. Although I chose to focus on successful programs to focus on how the DoD shifted between immediate and long-term investments, there is still benefit in examining instances when the DoD was not able to shift between investments. As with an examination based on rapid acquisition organizations, it will be interesting to see if my findings here are confirmed through the examination of failed cases.

Lastly, this research can be extended to explore the intersection between rapid acquisition and defense innovation. In this research, I observed innovative processes and outcomes in several cases, but did not explore them in depth. For example, the initial development of the MQ-1A and MQ-1B featured early prototyping, a focus on end users, fast iterations, and other aspects of its development that could be considered innovative. The same could be said of the PRC-117G, Palantir, and CREW. Do the organizational conditions that are enabled by rapid acquisition processes (e.g., better communication between stakeholders, end user input, and access to decision-makers) foster innovative practices? Can an innovative environment exist in other DoD organizational structures? How can those practices be adapted to deliberately emphasize innovation? These questions can be answered with further research. 


\section{Recommendations}

In this section, I will return to the topic at hand and discuss the implications of my findings to the rapid acquisition process across the DoD. I will first discuss how six of the 12 key findings warrant three particular policy changes. I will then argue that those policy changes are marginal improvements to the existing system and that the remaining six key findings indicate that the DoD's rapid acquisition policies are largely sufficient and should not be substantially changed.

\section{Widen the Intake of Rapid Acquisition Ideas}

Joint and service rapid acquisition policies should uniformly and explicitly allow any service member to initiate a rapid acquisition request. This recommendation stems from the following key finding from Chapter One:

- All pathways except REF required O-6 or higher entry to the system

This finding is incongruous with data collected from three case studies not previously discussed that suggest that bottom-up ideas from the operator level may yield useful innovations and improvements. ${ }^{82}$ For example, the MQ-1B's ROVER III mobile video feed was first imagined by an enlisted Army SF soldier who took the initiative to contact GA-ASI directly with the concept. Both Palantir Technologies and Harris Communications observed their users closely through field service representatives (FSR) and after action input and responded to their needs quickly. The value of bottom-up inputs from those who would be using these capabilities in the field can be significant and should be harnessed. While an organized and prioritized process to capture and validate rapid acquisition requests should exist, three improvements to capitalize on these inputs should be made.

First, service and joint policies should all explicitly state that any servicemember can initiate a request. Currently, all policies except the Army REF and Marine Corps UUNS either do not explicit state this or require O-10 initiation in the case of JUONS. Figure 1.3 (reprinted here as Figure 4.1) describes the current paths to initiation:

Figure 4.1: Rapid Acquisition Initiating Authorities

\begin{tabular}{l}
\hline \multicolumn{1}{c}{ Process } \\
\hline Initiator \\
${ }^{82}$ The evidence from the Predator, $\mathrm{PRC}-117 \mathrm{G}$, and Palantir cases was not previously discussed because \\
they were not part of the framework discussed in Chapter Three. In light of the findings from Chapter One, \\
they are presented here.
\end{tabular}




\begin{tabular}{ccc}
\hline JUONS & Combatant Commander & None \\
Army ONS & Any (implied) & First O-6 in chain of command \\
Army REF & Any & None \\
Navy UON & Any (implied) & First flag officer in chain of \\
command \\
Marine Corps UUNS & Any & COMMARFOR (O-9) \\
Air Force QRC & Any (implied), & Needs to be submitted by \\
& Cource: Author analysis of rapid acquisition policies
\end{tabular}

For the JUONS process, the policy should be changed so that any servicemember can initiate a rapid acquisition request. For the service policies, implied permission to initiate a request should be changed to explicitly allow it, as it is stated in the Army REF and Marine Corps UUNS policies. That explicit permission should be accompanied by a simple submission format, similar to the Army REF 10-liner template.

Second, the endorsement requirement should be modified so that requests must still be routed to the rapid acquisition process owners, even in the case of a non-endorsement by the chain of command. The process owner should still give greater consideration to endorsed requests, but allowing all requests to flow to the process owner can help identify trends in requests across different units and endorsing officials. Process owners can use simple analytic toolkits (similar to ones used by many marketing firms to analyze internet traffic) and standardized categorical responses from the submission forms to better anticipate, understand, and (possibly) act on needs being expressed by forces in the field.

Third, the expanded intake of rapid acquisition requests should be accompanied by an educational component. The imaginative non-commissioned officers and junior officers who are likely to have ideas will not likely know about rapid acquisition processes buried in obscure policy publications. Nor should their precious training and education time be taken up by learning specifically about it. Rather, the E-9s, E-10s, O-4s and O-5s who are their natural mentors should be ready to shape those ideas into rapid acquisition requests. Therefore, career-level education (e.g., SNCO and CPO academies and service command and staff colleges) should devote part of their curriculum on the acquisition process to the policies and processes for rapid acquisition. The goal is to give these experienced SNCOs and field grade officers a better understanding of what rapid acquisition is, when it should 
be used, and how to initiate requests. This education gives the expanded intake of requests the necessary guidance and in addition to providing a modicum of moderation.

\section{Scalable Rapid Acquisition Authority for Services}

Congress should enact legislation increasing the authority of each service to cumulatively reprogram up to $\$ 50 \mathrm{~m}$ across appropriations annually (up from $\$ 20 \mathrm{~m}$ ) for funding rapid acquisition programs without seeking prior approval from Congress. This recommendation is based on three findings from Chapters One and Two:

- Some funding for rapid acquisition was allocated. For other cases, policies for shifting funds implied the need for program officers to identify funding sources and gain buy-in for reprogramming for all pathways except REF and JIEDDO.

- $46 \%$ of immediate investments from FY02-12 were either identifiably or likely linked to changes in DoD rapid acquisition policies.

- $51 \%$ of immediate investments from FY02-12 were MRAP investments linked to senior leader intervention outside of rapid acquisition policy.

These findings indicate that funding for rapid acquisition priorities is not built into policy, but that the DoD collectively took advantage of reprogramming authorities for $46 \%$ of immediate investments. For MRAP-related investments (that made up $51 \%$ of immediate investments), policymakers had to intervene and fund that effort separately.

This implies that while there are instances in rapid acquisition programs where flexibility is taken advantage of, there was no guidance to rapid acquisition program officers and other stakeholders on funding rapid acquisition. Scalable rapid acquisition authority can help provide the necessary leadership signal to subordinate stakeholders in regard to funding rapid acquisition.

This authority would mirror the current rapid acquisition authority granted to the Secretary of Defense. Additionally, that authority should increase to $\$ 75 \mathrm{~m}$ for services and up to $\$ 150 \mathrm{~m}$ for the Secretary of Defense upon the declaration of war, authorization of the use of military force, or other statue signifying the beginning of a conflict. This authority should be granted to the service secretary, delegable to the service acquisition executive (SAE).

Some level of assured funding is vital to the rapid acquisition enterprise. The findings from Chapter One and Two implied that the process of identifying funding sources (known as "bill-payers" in DoD parlance), enlisting stakeholder support, and reprogramming the funding is highly dependent on the skills of individual program 
officers. The DoD should not depend on this arbitrary factor to support rapid acquisition. Nor should it expect the generous level of supplemental funding that underpinned many rapid acquisition programs during OIF/OEF. Therefore, the only remaining option to fund these priorities is to grant more authority for the services to move funds from across appropriations to the rapid acquisition enterprise through the existing policies. This will be inadequate to address large capability gaps like the MRAP (those should be addressed in the recommendation below), but it will be sufficient for a variety of rapid acquisition needs.

Currently, the DoD Financial Management Regulation states that any procurement reprogramming that does not require Congressional approval (known as below the threshold, or BTR) is limited to $\$ 20 \mathrm{~m} .{ }^{83}$ This reprogramming does not allow for transfers between appropriations. Additionally, the 2003 NDAA authorized the Secretary of Defense up to $\$ 100 \mathrm{~m}$ annually of reprogramming authority without prior Congressional approval. ${ }^{84}$ The current $\$ 20 \mathrm{~m}$ BTR would not be sufficient to procure even low cost programs like the $\$ 35 \mathrm{~m}$ Palantir investment. Without a high level of supplemental funding, the reprogramming status quo is inadequate for the task of simultaneously addressing multiple capability gaps within a fiscal year.

Furthermore, this authority should be explicitly mentioned in rapid acquisition policies if enacted. By explicitly citing service rapid acquisition authority, program managers and requestors will have a citable resource for identifying funding sources. While it will add nothing to the authority itself, this explicit mention will clear up any confusion about how to seek out rapid acquisition funding.

\section{Be Prepared to Use Single-Purpose Task Forces}

The DoD should expect to continue to use single-purpose task forces to rapidly and effectively address missed opportunity gaps. This recommendation is based on the following findings from Chapters Two and Three:

- $51 \%$ of immediate investments from FY02-12 were MRAP investments linked to senior leader intervention outside of rapid acquisition policy.

- The cases that showed evidence of the most institutional resistance to implementation were the MRAP and Predator, both of which were missed opportunity investments.

\footnotetext{
${ }^{83}$ Department of Defense. 
- Cost levels did not contribute to the acceptance or resistance of five of the six cases. For the MRAP, high cost was a factor that contributed to institutional resistance to its implementation.

The MRAP and MQ-1B case studies clearly show that there are instances when a capability gap that needs to be addressed exceeds the ability of any policy, no matter how well written, to address. This is particularly true for missed opportunity capabilities that had already been considered and rejected by the conventional acquisition system.

In such cases, intense disagreement about filling the capability gap should be expected, requiring senior leader intervention in the form of a task force empowered by the authority of a service secretary, the Deputy Secretary of Defense, of the Secretary of Defense to undo the previous consensus and positions formed about the missed opportunity. Such task forces should be chartered so that they are able to break through the organization's previous decision by:

- Being bound solely by statute and regulation, not by policies set by the organization

- Having direct access to the principal in order to signal the importance of the issue to the organization and to trigger funding reprogramming (see scalable rapid acquisition authority recommendation above)

- Being led by an O-9 (or civilian equivalent) or higher rank in order to have sufficient seniority to interface on a peer basis with service acquisition organizations.

Attempting to rapidly address a missed opportunity through a targeted policy (and not a task force) is inadvisable. Having a policy that specifically undoes the results of the acquisition process would further muddle that process by opening up the possibility that any decision made by the service or joint acquisition process can be held up by stakeholders wielding such a policy.

\section{Conclusion: An Adequate Status Quo}

Surprisingly, the rapid acquisition enterprise today does not need significant reform. Although it took time (and lives) to develop, the rapid acquisition system grew into a capable set of tools that helped troops in the field quickly identify and procure needed equipment. This assessment is supported by the following findings from Chapters One, Two, and Three: 
- The DoD increased the pathways to rapid acquisition.

- The policies emphasized speed in validating urgent needs, but remained otherwise ambiguous about the speed at which each pathway performed at overall.

- All pathways except REF required senior (O-9 or civilian equivalent and above) leaders to be actively involved in approving or turning down urgent needs.

- DoD increased its immediate investments as a share of total procurement budget requests during the course of OIF/OEF.

- $46 \%$ of immediate investments from FY02-12 are either identifiably or likely linked to changes in DoD rapid acquisition policies.

- DoD stakeholders in the six cases were driven by both the need to react to the enemy threat and the desire to capture technological advances. These stakeholders were not biased towards one driver or the other, but capitalized on both in ways that best fit the context for each case.

- Analysis of four cases showed that the service sponsor (Army and Marine Corps in this research) was not a significant factor in the acceptance of or resistance to an immediate investment.

I did not expect to find a rapid acquisition system that - perhaps inadvertentlybalances speed with effectiveness and oversight with responsiveness. Whether it was intentional or not, the DoD's rapid acquisition enterprise is a surprisingly nuanced, versatile, and effective set of policies. It leaves just enough room to allow imaginative and mission-driven individuals the chance to quickly generate equipment solutions, without giving too much license to wasteful, fanciful, or infeasible ideas. It is telling that the three recommendations above are not fundamental reconsiderations of the rapid acquisition enterprise. Rather, they seek to improve on attributes that already exist.

The three policy recommendations made in this chapter can be best described as evolutionary. More dramatic changes are not warranted. Given the uncertainty of the timing associated with these policies and the high speed and performance demanded of them when they are used, it is best to resist the temptation to tweak it for greater accountability, or to give it a line item in service procurement budgets. The delicate balance between speed, performance, accountability, and initiative that these policies have created served the DoD well in the past ten years should be preserved to the extent possible. 


\section{Appendix A: Rapid Acquisition Policy Scan}

The following charts detail the investment flexibility metrics of six different rapid acquisition policies between FY002-12. 


\section{Joint Process}

\begin{tabular}{|c|c|c|c|c|}
\hline & $\begin{array}{l}\text { JUON } \\
2012\end{array}$ & $\begin{array}{l}\text { JUON } \\
2010\end{array}$ & $\begin{array}{l}\text { JUON } \\
2005\end{array}$ & $\begin{array}{l}\text { IWN } \\
2004\end{array}$ \\
\hline $\begin{array}{l}\text { Minimum Speed of } \\
\text { Performance }\end{array}$ & - No change & - No change & $\begin{array}{l}\text { - See Appendix F: CREW Case Study } \\
\text { for details. }\end{array}$ & - Not specified, but fast. \\
\hline $\begin{array}{l}\text { Maximum Funding } \\
\text { Allowed }\end{array}$ & - No change & $\begin{array}{l}\text { - Recommends using existing non-RAA } \\
\text { authorities to accomplish mission }\end{array}$ & $\begin{array}{l}\text { - Only allowed to field up to ACAT II } \\
\text { equivalents. } \\
\text { - Can tap into CbtRIF, CCIF, C2IP, } \\
\text { other funding lines, or supplementals }\end{array}$ & - Not specified \\
\hline Level of Secured Funding & - No change & - No change & - $\$ 0$. Relies on reprogrammed funds. & - Not specified \\
\hline $\begin{array}{l}\text { Senior Leader Attention } \\
\text { Required }\end{array}$ & $\begin{array}{l}\text { - SIG (DepSecDef) established } \\
\text { to ensure senior leader attention }\end{array}$ & • & $\begin{array}{l}\text { - DoD Comptroller has highest } \\
\text { visibility. } \\
\text { - JRAC (and thus the DepSecDef) also } \\
\text { has visibility. }\end{array}$ & $\begin{array}{l}\text { - Not specified, but directed } \\
\text { AT\&L and Comptroller to get } \\
\text { on it. }\end{array}$ \\
\hline $\begin{array}{l}\text { Number of Approvals } \\
\text { Required }\end{array}$ & - No change & - No change & $\begin{array}{l}\text { - } 8 \text {-step process } \\
\text { - Starts w/ CCDRs } \\
\text { - Approved by 6-member BOD led by } \\
\text { Deputy OUSD(Comp) }\end{array}$ & - Not specified \\
\hline Other Constraints & - Elevated to DoDD & - DepSecDef Memo & $\begin{array}{l}\text { - Must not require new tech } \\
\text { development. Exception is if ACTD } \\
\text { can be accelerated. } \\
\text { - Addresses theater-wide, multi-service } \\
\text { needs } \\
\text { - Must be inherently joint } \\
\text { - Not currently addressed by } 5000 \\
\text { series or service process }\end{array}$ & $\begin{array}{l}\text { Policy memo directs creation } \\
\text { of JRAC to break through } \\
\text { bureaucratic inertia that } \\
\text { prevents DoD from utilizing } \\
\text { full policy flexibility. }\end{array}$ \\
\hline
\end{tabular}




\section{Army Process}

\begin{tabular}{|c|c|c|}
\hline & $\begin{array}{l}\text { ONS } \\
2009\end{array}$ & $\begin{array}{l}\text { ONS } \\
1997\end{array}$ \\
\hline $\begin{array}{l}\text { Minimum Speed of } \\
\text { Performance }\end{array}$ & $\begin{array}{l}\text {-Initial response from G-3/5/7 within } \\
14 \text { days as guidance } \\
\text { - Notes that timelines depend on } \\
\text { complexity of need. }\end{array}$ & $\begin{array}{l}\text {-Will provide at least an interim } \\
\text { response within } 120 \text { days }\end{array}$ \\
\hline $\begin{array}{l}\text { Maximum Funding } \\
\text { Allowed }\end{array}$ & $\begin{array}{l}\text {-No guidance, notes that DCS G-8, } \\
\text { DCS G-4, ASA(ALT), AMC, or REF } \\
\text { provides resourcing solution }\end{array}$ & $\begin{array}{l}\text { - No guidance. Discouragingly } \\
\text { highlights fact that validation doesn't } \\
\text { imply funding or fielding. }\end{array}$ \\
\hline Level of Secured Funding & $\begin{array}{l}\text { - } \$ 0, \text { but can draw from JIEDDF and } \\
\text { service budgets }\end{array}$ & $\begin{array}{l}\text { - None, although it allows MACOM } \\
\text { funding as an alternative to competing } \\
\text { for existing funds. }\end{array}$ \\
\hline $\begin{array}{l}\text { Senior Leader Attention } \\
\text { Required }\end{array}$ & $\begin{array}{l}\text {-DCS G-3/5/7 Current and Future } \\
\text { Warfighting Capabilities Div is } \\
\text { decision authority } \\
\text {-Directed Requirement can be made by } \\
\text { VCS or DCS G-3/5/7 unless ACAT I }\end{array}$ & $\begin{array}{l}\text {-DCS Operations and Plans (3-star) } \\
\text { executes ONS process, }\end{array}$ \\
\hline $\begin{array}{l}\text { Number of Approvals } \\
\text { Required }\end{array}$ & $\begin{array}{l}\text {-Initiated by any O- } 6 \text { level command } \\
\text { - } 3 \text { star AR2B validates. }\end{array}$ & $\begin{array}{l}\text { - A general officer must endorse. } \\
\text { - Does not describe staffing process } \\
\text { within HQDA (DCSOPS). }\end{array}$ \\
\hline Other Constraints & $\begin{array}{l}\text {-Army only } \\
\text { - Deployed units get the first priority, } \\
\text { then deploying soon, then everyone } \\
\text { else. }\end{array}$ & $\begin{array}{l}\text { - Combat, material, and training } \\
\text { development commands cannot } \\
\text { initiate ONS. }\end{array}$ \\
\hline
\end{tabular}




\section{Army Process (REF)}

\begin{tabular}{|c|c|c|}
\hline & $\begin{array}{l}\text { Army REF } \\
2010\end{array}$ & $\begin{array}{l}\text { Army REF } \\
2005\end{array}$ \\
\hline $\begin{array}{l}\text { Minimum Speed of } \\
\text { Performance }\end{array}$ & - No change & $\begin{array}{l}\text { Equipped in } 90 \text { days or less, but } \\
\text { another presentation cites } 180 \text { days. } \\
\text { Unclear. }\end{array}$ \\
\hline $\begin{array}{l}\text { Maximum Funding } \\
\text { Allowed }\end{array}$ & - No change & $\begin{array}{l}\text { - REF funding is not meant to exceed } \\
\text { ACAT III equivalent. }\end{array}$ \\
\hline Level of Secured Funding & - No change & - REF has a budget line. \\
\hline $\begin{array}{l}\text { Senior Leader Attention } \\
\text { Required }\end{array}$ & - No change & $\begin{array}{l}\text { - Approval by REF Director (O-6). } \\
\text { - All REF programs designated as } \\
\text { special interest ACAT III programs } \\
\text { by AAE. REF Director briefs } \\
\text { projects quarterly. }\end{array}$ \\
\hline $\begin{array}{l}\text { Number of Approvals } \\
\text { Required }\end{array}$ & - No change & $\begin{array}{l}\text { - } 10 \text {-liner can be submitted by soldier. } \\
\text { Four decision points: requirement, } \\
\text { cost/sched/performance approval, } \\
\text { equipping decision, disposition } \\
\text { decision }\end{array}$ \\
\hline Other Constraints & $\begin{array}{l}\text { REF projects should prioritize nine } \\
\text { specific lines of effort. Other } \\
\text { programs are given priority as } \\
\text { resources allow. }\end{array}$ & - Army only \\
\hline
\end{tabular}




\section{USMC Process}

\begin{tabular}{|c|c|c|c|c|}
\hline & $\begin{array}{l}\text { UUNS } \\
2008\end{array}$ & $\begin{array}{l}\text { UUNS } \\
2006\end{array}$ & $\begin{array}{l}\text { UUNS } \\
2004\end{array}$ & $\begin{array}{l}\text { UUNS } \\
2003\end{array}$ \\
\hline $\begin{array}{l}\text { Minimum Speed of } \\
\text { Performance }\end{array}$ & $\begin{array}{l}\text { - } 60 \text { days from receipt to CD\&I for } \\
\text { action to MROC decision maker. } \\
\text { - No other time limit to accommodate } \\
\text { needs requiring tech development. }\end{array}$ & - No change & - No change & $\begin{array}{l}\text { - Timeline for submission driven by } \\
\text { impending OIF II deployment. } \\
\text { - Does not discuss speed of response } \\
\text { to submissions. }\end{array}$ \\
\hline $\begin{array}{l}\text { Maximum Funding } \\
\text { Allowed }\end{array}$ & - No change & $\begin{array}{l}\text { Does not specify, but assigns } \\
\text { DC P\&R as entity responsible } \\
\text { for identifying resourcing. }\end{array}$ & - No change & $\begin{array}{l}\text { Does not specify. RAA can be used, } \\
\text { but is not mentioned. }\end{array}$ \\
\hline Level of Secured Funding & $\begin{array}{l}\text { - } \$ 0 \text {, but can draw from JIEDDF and } \\
\text { service budgets }\end{array}$ & - No change & - No change & - None. Does not specify. \\
\hline $\begin{array}{l}\text { Senior Leader Attention } \\
\text { Required }\end{array}$ & - No change & - No change & - No change & - 3-star MROC votes (12 members) \\
\hline $\begin{array}{l}\text { Number of Approvals } \\
\text { Required }\end{array}$ & $\begin{array}{l}\text { - Makes 5-member CDIB the entity } \\
\text { that conducts DOTMLPF analysis. }\end{array}$ & $\begin{array}{l}\text { - Same process, but generalizes } \\
\text { MEF and MARFOR (Marine } \\
\text { component). }\end{array}$ & $\begin{array}{l}\text { - Same steps and process, except } \\
\text { II MEF and MARCENT replace } \\
\text { I MEF and MARFORPAC. }\end{array}$ & $\begin{array}{l}\text { - } 4 \text { step process } \\
\text { - I MEF consolidates all requests } \\
\text { - MARFORPAC endorses. } \\
\text { - DC CD conducts expedited } \\
\text { DOTMLPF assessment } \\
\text { - Staffed to MROC for decision. }\end{array}$ \\
\hline Other Constraints & $\begin{array}{l}\text { - Marine Corps only } \\
\text { - Very broad }\end{array}$ & $\begin{array}{l}\text { - Generalizes audience to beyond } \\
\text { OIF/OEF to any operation. } \\
\text { - Assigns tracking and usage } \\
\text { reporting requirements to MEFs. }\end{array}$ & $\begin{array}{l}\text { Guidance updated for OIF III, } \\
\text { only applies to units falling } \\
\text { under II MEF's deployment. }\end{array}$ & $\begin{array}{l}\text { - Highlights the fact that UUNS are an } \\
\text { accelerated version of the EFDS. } \\
\text { - Meant to support OIF II }\end{array}$ \\
\hline
\end{tabular}




\section{Air Force Process}

\begin{tabular}{|c|c|c|c|c|}
\hline & $\begin{array}{l}\text { Quick Reaction } \\
\text { Capability Process } \\
2011\end{array}$ & $\begin{array}{l}\text { Rapid Response Process } \\
2008\end{array}$ & $\begin{array}{l}\text { Rapid Response Process } \\
2005\end{array}$ & $\begin{array}{l}\text { Rapid Response Process } \\
1994\end{array}$ \\
\hline $\begin{array}{l}\text { Minimum Speed of } \\
\text { Performance }\end{array}$ & $\begin{array}{l}\text { Expands initial solution, must } \\
\text { be fielded NLT } 180 \text { days after } \\
\text { validation }\end{array}$ & - No change & - Expands to 20 days for action. & $\begin{array}{l}\text { - } 16 \text { days from receipt of C-MNS to } \\
\text { PMD issuance }\end{array}$ \\
\hline $\begin{array}{l}\text { Maximum Funding } \\
\text { Allowed }\end{array}$ & $\begin{array}{l}\text { RDA theoretical maximum. } \\
\text { Offers more generalized } \\
\text { funding guidance, removes } \\
\text { language about preferred } \\
\text { options. } s\end{array}$ & - No change & $\begin{array}{l}\text { Still emphasizes MAJCOM } \\
\text { internal funding, but suggests three } \\
\text { funding options: internal, internal } \\
\text { with HAF help in reprogramming } \\
\text { to cover costs, or seek CSAF help } \\
\text { in identifying external funding } \\
\text { (discouraged). }\end{array}$ & $\begin{array}{l}\text { - Mentions role of comptroller in } \\
\text { identifying below threshold } \\
\text { reprogramming. } \\
\text { - MAJCOMs are encouraged to } \\
\text { identify internal funding, with } \\
\text { general USAF TOA considered } \\
\text { only as a last resort. }\end{array}$ \\
\hline $\begin{array}{l}\text { Level of Secured } \\
\text { Funding }\end{array}$ & - No change & - No change & - No change & $\begin{array}{l}\text { - None. Predates RAA specified in } \\
2003 \text { and } 2005 \text { NDAAs. }\end{array}$ \\
\hline $\begin{array}{l}\text { Senior Leader } \\
\text { Attention Required }\end{array}$ & - No change & $\begin{array}{l}\text { - CSAF is notified of RRP proposal } \\
\text { earlier in process (at MAJCOM } \\
\text { submission). } \\
\text { - Adds guidance on New Start } \\
\text { notification to Congress if needed }\end{array}$ & - No change & $\begin{array}{l}\text { Decision authority is Rapid } \\
\text { Response Process Council that } \\
\text { consists of unspecified 1-2 stars or } \\
\text { civilian equivalents for "yes" } \\
\text { decisions. } \\
\text { - CSAF has final say on "no" } \\
\text { decisions. }\end{array}$ \\
\hline $\begin{array}{l}\text { Number of Approvals } \\
\text { Required }\end{array}$ & $\begin{array}{l}-\quad<180 \text { days MAJCOM lead } \\
\text { command (3-4 star) endorses } \\
\text { for MDA to approve } \\
\text { - } 12 \text { step process with discrete } \\
\text { tasks for every player }\end{array}$ & $\begin{array}{l}\text { - Specifies } 12 \text { members of RRAC } \\
\text { assessment committee and } 12 \\
\text { member process committee. } \\
\text { - Adds JUON on-ramp. }\end{array}$ & - No change & $\begin{array}{l}\text { Can be submitted by MAJCOM, } \\
\text { HAF, or component CCDRs } \\
\text { Seven step process, includes } \\
\text { feasibility study and executive and } \\
\text { sub-executive councils prepping }\end{array}$ \\
\hline
\end{tabular}




\begin{tabular}{|c|c|c|c|c|}
\hline & & & & information. \\
\hline Other Constraints & $\begin{array}{l}\text { - Seems to delegate validation to } \\
\text { MAJCOMs. }\end{array}$ & $\begin{array}{l}\text { - Specifies that solutions must be at } \\
\text { TRL } 6 \text { or greater. } \\
\text { - Must be operationally safe, suitable, } \\
\text { and effective and CONOPS must be } \\
\text { in place. }\end{array}$ & - $\quad$ No change & $\begin{array}{l}\text { - Explicitly notes that it speeds up } \\
\text { procedures, does not replace them. } \\
\text { - Only considers material that can be } \\
\text { fielded within } 60 \text { days of RRP } \\
\text { decision. }\end{array}$ \\
\hline
\end{tabular}




\section{Navy UON}

\begin{tabular}{|c|c|c|c|c|c|c|}
\hline & $\mathbf{U O N}$ & $\begin{array}{l}\text { RDC } \\
2008\end{array}$ & $\begin{array}{l}\text { RDC } \\
2007\end{array}$ & $\begin{array}{l}\text { RDD } \\
2007\end{array}$ & $\begin{array}{l}\text { RDC } \\
2004\end{array}$ & $\begin{array}{l}\text { RDC } \\
1996\end{array}$ \\
\hline $\begin{array}{l}\text { Minimum Speed of } \\
\text { Performance }\end{array}$ & - No change & - No change & $\begin{array}{l}\text { - Specifies goal of } 37 \\
\text { days to approval and } \\
\text { fielded solution from } \\
\text { USFF endorsement. }\end{array}$ & $\begin{array}{l}\text { - Goal is to get a } \\
\text { prototype fielded by } \\
270 \text { days after } \\
\text { validation. }\end{array}$ & - No change & - Not specified \\
\hline $\begin{array}{l}\text { Maximum Funding } \\
\text { Allowed }\end{array}$ & - No change & - No change & - No change & - No change & - No change & - Not specified \\
\hline Level of Secured Funding & - No change & - No change & - No change & - No change & - No change & - Not Specified \\
\hline $\begin{array}{l}\text { Senior Leader Attention } \\
\text { Required }\end{array}$ & - No change & - No change & - No change & $\begin{array}{l}\text {-3-star RDDC with N8, } \\
\text { MCCDC, and } \\
\text { ASN(RD\&A) co- } \\
\text { chairing. }\end{array}$ & - No change & $\begin{array}{l}\text { - ASN(RD\&A) } \\
\text { approves RDC } \\
\text { requests }\end{array}$ \\
\hline $\begin{array}{l}\text { Number of Approvals } \\
\text { Required }\end{array}$ & $\begin{array}{l}\text { - Specifies CD\&I } \\
\text { instead of MCCDC } \\
\text { generally as USMC } \\
\text { validator. }\end{array}$ & - No change & - No change & $\begin{array}{l}\text { - N8/MCCDC } \\
\text { coordinates w/ NaIL } \\
\text { to develop proposal. } \\
\text { RDDC approves. } \\
\text { NaIL convenes tiger } \\
\text { team to execute. }\end{array}$ & - No change & $\begin{array}{l}\text { - One set of approvals } \\
\text { from ASN(RD\&A). } \\
\text { PEOs, SYSCOMs, } \\
\text { and DRPMs must } \\
\text { implement if ASN } \\
\text { approves. }\end{array}$ \\
\hline Other Constraints & - No change & $\begin{array}{l}\text { - Adds coordinating } \\
\text { language about RDC } \\
\text { programs with IT } \\
\text { components. }\end{array}$ & - No change & $\begin{array}{l}\text { - Added in a } \\
\text { SECNAVNOTE. Not } \\
\text { referenced in } \\
\text { subsequent } \\
\text { SECNAVINST. }\end{array}$ & $\begin{array}{l}\text { - Adds interoperability } \\
\text { as a goal. }\end{array}$ & $\begin{array}{l}\text { - Specifies that it is } \\
\text { meant to streamline } \\
\text { dialogue and expedite } \\
\text { existing processes. }\end{array}$ \\
\hline
\end{tabular}




\section{Joint Process (JIEDDO)}

\begin{tabular}{|c|c|c|}
\hline & 2006 & 2004 \\
\hline $\begin{array}{l}\text { Minimum Speed of } \\
\text { Performance }\end{array}$ & - No change & - Not stated \\
\hline $\begin{array}{l}\text { Maximum Funding } \\
\text { Allowed }\end{array}$ & - No change & $\begin{array}{l}\text { - JIEDDO will have a } \\
\text { budget. }\end{array}$ \\
\hline Level of Secured Funding & $\begin{array}{l}\text { - Budget will be } \\
\text { identified as part of } \\
\text { Army base budget. }\end{array}$ & $\begin{array}{l}\text { - Charter directs } \\
\text { Comptroller to } \\
\text { establish central } \\
\text { program fund }\end{array}$ \\
\hline $\begin{array}{l}\text { Senior Leader Attention } \\
\text { Required }\end{array}$ & - No change & $\begin{array}{l}\text { - JIEDDO director O- } \\
\text { 7/O-8 has final say } \\
\text { - DEPSECDEF } \\
\text { approves }>\$ 25 \mathrm{k} \\
\text { projects, JIEDDO Dir } \\
\text { does others }\end{array}$ \\
\hline $\begin{array}{l}\text { Number of Approvals } \\
\text { Required }\end{array}$ & $\begin{array}{l}\text { •Vague language about } \\
\text { using IPTs }\end{array}$ & - No process specified \\
\hline Other Constraints & - No change & $\begin{array}{l}\text { - Only deals with } \\
\text { IEDs, although the } \\
\text { definition is wide }\end{array}$ \\
\hline
\end{tabular}




\section{Appendix B: PRC-117G Case Study}

\section{Description}

The PRC-117G is a commercially-developed single-channel tactical radio that is capable of simultaneously transmitting voice and data over a wide range of frequencies. ${ }^{85}$ The PRC-117G is capable of sharing data across multiple users through technology that enables individual radios to collectively establish wireless networks without the need for fixed network infrastructure such as cellphone towers or routers commonly found in civilian wireless networks.

\section{Investment Drivers}

In this section, we examine the degree to which DoD investments in the PRC-117G were driven by:

- A need to react to an enemy threat

- A desire to capitalize on technological advances

We found that the DoD invested in the PRC-117G for both reasons. The DoD's struggle to develop its next generation of radios (the Joint Tactical Radio System, or JTRS) in the late 1990s and early 2000s led it to create new processes to capture and capitalize on private-sector advances in tactical radio technology. At the same time, the demands of the wars in Iraq and Afghanistan required the DoD to make immediate investments in commercially-developed radios such as the PRC-117G to meet the unexpectedly high need for radios by deployed forces that could not wait for JTRS to be developed. ${ }^{86}$ Both drivers of innovation played equally important roles in the development of the PRC-117G.

\section{JTRS and the Enterprise Business Model}

The development of the PRC-117G is best understood when we consider it in the context of the more ambitious JTRS program. In this section, we will describe the JTRS program, why it failed, and how the development of the PRC-117G was informed by both

\footnotetext{
${ }^{85}$ Harris RF Communications, "AN/PRC-117G(V)1(C): Type-1 Wideband Multiband Multimission Radio with Internatl SAASM GPS."

${ }^{86}$ Other radios included increased procurement of existing radios and other commercially-developed radios such as the Thales PRC-148, the Harris PRC-152, and the less developed Harris PRC-117F.
} 
the technological insights discovered by JTRS' efforts and advances in civilian telecommunications R\&D strategies that occurred at the same time.

\section{The Joint Tactical Radio System (JTRS)}

The PRC-117G would not exist had it not been for the DoD's more ambitious longterm investment in tactical communications. The Joint Tactical Radio System (JTRS) program was inaugurated in 1997 and had three goals:

- Consolidate the variety of HF, UHF, and VHF radios used by the military services into one common radio that could operate across all three segments of the electromagnetic spectrum.

- Rely on software rather than hardware to define its modes of operation (such radios are known as software-defined radios, or SDRs).

- Allow the speedy exchange of digital information, such as position location, imagery, video, and text. ${ }^{87}$

At the time of JTRS' inception, DoD technologists believed that the best way to achieve these goals was to develop three sets of radios (for air, maritime, and ground forces) that could accommodate a wide variety of frequencies and waveforms (waveforms are the standards by which radios exchange information among each other). DoD wanted a radio that could accept old ("legacy") waveforms such as SINCGARS and HAVEQUICK, as well as new waveforms that could be upgraded over time without needing to frequently change radio hardware. The assumption at the time was that a robust and relatively static hardware platform combined with ever-advancing software upgrades would be more cost-effective than repeatedly fielding newer radio hardware to the force. ${ }^{88}$ At the same time, JTRS' expected capability to accept legacy waveforms would enable a smooth transition. ${ }^{89}$ In this case study, we will focus exclusively on the ground portions of the JTRS program, since it is the only portion of the JTRS program that is applicable to our study of the PRC-117G.

By 2011 JTRS program made significant progress in waveform development, but it failed to field an effective radio system. Some radios were too heavy, required too much power, and generated too much heat. ${ }^{90}$ Radios also took too long to start up and were

\footnotetext{
87 Department of Defense, "Mission Need Statement (MNS) for the Joint Tactical Radio (JTR)," (1997).

${ }^{88}$ David M. Tate Lawrence N. Goeller, A Technical Review of Software-Defined Radios: Vision, Reality, and Current Status: Institute for Defense Analyses, NS D-4878, May, 2013.

89 John T. Armantrout S.S. Kamal, "The U.S. Military's Joint Tactical Radio System: Why is it More Relevant than Ever for the US Navy?," CHIPS: The Department of the Navy's Information Technology Magazine, January-March 2013.

90 Gallagher and Lawrence N. Goeller.
} 
incapable of maintaining stable networks at the scale demanded by tactical units. ${ }^{91}$ These failures stemmed from two programmatic issues:

- DoD incorrectly assumed that hardware upgrade costs would be high enough to warrant investment in more technically-challenging software-defined radio waveforms.

- DoD took on too many development risks by trying to develop the hardware and software components for the JTRS radio simultaneously.

Consequently, the joint program was cancelled and its constituent programs were devolved back to the individual services in 2012 for continued development. ${ }^{92}$

\section{A Wrong Bet on Software}

When JTRS was inaugurated in 1997, the DoD assumed that software-defined radios would enable it to keep up with fast-moving technological advances in the civilian marketplace without having to make frequent and costly hardware upgrades. In the original JTRS mission needs statement, the DoD predicted that the pace of technological development would require frequent and expensive hardware upgrades that ". . . could not compare to the advantages of a consolidated systems approach to provide substantial benefits in the overall space, weight, power and cost."93 The DoD also noted that traditional, single-purpose radios could not meet the DoD's needs without procuring an unwieldy variety of radios, each with a "costly logistics infrastructure."94

These assumptions about the relative cost and effectiveness of future hardware and software development turned out to be wrong. The DoD failed to foresee that hardware costs would continue to drop over time (the phenomenon commonly known as Moore's Law), making the cost difference between periodic hardware modernization and costly development of a software-only equivalent less attractive. ${ }^{95}$ This phenomenon can be observed in civilian telecommunications development - consumers routinely buy new cellphones as technology advances, for instance. By failing to foresee that hardware was a commodity that could be cheaply replaced, JTRS went down the path of try to develop costly software-reliant methods of achieving performance goals and hardware to support it.

\footnotetext{
${ }^{91}$ Bradley Wilson Isaac R. Porche III, Matthew J. Schneider, Chuck Stelzner, J. R. Lockwood, Shawn McKay, Kate Giglio, (U//FOUO) Assessing the Performance of Mobile Ad Hoc Networks Using Statistical Analysis Techniques, Santa Monica: RAND Corporation, RR-494-OSD, November, 2014.

92 Joint Tactical Networking Center, Oct 282015 b.

${ }^{93}$ Department of Defense.

94

${ }^{95}$ Lawrence N. Goeller.
} 


\section{Taking on Too Much Risk}

The DoD's assumption about the relative costs of software and hardware development led to an R\&D strategy that assumed too much technical risk and consequently made overly-optimistic planning decisions and set budgets too low. This resulted in program cost and schedule overruns that doomed the program politically. A recent cost comparison of JTRS development to a civilian equivalent (the LTE cellphone network) makes the overly-optimistic nature of these decisions particularly stark. JTRS was more technologically complex, requiring the integration of 30 different waveforms and radios, along with higher security, durability, and portability standards, but had a much smaller budget than industry R\&D costs for LTE (estimated to be four to 24 times smaller). ${ }^{96}$ The DoD's optimism also resulted in a development schedule that required it to meet all the JTRS goals at once, in order to field a fully-developed radio system that could support further software-driven modernization. ${ }^{97}$ This was a typical approach for a defense acquisition project but did not fit well with the needs of the JTRS program.

By comparison, the civilian consortium of telecommunications organizations and manufacturers recognized that some LTE goals would be harder to achieve than others and decided to approach the program incrementally, allowing engineers and software developers to solve each problem as it came up. In essence, the LTE consortium divided its technical risks into manageable chunks that could be solved without having to delay other parts of the program. The result was a series of evolutionary hardware roll-outs that transitioned cellphone users toward an increasingly-capable cellphone network over a period of years, rather than all at once. The different R\&D strategies and resource allocations by DoD and LTE industry stakeholders show how difficult it would have been for JTRS to meet its performance, cost, and schedule goals given the technical risks involved and $R \& D$ resources allocated to the endeavor.

\section{Turning to an Enterprise Business Model}

After numerous cost and schedule overruns and a reorganization of the program in 2005, the JTRS program began to consider alternative approaches. ${ }^{98}$ The JTRS program office was aware that some tactical radio contractors were moving forward with radio

\footnotetext{
96 Irv Blickstein Mark V. Arena, Daniel Gonzales, Sarah Harting, Jennifer Lamping Lewis, Michael McGee, Megan McKernan, Charles Nemfakos, Jan Osburg, Rena Duavsky, Jerry M. Solinger, DoD and Commercial Advanced Waveform Developments and Programs with Multiple Nunn-McCurdy Breaches, Santa Monica: RAND Corporation, MG-1171/5-OSD, 2014.

97 Sean Gallagher, "How to blow \$6 billion on a tech project," Ars Technica, June 182012 b.

98 Government Accountability Office, Department of Defense Needs Framework for Balancing Investments in Tactical Radios: Government Accountability Office, GAO-08-877, August, 2008.
} 
projects that were outside of the JTRS program. The DoD sought to capture these developments through a program called the Enterprise Business Model (EBM) in 2006.

The EBM sought to make the relationship between the DoD and radio contractors resemble the competitive market structure in the civilian world more closely. To allow more open competition, it allowed contractor-developed radios to compete against JTRS radios and each other in periodic evaluations that helped military services decide what radios to buy. To maintain compatibility between radios, the EBM allowed contractors to use government-developed waveforms and held contractors to certain interoperability standards. ${ }^{99}$ The DoD hoped to not only attract outside technological advances, but also to save costs as well.

Why would contractors choose to participate, knowing that the DoD was already committed to the JTRS program of record? One reason was that the EBM allowed contractors who did not win JTRS contracts a chance to capture some part of DoD business, at the cost of conducting their own R\&D. This independence also allowed contractors to work as creatively as they wished, unconstrained by the JTRS requirements. ${ }^{100}$

\section{The PRC-117G Experience in the EBM}

Harris Corporation was one of the outside contractors that capitalized on this opportunity. In fact, it anticipated the DoD's EBM initiative by two years. In 2004, the company was part of a consortium of contractors led by ITT that lost the bid for the JTRS handheld and manpack radios. ${ }^{101}$ According to company representatives, it decided within weeks of that announcement to look for opportunities to salvage its investment in tactical radios. ${ }^{102}$ Harris commissioned a market analysis on the DoD's previous largescale tactical radio program (SINCGARS) and saw that the program took more than 10 years to field a working radio. ${ }^{103}$ Knowing the technical challenges that the JTRS program was facing, Harris decided to embark on its own attempt to develop a networkcapable radio that could be brought to market in a shorter timeframe.

\footnotetext{
99 Matthew D. Guerrieri, "Buying a Better Radio," Army AL\&T Magazine, September 2012.

100 Contractors are still constrained by the need to develop radios that were compatible with JTRS. See Barry Rosenberg, "JTRS Business Model Opens Doors to Innovation," Defense Systems, July 2010.

101 Wrobel.

102

103
} 
Harris was correct that it could deliver its radio faster than the JTRS program. By 2008, it had completed work on a proprietary waveform called ANW2 was capable of supporting networks with up to hundreds of nodes. ${ }^{104}$ By 2011, it had completed development on the PRC-117G, which used the ANW2 waveform, working closely with potential clients (particularly the Marine Corps) to ensure that it met their needs. ${ }^{105}$ After being certified and evaluated at the Army's Network Integration Evaluation (NIE) in November 2011, it was purchased by Marine and Army units destined for deployment to Afghanistan. Since then, over 30,000 PRC-117G radios have been purchased by Marine and Army units.

\section{The Pent-Up Demand for Tactical Radios}

Even if the DoD had decided not to capture external innovations through the EBM, the demand for radios by deployed forces would have forced it to make immediate investments in tactical radios in any event. This was because the services were directed by DoD to stop development and procurement of non-JTRS style radios in the mid-1990s to concentrate resources on JTRS. ${ }^{106}$ This action created a pent-up demand for updated radios, as the Army and Marine Corps were forced to make do with outdated radios that were insufficient to meet the expectations of ground commanders who could easily observe the fast-paced communications innovations taking place in the civilian technology sector.

This pent-up demand was exacerbated by the Iraq and Afghanistan Wars, which exposed the DoD's shortfalls in tactical communications capabilities. The asymmetric nature of the wars required all vehicles and many more ground troops to be equipped with radios in order to accomplish their missions safely and effectively. Additionally, demand for voice and data communications between units and headquarters increased as the war devolved into an insurgency that required the Army and Marine Corps to emphasize responsive, activity-based intelligence and greater information sharing. ${ }^{107}$ These demands underscored the need for the enhanced features that JTRS radios were supposed to deliver but had not made good on. Finally, the Army reorganized from divisions to brigades as their chief deployable units in order to mitigate the manpower

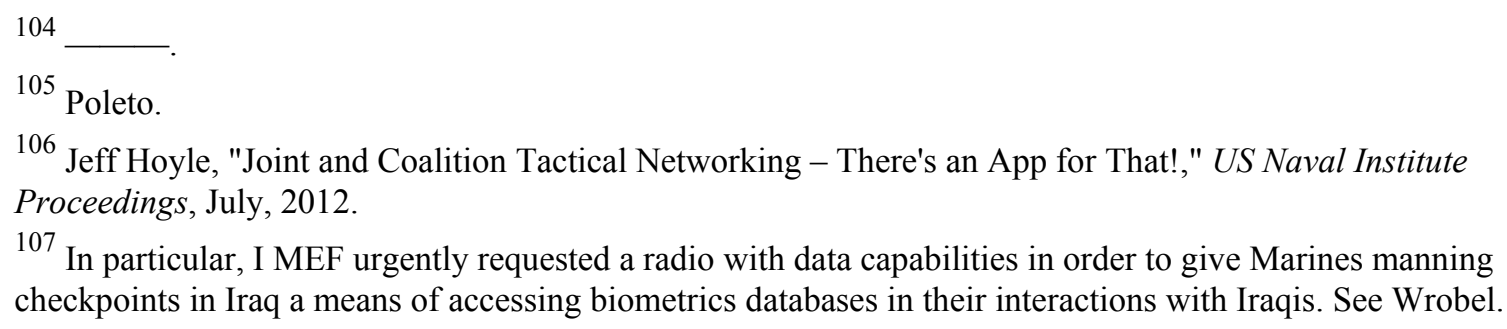


strain caused by the increased operational tempo in Iraq. This required more radios than the Army had in its inventory, further driving up demand.

The result was that the DoD was forced to buy more non-JTRS (also called legacy) radios. The DoD granted waivers to the services to allow them to procure more legacy radios, which the Army and Marine Corps did in earnest. A 2008 GAO study showed that although the DoD planned to spend \$3.2 billion on JTRS from 2003-2007, it actually ended up spending $\$ 8.3$ billion during that time period, only $\$ 2.5$ billion of which was spent on JTRS. The remaining $\$ 5.7$ billion was spent on increased procurement of legacy radios. $^{108}$

Some of these radios were previously-fielded models such as the PRC-119 SINCGARS radio. The EBM initiative though, allowed the services (and individual commands) to purchase more modern radios such as the PRC-117G. The DoD needed a large quantity of modern radios and was willing to accept radios that fell outside the scope of the JTRS program. Thus, by 2012 the Army and Marine Corps had modernized and expanded its radio inventory to more than 200,000 legacy radios with JTRS-like features, including over 30,000 PRC-117Gs. ${ }^{109}$ These decisions over the past decade show that that the DoD was strongly motivated to invest in the PRC-117G as part of a broader response to the needs of the forces engaged in combat operations in Iraq and Afghanistan.

\section{Implementation Obstacles and Mitigations}

\section{Obstacles}

Although Harris rapidly developed a very capable radio, it created the PRC-117G outside of the conventional defense acquisition process. That process begins with the customer (the DoD) deliberately developing a need through the JCIDS process. Since the PRC-117G was developed completely outside of that process, Harris and interested parties within the DoD had to find openings in the defense acquisition system for the PRC-117G through which to enter. ${ }^{110}$ This was particularly difficult since Harris decided to develop the PRC-117G before the DoD and the JTRS program launched the EBM initiative.

\footnotetext{
108 Government Accountability Office.

109 See Sandra I. Erwin, "Delays in 'joint tactical radio' program cast doubts on future " National Defense February 2007. and Harris RF Communications, "Harris Corporation Completes Successful Interoperability Testing of Falcon III Manpack Radio with Mobile User Objective System," (2014).

${ }^{110}$ Wrobel.
} 


\section{Mitigation}

To overcome the commercial origins of the PRC-117G, Harris first had to make the DoD aware of the value of its radio and then find the procedural methods to allow the DoD to purchase it. Additionally, to make the DoD aware of the capabilities of the radio, it engaged senior JTRS and DoD acquisition officials as well as tactical users. Harris emphasized to senior leaders that there would be long delay before JTRS was ready to be fielded and that they needed to be open to the possibility of commercially-developed radios to meet the interim demand. ${ }^{111}$ Harris' efforts to engage with tactical users during the PRC-117G development process also won it a number of supporters who were willing to make extra efforts to bring the PRC- $117 \mathrm{G}$ into the acquisition system. ${ }^{112}$

These service interlocutors used the urgent needs process and the liberal supplemental funding environment during the late 2000s to field the PRC-117G. As previously mentioned, I MEF submitted an urgent needs request for network-capable radios to enable Marines manning checkpoints to have access to real-time biometrics databases. ${ }^{113}$ The Army's $82^{\text {nd }}$ Airborne Division also sought out a smaller, lighter radio. Both organizations knew about the PRC-117G and worked through the maturing urgent needs processes to request that radio. To avoid rejection by urgent needs authorizers, all the requesting units emphasized that they were seeking an interim capability to temporarily meet their needs. Since the JTRS program of record continued during this time, the requestors took care to phrase their requests in this manner.

\section{Outcome}

Despite its status as a non-developmental item with no long-term sustainment plan, the DoD's investment in the PRC-117G has effectively modernized the Army and Marine Corps' tactical radio capabilities. The 30,000 PRC-117Gs currently fielded have given commanders new capabilities to share information over secure networks that was not previously possible, and it is unlikely that they will be willing to give up that capability as they continue to train and deploy. This is borne out in the Marine Corps' plan for redistributing PRC-117Gs returning from Afghanistan-it has identified an enduring requirement for over $90 \%$ of its current stock in the Operating Force (those units that are deployable) out to FY2017. ${ }^{114}$ While JTRS itself failed as it was originally conceived, the

\footnotetext{
${ }^{111}$ Harris was also careful to emphasize that they were interested in providing an interim capability, not a permanent solution. In the words of a Harris representative, the company could not "drive too hard to the hoop" to advocate for their approach. See — Nov 2 2015a.

112 Poleto.

${ }^{113}$ Wrobel.

114 Headquarters Marine Corps (Installations and Logistics), "Ground Equipment Reset Playbook," (2012).
} 
processes and marginal technological advances that it yielded have resulted in a de facto modernization of a significant portion of the DoD's tactical radio inventory.

Not only has the DoD modernized its tactical radio inventory, its investment in the PRC-117G and other interim radios has yielded a new approach to tactical radio development. This approach is similar to technology development strategies in the civilian sector that rely on open architectures and standards from which individual vendors can work. The successor to the JTRS program office (the Joint Tactical Networking Center, or JTNC) has embraced its role as a guardian of standards and waveforms. ${ }^{115}$ The establishment of regular evaluations of vendor offerings (in the form of the Army Network Integration Exercises) also hints at a new process for tactical radio development. JTNC sees itself as the organization that balances the competing needs for flexibility and timeliness with coordination, standards, and compliance for tactical radios. Whereas the DoD once emphasized only the latter values, it now seeks to foster elements of both. ${ }^{116}$

115 Joint Tactical Networking Center, "About JTNC," 2015a, http://jtnc.mil/Pages/AboutJTNC.aspx. 116 


\section{Appendix C: Palantir Case Study}

\section{Description}

Palantir is a software program and company that helps intelligence analysts examine raw intelligence to find patterns, links, and correlations within large amounts of data. Palantir was privately developed by programmers and engineers based in Silicon Valley, with input and funding by non-military members of the intelligence community. ${ }^{117}$ It has since been used by the DoD's intelligence analysts in Afghanistan and among other government and commercial clients.

For the purpose of this case study, we will refer to Palantir as the software program, rather than the company that developed it.

\section{Investment Drivers}

Like other alternative investments, DoD investment in Palantir was simultaneously driven by the need to address a threat as well as a desire to capture technological advances. Additionally, there was an element of commercial, non-DoD investment to help jump-start development. In this section, we will examine the variety of stakeholders involved and their (slightly) differing conceptions of threat and technological capture.

Palantir's initial investment came not from the DoD, but from a group of investors led by Peter Thiel. Thiel had previously been part of the group that started the online payment company PayPal and believed that the advances in fraud detection algorithms developed there could be useful in other applications such as intelligence analysis. ${ }^{118}$ Specifically, Thiel and a small group of investors believed that they could use their PayPal experience to develop software that could uncover terrorist networks with greater accuracy and fewer intrusions on civil liberties than existing methods. A well-known libertarian, Thiel emphasized this ethical and legal component as a key aspect of Palantir software. In 2004, Thiel and his fellow investors founded Palantir Technologies in Palo Alto, CA, with $\$ 30 \mathrm{~m}$ from Thiel's own venture capital fund to develop and market the software.

\footnotetext{
${ }^{117}$ Brad Stone Ashlee Vance, "Palantir, the War on Terror's Secret Weapon," Bloomberg Businessweek, November 222011.

${ }^{118}$ Siobhan Gorman, "How Team of Geeks Cracked Spy Trade," Wall Street Journal, Sept 42009.
} 
Thiel's initial investment was a case of simultaneous drivers at work. Thiel wanted to capture the technological advances that PayPal had made in detecting fraudulent transactions. Thiel was also quite clear in interviews that the concept of Palantir stemmed from his observations on the emphasis on anti-terrorism and security in the wake of 9/11. ${ }^{119}$ Thiel's comments also imply that both of these drivers were necessary inspirations in his conception of Palantir. Thus, this initial investment was a case of simultaneous threat and technology capture-driven investment.

Although Palantir was founded with significant talent and domain expertise, it failed to attract additional investors amongst the myriad of venture capital firms in Silicon Valley. Investors there did not believe that the idea was profitable, at least for the civilian market. ${ }^{120}$ However, one group of investors suggested that Palantir pitch their idea to InQ-Tel, the CIA's venture capital organization. Palantir did so and In-Q-Tel responded favorably, investing $\$ 2 \mathrm{~m}$ in September 2005. ${ }^{121}$

In-Q-Tel's investment introduced Palantir to the intelligence community (IC). From 2005-08, Palantir engineers worked with intelligence analysts to test-drive and refine the Palantir product. ${ }^{122}$ This included one beta test that linked a Palantir prototype to live databases in the DNI's National Counterterrorism Center. During this period, Palantir worked for long stretches of time without compensation or the promise of a contract. ${ }^{123}$

By 2008, Palantir had secured its first government contracts. Among its first clients was the Joint IED Defeat Organization (JIEDDO). ${ }^{124}$ JIEDDO was chartered in 2006 to combat the use of improvised explosive devices (IEDs) that were inflicting casualties and strategic setbacks to the US mission in Iraq (and later Afghanistan). ${ }^{125}$ One of JIEDDO's main lines of effort in this was to attack the network of IED financiers, makers, and emplacers. Palantir's link analysis and collaboration capabilities were well suited for this

\footnotetext{
${ }^{119}$ For example, Thiel was quoted in the New York Times as saying "I felt we were drifting to a place in the U.S. we'd have a lot fewer civil liberties and no real effective protection" in regard to the lack of intelligence analysis tools that could be effective while still maintaining a level of respect for civil liberties. See Quentin Hardy, "Unlocking Secrets, if Not Its Own Value," New York Times.

${ }^{120}$ The views of these investors suggest that they subscribe to simultaneity. That is, the investors understood that Palantir had significant technical talent, but did not believe that the "threat" in the civilian sector was such that Palantir could be successful (i.e. profitable).

121 In-Q-Tel, "Portfolio," 2015, https://www.iqt.org/.

122 Shane Harris, "Palantir Technologies spots patterns to solve crimes and track terrorists," Wired UK, July 312012.

${ }^{123}$ UK Wired Article

${ }^{124}$ Harris.

${ }^{125}$ Dan Lamothe, "The legacy of JIEDDO, the disappearing Pentagon organization that fought roadside bombs," Washington Post, March 172015 b.
} 
task. JIEDDO advertised Palantir as a major success story in its 2008 annual report, reporting that it was used to support 600 investigations of IED networks. ${ }^{126}$

Once JIEDDO made the initial DoD investment, other intelligence entities in the DoD became aware of Palantir and began to invest as well. All were interested in Palantir's contribution to the counter IED mission. These entities were also conscious of their needs for intelligence analysis capabilities to support the US counterinsurgency mission. The need for intelligence-driven operations in Iraq and Afghanistan resulted in a deluge of raw intelligence generated by human reporting from troops and trained HUMINT collectors, as well as ISR platforms and SIGINT data. ${ }^{127}$ Taking advantage of the increased volume of raw intelligence data was critical to overall mission success in Iraq and Afghanistan.

However, the flood of data was overwhelming an existing database and analysis program that was being developed and procured by the military services. Those systems, known collectively as the Distributed Common Ground Sensor (DCGS) system, was meant to integrate the disparate sources of raw intelligence into a set of common formats and repositories that could be accessed, analyzed, and fused by intelligence analysts across different specialties, services, and regions. ${ }^{128}$ Each service ran their own DCGS program according to their services' needs to varying degrees of success. The Army's version of DCGS (DCGS-A) was most applicable to the mission in Iraq and Afghanistan, but it was falling behind schedule as it tried to integrate the hundreds of data sources used by Army intelligence analysts, not all of which were applicable to operations in Iraq and Afghanistan. The myriad of functions in DCGS-A also made it difficult to learn.

Parts of the DoD began investing in Palantir in the late 2000s to meet the operational demands that DCGS-A could not meet. Palantir software was tailored to meet the immediate needs of analysts and did not suffer from the problems that DCGS-A faced by attempting to craft a more general-purpose program. Various units began requesting

\footnotetext{
${ }^{126}$ Joint IED Defeat Organization, Annual Report, 2008, https://www.jieddo.mil/content/docs/20090625_FULL_2008_Annual_Report_Unclassified_v4.pdf (as of Sept 21, 2015).

${ }^{127}$ A 2008 Intelligence Science Board report noted that "The rapid proliferation of sensors both enables and overwhelms the current ISR infrastructure. The number of images and signal intercepts are well beyond the capacity of the existing analyst community so there are huge backlogs for translators and image interpreters and much of the collected data are never reviewed." See Intelligence Science Board, Report of the Joint Defense Science Board Intelligence Science Board Task Force on Integrating Sensor-Collected Intelligence November 2008, https://fas.org/irp/agency/dod/dsb/sensors.pdf (as of November 30, 2015).

${ }^{128}$ For a general description of DCGS, see George I. Seffers, "Making Battlefield Intelligence "iPad Easy" " Signal, July 2012.
} 
Palantir through a variety of urgent needs processes. In 2009, the Army's Rapid Equipping Force (REF) approved a request to purchase Palantir licenses by an Army brigade combat team (BCT) deployed in Afghanistan. ${ }^{129}$ In 2010, the Deputy Commanding General for Support USFOR-A requested an "advanced analytic capability" that could handle the amount of data being generated and help analysts make sense of it using easy-to-understand and intuitive user interfaces. ${ }^{130}$ This request asserted that there was no existing capability and that Palantir was the best available choice to meet their needs. ${ }^{131}$ The request was ultimately fulfilled by Palantir and exposed many intelligence analysts to the product.

Further requests from specific units, commands, and services followed as Palantir's reputation for effectiveness and ease of use grew. The Marine Corps decided to renew its Palantir licenses (obtained as part of the joint 2010 request) while it continued to wait for DCGS to mature. ${ }^{132}$ The $3^{\text {rd }}$ Infantry Division requested Palantir licenses to support its pre-deployment training. ${ }^{133} \mathrm{In}$ all, DoD rapid acquisition organizations invested $\$ 35 \mathrm{~m}$ in Palantir over a period of three years.

In addition to the DoD's threat-based investment, some of these DoD elements also invested to capitalize on Palantir's technology. This was characterized by efforts to integrate Palantir with the DCGS family of systems. US Special Operations Command (USSOCOM) managed to achieve partial integration of Palantir into its version of DCGS (known as DCGS-SOF) that required some manual importing and exporting of data. ${ }^{134}$ The Army's DCGS-A program office also entered into a collaborative research agreement with Palantir, although it is unclear how fruitful this arrangement has been. ${ }^{135}$ In any case, these efforts show a desire to capture Palantir's technological advances.

The DoD's collective actions during the 2008-2012 timeframe showed that it invested in Palantir to meet operational needs (the threat driver) as well as a desire to capture Palantir's technological advances. While these actions and motivations differed across

${ }^{129}$ COL Peter E. Newell, July 282010.

${ }^{130}$ Flynn JUON

${ }^{131}$ Flynn JUON

132 Marine Corps UUNS

${ }^{133}$ Paul McLeary, "Army Orders Intelligence Servers Shut Down, Threatens Palantir, Continues 3rd ID Probe," DefenseNews, Sept 212012.

${ }^{134}$ GAO FOUO Report

135 Joe Gould; Paul McLeary, "Army may work with Palantir on intel software," Navy Times, Jan 32013. 
units and services, the collective result was that the DoD was driven to invest in Palantir by both the threat and technological capture drivers.

\section{Implementation Obstacles and Mitigations}

\section{Obstacles}

One of Palantir's key challenges was the fact that it was privately developed and not requested by the conventional acquisition system. As such, the DoD was not instinctively disposed to provide support and resources to Palantir as it would with a conventional contractor that was responding to a DoD request. This was a particularly difficult obstacle because Palantir's success depended on it being able to integrate with existing intelligence data sources. This made Palantir even more dependent on DoD cooperation during development. Palantir's Silicon Valley organizational culture and lack of experience in dealing with the DoD also did not help matters. ${ }^{136}$

Another obstacle was the same data integration problem that vexed the DCGS program. The data integration challenge was multi-faceted. Not only did Palantir have to pull together data from over 32 existing databases and formats into a common structure, it also had to partition the information based on classification level, matched with the user's permission level (e.g., their security clearance). Also, Palantir engineers had to devise a way of maintaining version control across all users in its network, so that an unbroken audit trail could be maintained between the moment the data was entered into Palantir and its use in a finished intelligence product.

\section{Mitigation}

Palantir's approach to its outside status was to take a very entrepreneurial approach to the way it promoted its product to the DoD. From the time that it first caught the attention of In-Q-Tel and gained entry into the IC, Palantir worked diligently and aggressively to promote its product. It did so in three key ways that allowed it to overcome its outsider status.

First, it made itself easily available to potential users. In several instances, Palantir allowed potential users to try its products before it bought them. In its initial development period from 2005-08, it worked diligently to respond to potential IC customers' needs without requiring any contract or payment up front. ${ }^{137}$ It also allowed potential military clients (including the $3^{\text {rd }}$ Infantry Division) to use its products free of charge for short

\footnotetext{
${ }^{136}$ For a description of this clash of organizational cultures, see Gorman.

${ }^{137}$ See Harris. and McLeary.
} 
periods of time. It also offered free or reduced-price training to units that did purchase its software. These steps made it easy for potential users to try Palantir with little risk or commitment.

Secondly, it assiduously listened to the needs of its end users. This was not merely confined to the initial development phase prior to 2008. Palantir field service representatives deployed with military units and users and had the capability to implement requested changes quickly. ${ }^{138}$ This responsiveness allowed Palantir to adjust quickly to the needs of its users, making it more desirable than the existing DCGS program, which did not respond as quickly to user change requests.

Thirdly, Palantir was able to absorb these costs because it was not relying solely on DoD for funding and solvency. After initial lack of interest, Palantir was able to secure multiple rounds of venture capital funding by highlighting its utility beyond defense applications. Palantir signed contracts with the Centers for Disease Control to track epidemics, with the New York Police Department for its own anti-terrorism efforts, and with Morgan Stanley to root out financial fraud. These contracts and the renewed venture capital interest allowed Palantir the resources and breathing room to give DoD clients the chance to try out Palantir before committing to it.

Lastly and more generally, Palantir placed great faith in the ability of its product to overcome its outsider status. Implicit in Palantir's efforts to make itself known to the DoD was the assumption that Palantir only needed to be placed in front of the right people to prove its worth. Palantir's "try before you buy" approach to courting DoD clients and its investment in responsive field service representatives point to a company that was supremely confident in its product's abilities and utility to the DoD.

To deal with the data integration problem, Palantir simplified things for itself by concentrating on the data sources most useful to its end users. This selectivity was a byproduct of its user-driven refinements (see comments about responsive and empowered field service representatives in the previous section) and the context in which they operated. While DCGS-A attempted to integrate over 200 data sources as part of its goal of providing an all-purpose intelligence analysis tool, Palantir focused on the databases that were most useful to its users' CIED and COIN missions. Palantir also purposefully neglected integration of older databases and sources, further simplifying its integration

${ }^{138}$ ATEC report and Wired UK 
challenge. ${ }^{139}$ Although Palantir's structure and approach to sorting data had advantages over DCGS-A, its selectivity in integration also made its task much easier.

\section{Outcome}

Palantir's place within the DoD is still uncertain. There have been some efforts by the Army to collaborate with Palantir on improving DCGS-A, but these agreements have yet to yield results. Some Army military intelligence units continue to use Palantir, but the Army has been trying to minimize usage while they continue to refine DCGS-A.

Other Palantir DoD users see no problem with continuing to use Palantir. For example, the Marine Corps has renewed its Palantir licenses for another five years. While the Marine Corps characterizes Palantir as an interim solution while it continues to develop DCGS-MC, some intelligence officials in the Marine Corps state that they would not be surprised to see Palantir remain the de facto standard. ${ }^{140}$

${ }^{139}$ RAND Corporation Senior Engineer, Nov 92015.

${ }^{140}$ Marine Corps Intelligence Activity Analyst, Dec 2015. 


\section{Appendix D: Predator Case Study}

\section{Description}

The MQ-1B Predator is an unmanned aerial vehicle (UAV) capable of providing intelligence, surveillance, and reconnaissance (ISR) support, as well the ability to strike targets using Hellfire missiles. The Predator is controlled by Air Force pilots who are usually stationed in the continental United States. It has been used extensively in the Iraq and Afghanistan Wars.

This case study will exclude an examination of the MQ-9 Reaper, which was originally conceived as an advanced version of the Predator. Although both programs were rapid acquisition projects that shared a single program office until 2007, we will only be focusing on the Predator due to its first-of-its-kind status.

\section{Investment Drivers}

In this section, we examine the degree to which DoD investments in the Predator were driven by two factors:

- Threat driver: investments taken in order to react to an exogenous threat or environmental condition

- Technology driver: investments taken of the DoD's own accord, in order to capitalize on technological advancements that can yield militarily useful results

For the Predator, both types of investment drivers played a role in successive and sometimes simultaneous order (see Figure D.1). 
Figure D.1: Predator Investment Cycles

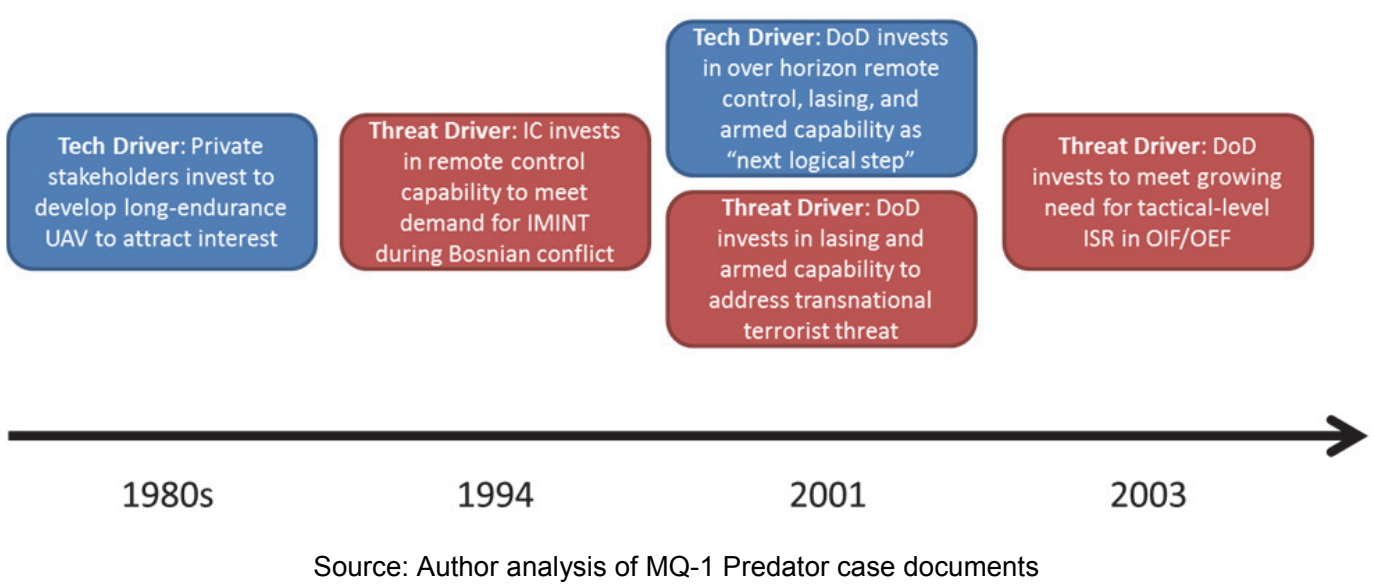

Initially, the technology driver spurred investment, but this was on the part of private stakeholders who wanted to develop long-endurance unmanned aerial surveillance systems to attract military customers (US and others). Next, the threat driver spurred a second round of investments by the CIA that added better remote control capability in response to a need for real-time surveillance of the breakup of Yugoslavia in the early 1990s. After the CIA's investments, the DoD made additional investments based on both the technology and threat drivers to further enhance payload (including arming the Predator) and over-the-horizon remote control capability. Lastly, the DoD made a final set of threat-driven investments to vastly expand the Predator fleet. In this section, we will discuss the four alternating investment drivers in detail.

Although the DoD had been interested in UAVs prior to its first experiences with the Predator, the inability to control UAVs over long (e.g., over the horizon) distances limited their usefulness. Efforts to overcome those difficulties through conventional procurement programs were uneven and after the significant cost and schedule overruns incurred during the Army's Aquila UAV project during the mid-1980s, many efforts were shelved and enthusiasm for UAVs waned (although it did not die off). ${ }^{141}$ Service procurement advocates felt that the UAVs that were available then were too primitive to be useful. UAVs with greater functionality (e.g., the Aquila) were too technically difficult to shepherd into development and procurement.

Despite a lack of interest in most quarters of the DoD, UAV technology advanced due to the disparate efforts of several groups, all of whom were interested in overcoming the technological obstacles to long-range, long-endurance UAVs. First, Israeli aircraft

${ }^{141}$ For a more complete treatment of military UAV development prior to the 1990s, see Dave Sloggett, Drone Warfare: The Development of Unmanned Aerial Conflict, ed., New York, Skyhorse, 2014. 
designer Abraham Karem worked to improve UAV endurance and reliability. Driven by a desire to develop an inexpensive substitute for manned aircraft that could serve as a decoy against the air defenses of Israel's Arab neighbors, Karem became obsessed by pushing UAV state-of-the-art technology to the furthest degree. ${ }^{142}$ Karem pursued this goal to the point of leaving his career at Israeli Aircraft Industries (IAI) and emigrating to the United States in 1978 to escape what he felt were constraints at IAI that prevented him from pursuing his UAV ideas. ${ }^{143}$

In the United States, Karem developed the Albatross demonstrator with a small team of engineers using homemade components. The Albatross' ability to stay aloft for 56 hours attracted the attention of the Defense Advanced Research Projects Agency (DARPA) in 1983. Unlike the rest of the DoD, DARPA was undeterred by the underwhelming performance of previous DoD UAVs and the procurement problems of the UAVs in development. DARPA was very interested in the potential for Karem's UAV designs to demonstrate the ability to remain airborne for days at a time, rather than a ready-to-procure package. DARPA invested money in Karem's company (Leading Systems, Inc.), which developed a more advanced demonstrator, the Amber. ${ }^{144}$ However, the Amber program failed to attract much attention outside of DARPA, and Karem's company struggled to stay solvent after DARPA funding ended. By late 1990, Leading Systems was bankrupt and the Amber UAVs were ordered into storage.

Following the end of the DARPA program, Karem and his company were bought by General Atomics Aeronautical Systems Inc. (GA-ASI) in 1990, which continued to push for development of UAV technology outside of the normal DoD-driven process. GAASI's interest in UAV technology stemmed from their two entrepreneurial owners, brothers Neal and Linden Blue. Throughout the 1980s, the Blue brothers believed that UAVs combined with GPS technology could be useful in halting a Soviet tank invasion in Western Europe and could be a low-cost, low-risk weapon to counter Soviet-armed Sandinistas in Nicaragua. ${ }^{145}$ They were interested in the intellectual capital that Leadings Systems had developed over its decade of existence and bought the company and its assets for \$1.8 million. Having bought Leading Systems, the Blue brothers committed GA-ASI to improving UAV endurance and cost-effectiveness. GA-ASI's internal desire

\footnotetext{
${ }^{142}$ Richard Whittle, Predator: The Secret Origins of the Drone Revolution, ed., New York, Holt, $2014 ., 24$. 143 ed., 19.

145 The Blue brothers envisioned a UAV employment concept common during the late 1970s, when scientists and engineers had not yet made the breakthroughs in satellite communications and high-fidelity realtime imagery transfer that were necessary for UAVs to operate as reconnaissance and surveillance assets. See Sloggett, ed..
} 
to move UAV technology ahead eventually became part of the corporate culture of innovation and anticipating DoD demands before contracts were awarded, as one GAASI program manager pointed out. ${ }^{146}$

The key to GA-ASI's internal UAV development efforts was the GNAT-750. This UAV was a derivative version of the Amber technology demonstrator that Leading Systems had developed for DARPA. As Leading Systems watched DoD interest fade after their successful Amber demonstrations, Karem's team of designers invested their dwindling resources into developing a less-advanced version of Amber for possible export sales.

The efforts of Karem and the Blue brothers indicate that investments in UAVs during this period were based on a desire to capture technological advances. These initial investors, along with DARPA, were not guided by any defined military need. Rather, these stakeholders were enthusiastic (or optimistic, in the case of DARPA) about UAV technology more generally.

Although GA-ASI purchased Leading Systems and its GNAT-750 UAV, many technical hurdles remained. The most glaring was the range limitations on the GNAT-750 and Amber imposed by its remote controls. Although the GNAT-750 could remain aloft for almost 40 hours, its radio link to its ground station required the GNAT-750 to remain within its line of sight. It would take a capability gap to force UAV technology past this obstacle.

The investor in this case was not the DoD, but the CIA. In 1993, the CIA was struggling to provide useful imagery intelligence (IMINT) of the breakup of Yugoslavia. As provinces and regional republics broke away from Yugoslavia, civil war broke out, accompanied by ethnic cleansing, mass migration, and other destabilizing and traumatic consequences. The landlocked, mountainous, and cloudy territory prevented the CIA from monitoring events on the ground using satellite reconnaissance. ${ }^{147}$ In fact, the demand for up-to-date imagery on the breakup of Yugoslavia would require persistent surveillance, with sensors that could linger over an area of interest for hours. ${ }^{148}$ The lack of US presence in Yugoslavia would also require long-range surveillance.

${ }^{146}$ Dusseault.

${ }^{147}$ Frank Strickland, "The Early Evolution of the Predator Drone: An Insider's Perspective on Innovation During Fiscal Austerity," Studies in Intelligence, Vol. 57, no. 1, 2013. 148 
Within the CIA, one group of engineers was attempting to tackle the range problem in a research effort that was unrelated to the GNAT-750 and events in Yugoslavia. ${ }^{149}$ Their chosen solution was a relay system that passed commands and imagery between the UAV and its ground station through a relay aircraft, thereby extending its range. As the CIA team developed the relay technology, they sought a UAV that had the range that could take advantage of their efforts. In 1993, they happened upon the GNAT-750 and GAASI. ${ }^{150}$ The two streams of technological advancement were converging, but they would need an extra push to get the funding and attention needed to bring them together.

The breakup of Yugoslavia provided the impetus for combining the two streams of technology. CIA Director James Woolsey was already an advocate of UAVs, and when his subordinates presented him with the GNAT-750 as a possible solution to the lack of coverage over the breakaway state of Bosnia, he was receptive. The CIA moved quickly to integrate the relay technology with the GNAT-750 and deploy it to Yugoslavia (specifically, the newly independent country of Bosnia) six months after it committed itself to improving and deploying the GNAT.

Although the GNAT's ability to loiter over a target was limited due to the jury-rigged nature of the relay system (it relied on a light manned aircraft that could not stay aloft as long as the GNAT), the CIA was very satisfied with the improved quality and quantity of imagery over Bosnia. In addition, the GNAT-750's real-time, full-motion video feed captivated policymakers in the United States. This was a clear demonstration of the potential for unmanned aerial surveillance.

In this round of investments, the CIA was motivated by real-world events and a pressing need for surveillance to invest in UAV technology. The GNAT-750 happened to fill those needs through a combination of coincidence and engaged senior leadership. However, the CIA only employed a small number of GNAT-750s for a limited purpose. It would take much greater investment to realize the full potential of the GNAT and its eventual successor, the Predator.

Following the CIA's investment in the GNAT-750 to fill a surveillance capability gap during the breakup of Yugoslavia, the DoD made the next round of investments, driven by a desire to capitalize on advances in satellite communications technology to give the GNAT-750 additional range and utility. At the time, the DoD was consolidating various UAV programs run by the military services in an effort to pool resources, technology,

\footnotetext{
149

${ }^{150}$ Whittle, ed., 72.
} 
and best practices. ${ }^{151}$ As part of the effort, DoD organized UAVs into capability tiers, based on operating altitude, endurance, and other performance characteristics. After seeing the CIA's success with the GNAT-750, DoD felt that the GNAT could fill the role of a medium-altitude, long-endurance UAV, otherwise known as Tier II.

At the same time, some in the DoD realized that since the GNAT-750 was well developed, it could serve as the first candidate for the DoD's new Advanced Concept Technology Demonstrator (ACTD) process. The purpose of this process was to import militarily-useful technologies developed outside of the military research and development process. ${ }^{152}$ Since these technologies by definition would already be developed to some degree (as was the case for the GNAT-750), it would make little sense to retroactively insert the technology into the acquisition process at its starting point. The ACTD process was a shortcut for commercially-developed technologies to be imported into the procurement process quickly.

While the GNAT-750 was close to what the DoD wanted, there were still technological improvements to be made. The DoD needed the GNAT to carry a larger payload, requiring a new engine, longer wings, and new flight control software. The DoD also wanted the GNAT to communicate via satellite communications link, which would allow the new UAV to stay aloft longer and be controlled from further away than the CIA's GNAT-750. Although these improvements were substantial, the DoD knew that UAV technology had progressed to the point where they could invest a small amount of money (the ACTD contract awarded to GA-ASI in 1993 was for $\$ 31.7$ million) to fully integrate the technological progress that was being made in UAV and command and control systems. ${ }^{153}$

This third round of investment occurred over the course of three years (1993-96), to allow GA-ASI to make incremental improvements to the GNAT-750. See Figure D.2:

151 John M. Deutch, July 121993.

152 Michael R. Thirtle, Robert V. Johnson, and John L. Birkler, The Predator ACTD: A Case Study for Transition Planning to the Formal Acquisition Process, Santa Monica: RAND Corporation, MR-899-OSD, 1997, http://www.rand.org/pubs/monograph_reports/MR899.html., 13.

${ }^{153}$ Whittle, ed., 81. 
Figure D.2: Predator ACTD Planned Program Events
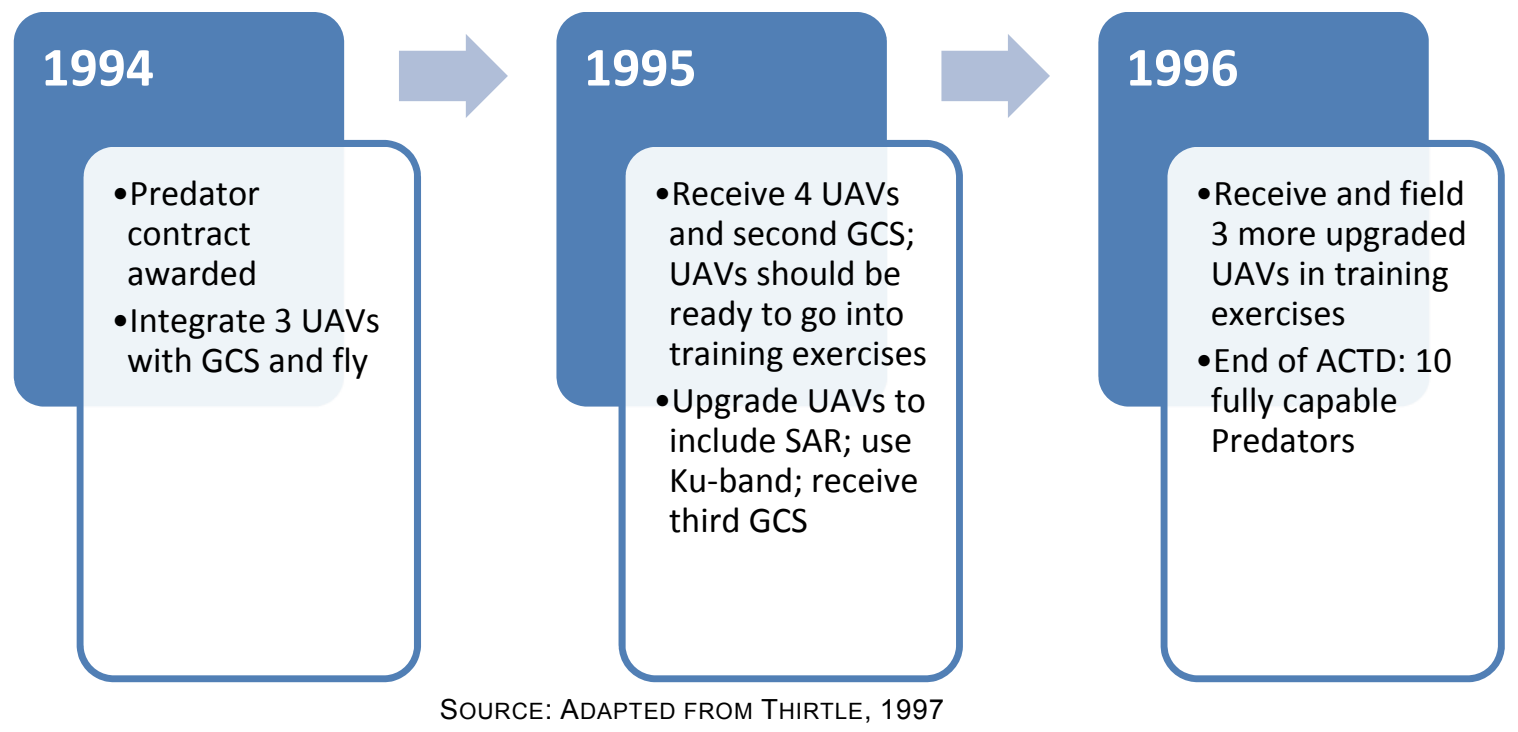

The methodical and incremental approach of adding more challenges (e.g., synthetic aperture radar payloads, usage of $\mathrm{Ku}$-band satellite links) and integration of operational testing shows that the DoD made its ACTD investments with a clear eye towards quickly capturing and integrating technological advancements into a complete UAV package. The result was a set of 10 UAVs and their associated control systems based on the GNAT-750, but with greater range and payload capacity. ${ }^{154}$ This new UAV was designated the RQ-1 Predator.

By 1995, it was clear that the Predator was useful enough to make the transition from ACTD to program of record. The Predator had participated in a variety of major training exercises, had been deployed overseas, and had met its intended testing and technology integration goals. However, the ACTD phase was only the beginning of a six-year period where various DoD stakeholders (the ACTD office and eventually the Air Force) continued to make investments to capture technological advances that were applicable to the Predator.

This was an unusual practice that was enabled by the Predator's ACTD roots. Unlike conventional defense acquisition programs, the Predator was not conceived to fulfill a specific set of requirements. Rather, it fulfilled a broad operational need identified by the Joint Staff for a platform capable of providing "continuous all-weather coverage of worldwide targets and intelligence information on mobile targets for the in-theater

${ }^{154}$ Thirtle, Johnson, and Birkler., 20. 
commander that the current national, theater, and tactical intelligence collection assets could not provide." 155 The broad interpretation and lack of a formal requirements document allowed the Air Force program office (a rapid acquisition organization known as Big Safari) to interpret its mandate liberally and invest in new capabilities that not only improved the Predator's reconnaissance capabilities but also gave it new and novel capabilities as well.

Of those investments, three stand out. Big Safari and GA-ASI worked to incorporate a laser designator to the Predator, giving it the ability to mark ground targets for other aircraft to attack. That investment was taken further by arming the Predator with Hellfire air-to-ground missiles, giving the Predator that ability to sense and strike targets. Finally, Big Safari and GA-ASI incorporated a defensive air-to-air missile capability by mounting Stinger missiles to the Predator. In each case, Big Safari and GA-ASI recognized that the technology was available and ready to be incorporated into the Predator. ${ }^{156}$ In the case of the Hellfire and Stinger missile investments, this was accompanied by operational needs that presented themselves simultaneously (the need to attack terrorist leaders in the wake attacks on US embassies and ships in the late 1990s in the case of the Hellfire, and the need to address Iraqi Air Force harassment of Predators enforcing no-fly zones in the early 2000s). During this round of investment, the technology driver and the threat driver both motivated the DoD to make investments in the Predator.

While the Predator was a highly successful iteration of the DoD's ACTD process and made a successful transition to a program of record, it remained a niche capability with a slowly-maturing concept of operations. The DoD's Predator fleet was small, with only 56 Predators procured by $2001 .^{157}$ Its uses were not well understood. ${ }^{158}$ The September $11^{\text {th }}$ attacks changed that. As the United States began operations in Afghanistan and Iraq in response to the $9 / 11$ attacks, the increased demand for ISR and precision strike during

\footnotetext{
155 Lee Carr et al., Unmanned Aerial Vehicle Operational Test and Evaluation Lessons Learned: Institute for Defense Analyses, P-3821, December, 2003.

156 Open source literature and discussions with GA-ASI representatives make clear that Big Safari and GAASI were accustomed to developing and rapidly implementing new capabilities for the sake of taking advantage of technological advances. See Richard Whittle, Predator's Big Safari: Air Force Association, August, 2011. and Dusseault.

${ }^{157}$ Department of Defense, Selected Acquisition Report (SAR): MQ-1B UAS Predator, Washington D.C., DD-A\&T(Q\&A)823-271, June 30, 2010.

158 One example of this occurred during the Predator's initial deployment to Bosnia, where GA-ASI representatives found intelligence analysts printing freeze-framed Predator images for analysis. The intelligence unit there was used to analyzing photos and was not analyzing the Predator video feed in its native form. See Whittle, ed.
} 
those campaigns demanded a higher number of Predators than expected. This operational need spurred a fourth round of investments in the Predator.

The increased ISR demands stemmed from the intimate nature of the fighting in Iraqi cities, and the emphasis on understanding the Iraqi population required constant surveillance, which the Predator pioneered for unmanned systems. ${ }^{159}$ Essentially, the Predator, which originally conducted national-level reconnaissance missions, was now being deployed as a tactical asset. This shift required a larger number of Predators (along with aircrews and support staff) to meet the demands of a far greater number of customers (tactical commanders, in this case). The Predator's strike capability, useful for attacking high-value targets, also demanded more investment.

Between 2006 and 2014, more than 25 urgent needs requests (in the form of JUONS, UNONs, and QRCs) were submitted to increase the number of Predator and MQ-9 Reaper combat air patrols (CAPs). ${ }^{160}$ A Predator CAP consists of three to four aircraft (one covering an area of interest, one in transit to the area, and one in transit back) and a ground control station (GCS). This requirement for Predator CAPs increased from five CAPs in 2004 to 47 CAPs in 2010 to 65 CAPs by 2014 (see Figure D.3 and Figure D.4 below). ${ }^{161}$ The increased demand was met by more efficient allocation of existing resources (airframes and trained aircrews) as well as increased production of Predators and MQ-9s.

\footnotetext{
${ }^{159}$ Marshall Curtis Erwin, Intelligence, Surveillance, and Reconnaissance (ISR) Acquisition: Issues for Congress, Washington D.C.: Congressional Research Service, R41284, Apriil 16, 2013., 10 and Report of the Defense Science Board Task Force on Defense Intelligence Counterinsurgency (COIN) Intelligence, Surveillance, and Reconnaissance (ISR) Operations, Washington D.C.: Department of Defense, February, 2011.

${ }^{160}$ A CAP is defined by the Air Force as a near 24-hour observation of a target using a given platform. See DoDIG MQ-9 report. In addition to Predator CAPs, MQ-9 Reapers (a derivative of the Predator) are also included in the CAP count. See United States Air Force, United States Air Force RPA Vector: Vision and Enabling Concepts 2013-2038, February 17, 2014., 17.

${ }^{161}$ Rojan J Robotham, "Predator Acquisition Program Transition From Rapid To Standard Processes" (U.S. Army Command and General Staff College, 2012), 67 and United States Air Force.
} 
Figure D.3: MQ-1 Quantities

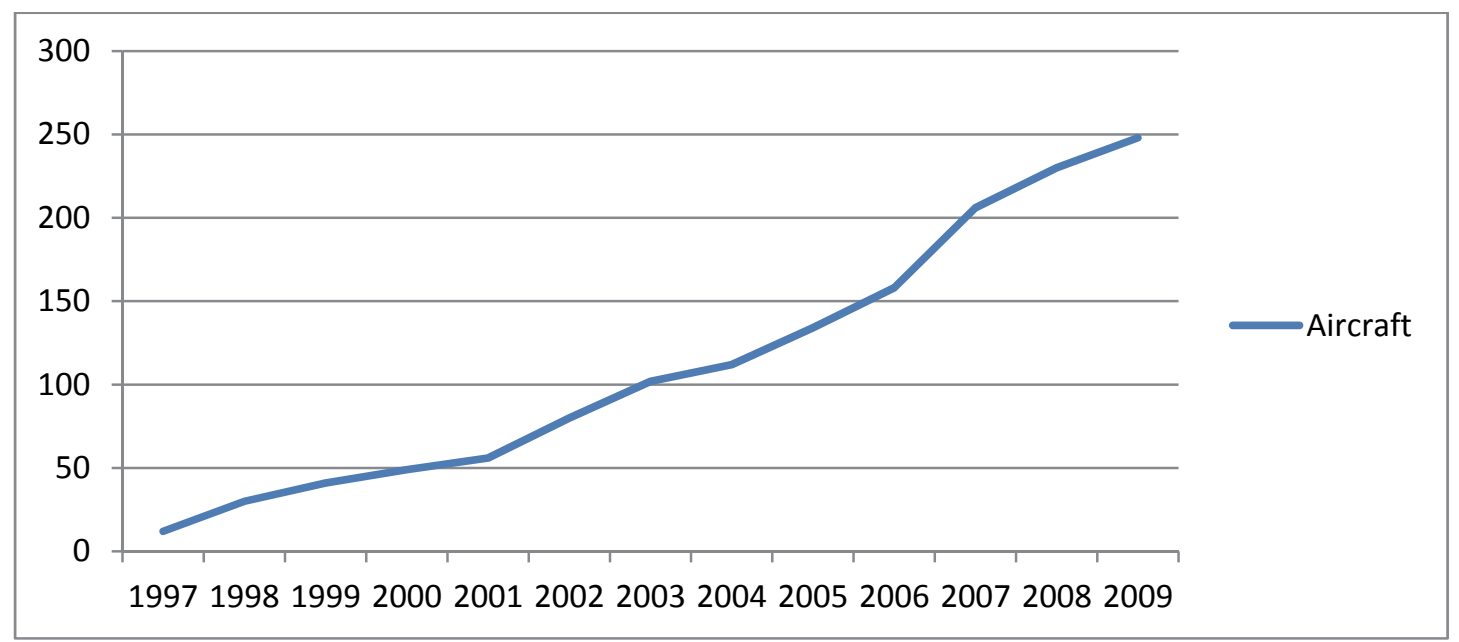

Source: 2010 Predator SAR

Figure D.4: MQ-1/9 Combat Air Patrol (CAP) Capacity

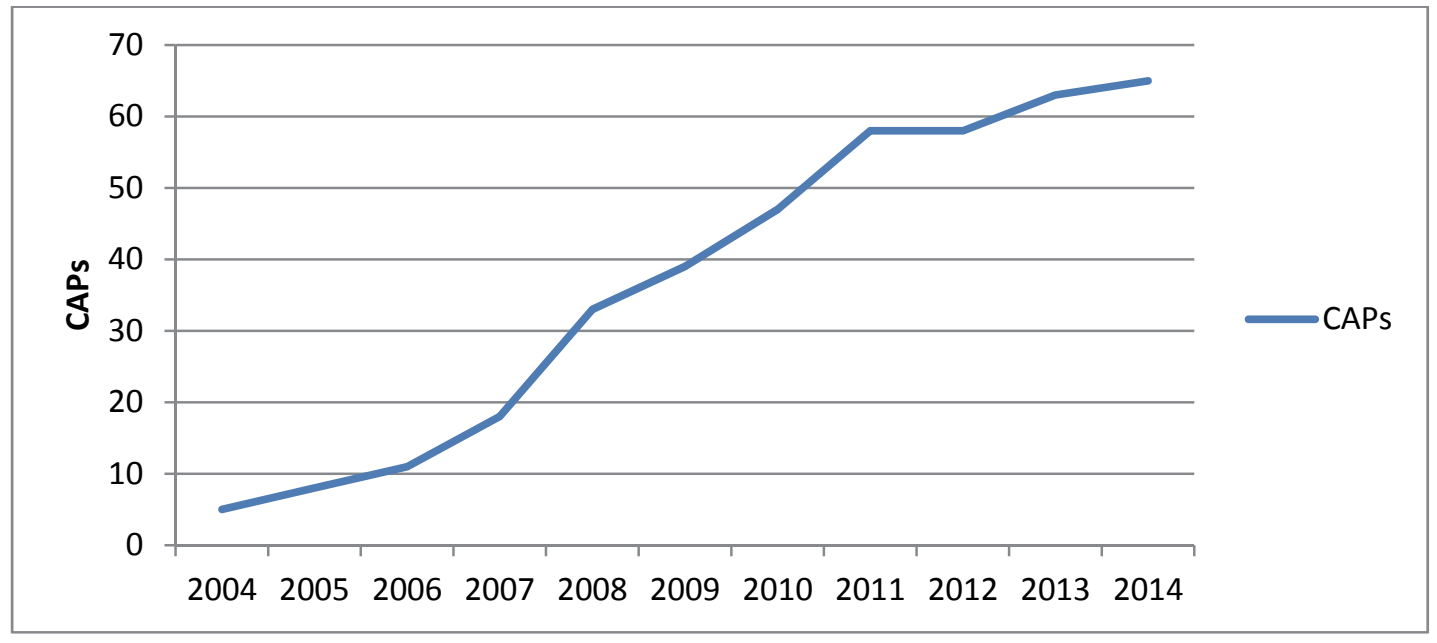

SOURCE: COMPILED FROM ROBOTHAM, 2012 AND USAF, 2014

Throughout this time of increased investment, demand for Predators and other ISR platforms continued to outpace the Air Force's capability to provide coverage. Demand outpaced ISR production to the point that senior leader intervention was required. In 2008, DoD formed an ISR Task Force to focus and prioritize resources on increasing ISR coverage in Iraq and Afghanistan, using the Predator and other platforms. ${ }^{162}$ Additionally, the demand for Predator and similar UAS platforms was so great that the Secretary of

${ }^{162}$ Gates, ed., 132 
Defense eventually intervened in 2011 and directed the Air Force to maintain 65 CAPs (which it achieved in 2014). ${ }^{163}$

Ultimately, the Air Force and the ISR Task Force's response to the increased demand produced the required 65 CAPs in 2014. Despite the end of large-scale commitments in Iraq and Afghanistan however, demand for the Predator continues, forcing the Air Force to push back the Predator's retirement date (it is now slated to be retired in 2018). The story for Predator investment since 2001 has been one driven mainly by the need to address threats. ${ }^{164}$

\section{Implementation Obstacles and Mitigations}

\section{Obstacles}

Over the course of its development, the Predator's design team faced a number of technical challenges. As the CIA, Army, and Air Force built on Karem's original GNAT750 design, each stakeholder came across different technical challenges.

Three specific challenges are worth noting. The first challenge was to create a reliable link between the Predator and controllers on the ground. To fully exploit the Predator range and endurance, the CIA and the Air Force had to devise a way to relay control inputs to the Predator without excessive lag time, which would be a problem during maneuvers that required fast responses, such as takeoff and landing. They first had to extend this control to beyond the line of sight to the Predator. Eventually, operational and legal demands required engineers to extend control to distances requiring satellite links. ${ }^{165}$

A second challenge was to integrate a variety of sensors with the Predator. Synthetic aperture radar (SAR) and thermal and day/night camera systems were both useful sensor payloads that required the GA-ASI team to make significant changes to the airframe to accommodate payload weight and transmitter requirements. Unlike manned aircraft, the Predators' long endurance required a relatively light and fragile airframe. This made the Predator more sensitive than most aircraft to the different payloads, weights, and power requirements.

\footnotetext{
163 Gates' memo directing the CAP increase is referenced in Department of Defense Inspector General, Air Force Did Not Justify the Need for MQ-9 Reaper Procurement Quantities, Washington D.C. , DODIG2014-123, September 30, 2014.

164 James Drew, "USAF plans to end MQ-1 Predator operations in 2018," Flight Global, August 142015.

165 The legal demands refer to the desires of some countries to allow Predator aircraft to be hosted, but not the control van. This forced the control van to remain in the United States. See Whittle, ed.
} 
The third challenge was to arm the Predator. This required integrating ordnance to the Predator, as well as updating command and control systems to enable controllers to accurately aim and fire the weapon. This was a greater challenge than it would be for manned aircraft. The Predator was the first unmanned aircraft and engineers were unsure as to what unforeseen challenges there would be in arming the aircraft. Additionally, the lightweight construction that gave the Predator its range and endurance also made it aerodynamically sensitive and structurally fragile.

While none of these technical challenges was insurmountable, the limited history of long-endurance UAVs meant that the GA-ASI team and its Air Force overseers had little previous technical experiences that they could draw on to solve these challenges.

The Predator's roots outside of the conventional acquisition system left it less prepared to deal with its rapid expansion, particularly after 2001. Although the Predator was made a program of record in 1998, it was overseen by an Air Force organization known as Big Safari, which specialized in customizing small numbers of aircraft for highly-sensitive (often classified) roles and missions. Big Safari had rapid acquisition authority and used it to experiment with new capabilities over the years without having to go through the more onerous conventional acquisition system. For a small program like the Predator (with only 56 aircraft in 2001), there was little harm in keeping the program in Big Safari.

Keeping the program in Big Safari allowed the Predator to rapidly and iteratively add capabilities to the platform, but the more informal environment in Big Safari was not conducive to standardizing processes, fully and systematically exploring the Predator's capabilities or its long-term needs. For example, new capabilities that were added to some Predators were not standardized across the fleet, resulting in an inventory of Predators with differing capabilities. This prevented the Predator from achieving design stability. Lack of design stability in turn prevented the Air Force from devising an effective sustainment plan. ${ }^{166}$ The ground control stations (GCS) built to fly the Predators also faced the same problem - at one point there were 12 different GCS configurations, which led to higher sustainment costs and was generally inefficient and sometimes dangerous for pilots (who might be familiar with one configuration but not another). ${ }^{167}$

${ }^{166}$ Robotham., 53

${ }^{167}$ King. 
As a whole, the Predator's roots as an ACTD, followed by its transition into another organization that did not emphasize normal acquisition practices and procedures, left it unready for the rapid demand increase that took place after 2001. The need for more ISR CAPs in Iraq and Afghanistan demanded more aircraft, more personnel, and longer flying hours for existing systems. Additionally, the program had to be transitioned to a larger program office, since Big Safari was not capable of managing the increased program size.

Once the program transitioned to the new program office in 2006, the lack of a thoroughly developed sustainment plan or a disciplined requirements prioritization process and overall contractor and program office inexperience with the acquisition process made management very difficult. The Predator program office had to backfill oversight requirements that were skipped while managing the expansion of the program without the plans and guidelines that oversight requirements normally would require. Once the program expanded to the point where it became an ACAT I program in 2009, the program office and GA-ASI had even more oversight tasks to deal with.

Although the Predator fulfilled an existing mission set (reconnaissance and eventually precision strike), its unmanned approach and the additional ad hoc capabilities were disruptive to the Air Force as an organization. Who would fly the Predator? Was it distinctive enough to demand its own qualifications and career paths? How should it be controlled and employed? Who had the authority to direct the Predator to fire at ground targets? The Predator's first-of-its-kind status and informal ACTD roots meant that many of these questions were not answered or even asked before the Predator was developed and fielded.

Indeed, the Air Force originally saw only limited benefit in the Predator, keeping the program running as a small, niche capability until the onset of the Iraq and Afghanistan Wars. During the ACTD phase (which was run by the Navy), the Air Force was not very involved in program events. When the Air Force was chosen as the lead service at the end of the ACTD, this lack of prior participation left the Air Force less institutionally knowledgeable about the capabilities and limitations of the Predator. ${ }^{168}$ This kept the service (and DoD generally) from developing a full appreciation for the Predator's capabilities and how it could contribute to a given mission or task.

This low estimation of the Predator was not helped by its lack of thorough, long-term planning, which was an artifact of its ACTD roots. The ACTD team did not have to consider long-term factors such as methods of employment, pilot accessions, training,

${ }^{168}$ Thirtle, Johnson, and Birkler., 3.5 
maintenance, and maintenance training. Normally, such issues are considered and carefully planned out before a program reaches low-rate initial production (LRIP). In the case of the Predator (and other ACTDs), these issues are considered only after the ACTD merits a transition to program of record status. During the Predator's transition, the ACTD program office attempted to develop some of these plans, but lacked the time, staff, and experience to do so effectively. Additionally, the Air Force's late arrival to Predator development (again, the ACTD was initially run by the Navy) would have complicated any attempts to develop service-specific manning and training plans.

Since the Predator was inserted into the conventional acquisition process in medias res, it was at odds with the Air Force's (and DoD's) prevailing organizational methods and preferences for deliberate, long-term procurement investments. This disconnect caused confusion and organizational friction. For example, the Predator failed its operational test and evaluation (part of the conventional acquisition process) at the same time that operational commanders requested more Predator support because the test criteria to which the Predator held itself was not the same as the requirements of operational commanders in Bosnia. ${ }^{169}$ The lack of maintenance manuals, documents, and training for uniformed personnel was also a hindrance, requiring GA-ASI to provide a higher level of costly contractor support personnel than is normal. ${ }^{170}$ The result of the Predator's inability to develop long-term plans was that the program was not prepared when the DoD made its fourth round of investments and scaled up the Predator program to meet surging ISR demands.

\section{Mitigations}

While the technical challenges encountered by the Predator's designers were not insurmountable, its status as an ACTD and eventually as a Big Safari program allowed for an unusually close relationship between the DoD and the GA-ASI. This close relationship allowed those working on the Predator to iterate through design issues more naturally and responsively than would be expected.

This close relationship first took shape during the ACTD phase of the Predator's development. One of goals of the ACTD process is to encourage heavy user involvement and feedback throughout. Operationally, this meant that the Predator program office was

\footnotetext{
169 As related to the author by Dusseault. For the test results, see Operational Test and Evaluation Office of the Director, Operational Test and Evaluation Report on the Predator Medium-Altitude Endurance Unmanned Aerial Vehicle(UAV), September, 2001.

${ }^{170}$ Former MQ-1 program officer David King observed that although contractor support is normal for most aviation programs, they are usually not essential to the normal operation of the platform, which was the case for the Predator. See King.
} 
kept small, with 10-12 people involved rather than hundreds. ${ }^{171}$ Documentation requirements were loosened, which meant that information was shared more frequently through informal means between the contractor and the DoD. A RAND report observed that ACTD's demonstration manager (DM) management approach looked more like that of a research and development initiative rather than a procurement program.

This close relationship between DoD and GA-ASI continued when the Predator was transitioned to a program of record. The Air Force was selected as the lead service and at the recommendation of Congress, placed the program under the purview of Big Safari, which operated under truncated acquisition rules and policies compared to other program offices. ${ }^{172}$ Both the ACTD and Big Safari management of the Predator emphasized fast, "good enough" and entrepreneurial attitudes over slower, more deliberate and conservative processes and mindsets.

This attitude was employed by GA-ASI as well. During the first three rounds of investment (1995-2003), GA-ASI was a small firm with considerable technical talent and little experience in DoD contracting. This combination resulted in a company that was willing to anticipate DoD needs and take action to fulfill them even before a contract was awarded. According to a former Predator program manager, the DoD was sometimes placed in situations where they were reacting to GA-ASI's actions. ${ }^{173}$ GA-ASI actions included purchasing raw materials ahead of contracts to meet production timelines and developing capabilities using internal research and development funds to spur the DoD to action. ${ }^{174}$ GA-ASI representatives confirmed this, citing this willingness to lean forward as an integral part of the company's business model and corporate philosophy. ${ }^{175}$ This willingness to anticipate and take on risks on the part of the contractor was an important factor in the close relationship between government customer and private contractor.

Unencumbered by the deliberate requirements and acquisition process, Big Safari and GA-ASI rapidly fielded a variety of capability improvements, including:

- On-board laser designation

- Air-to-ground missiles (Hellfire)

${ }^{171}$ Thirtle, Johnson, and Birkler., 29

172 Whittle., 15-28.

173 David R. King, Oct 7 2015a.

${ }^{174}$ A GA-ASI official noted that the company has a larger internal research and development (IRAD) budget than comparable companies, citing this as evidence of GA-ASI's willingness to lean forward and anticipate DoD's needs. See Dusseault. 175 
- Air-to-air missiles (Stinger)

- Real-time video streaming to troops on the ground

In each of these cases, Big Safari validated the requirement and began collaborating with GA-ASI almost as soon as they heard about it, producing working models within weeks, and deploying them to operational environments within months (see Figure D.5).

Figure D.5: Turnaround Times for Selected Predator Capabilities

\begin{tabular}{llcc}
\hline \multicolumn{1}{c}{ Capability } & \multicolumn{1}{c}{ Initiator } & $\begin{array}{c}\text { Time to first } \\
\text { working model }\end{array}$ & $\begin{array}{c}\text { Time to first } \\
\text { operational use }\end{array}$ \\
\hline $\begin{array}{l}\text { Laser designation } \\
\begin{array}{l}\text { Air-to-ground } \\
\text { missile }\end{array}\end{array}$ & SAF/AQ & 3 weeks & 3 months \\
$\begin{array}{l}\text { Air-to-ground } \\
\text { missile }\end{array}$ & ACC & 7 months & 15 months \\
ROVER Downlink & $\begin{array}{l}\text { Individual ARSOF } \\
\text { Soldier }\end{array}$ & 2 weeks & 2 months \\
& & & 2 months
\end{tabular}

Source: Whittle, 2011

The short turnaround times and effective results are indicative of the unusually informal and close relationship that GA-ASI and the Air Force shared. The relationship was mutually supportive and resulted in timely and innovative solutions to technical problems and capability gaps, unencumbered by onerous oversight.

The Predator's ACTD and Big Safari roots left it unprepared for its eventual expansion in the mid-2000s. The Air Force program office responsible for the Predator never did manage to catch up to the studies, analyses, and certifications demanded by the conventional acquisition cycle. The sustainment issues cited above (including the manpower shortages that were exacerbated by organizational cultural resistance) remained largely unsolved. Although a repair parts pipeline was established and technical guidance was eventually given, the Predator remained dependent on contractor support for some sustainment functions. More than 15 years after it transitioned to a program of record, the Predator has not been able to fully transition into a normal weapon system that is fully supported by military or government sustainment capabilities. 
Still, the Predator's high operational demands required that something be done about some of its sustainment needs. This goal was accomplished by a generous level of funding requested by the DoD and provided by Congress. These funds allowed the Predator program to "get by" with an expedient, but sometimes less cost-effective means of keeping Predators flying. Senior leader demands for increased Predator coverage and capabilities also forced program officers to create work-arounds and ad hoc solutions to make up for the lack of well-developed staffing and sustainment plans.

Senior leader intervention was required to address the Air Force's institutional preferences for manned systems over the Predator and other UAVs. This intervention took place in 2007-08, when unmet demand for ISR in CENTCOM was at its highest level. The Secretary of Defense, Robert Gates, observed that the Air Force's preferences stemmed from a belief that emphasis on UAVs would take away resources from manned systems. ${ }^{176}$ This was mitigated by executive and Congressional support for generous supplemental funding for UAVs (while manned systems remained relatively unaffected). To ensure effective implementation, Gates also established an ISR Task Force in 2008 to ensure that resources for ISR were put to best use (to include increased production and sustainment of MQ-1s). ${ }^{177}$ These actions by senior leaders left the long-term problems of the incomplete ACTD transition unresolved, but provided enough strategic guidance to implement inefficient (in terms of monetary and time costs) but effective actions to be taken to reduce the unmet demand for Predator coverage.

\section{Outcome}

Over the past decade, the Predator has made an impact far greater than its modest roots outside of the defense acquisition system would have predicted. Not only was it able to transition into a program of record, its development fundamentally altered the way that the US military operated and its expectations in terms of surveillance and precision strike capabilities. Furthermore, its abilities to conduct these missions more easily than was possible in the past sparked an ongoing public debate about the legality of its capabilities.

In terms of military concepts of operations, the Predator ushered in a new era of ISR and precision strike. It did so in two ways. First, Predator brought down the cost of aerial imagery and surveillance. This gave tactical commanders access to a level of information that was once only available for national-level tasking. It also allowed commanders and

\footnotetext{
176 Gates, ed., 132.

${ }^{177}$ House Permanent Select Committee on Intelligence, Performance Audit of Department of Defense Intelligence, Surveillance, and Reconnaissance, April, 2012, 15.
} 
defense leaders to linger over areas of interest far longer than would have been feasible using manned aircraft or space-based assets. ${ }^{178}$ With persistent ISR, intelligence analysts could establish patterns of life and provide a more nuanced and detailed picture of an area of interest. This relative wealth of ISR capability changed the way the commanders and defense leaders used ISR products to drive operations. Although it was not the only platform to accomplish this, the Predator was the first and the most influential.

Secondly, it fundamentally changed the way defense leaders and commanders weighed the costs and benefits of precision strikes against sensitive targets. These targets might be hard to locate, fleeting, or located in politically or physically-risky locations. Striking them with manned aircraft or even standoff weapons such as cruise missiles entailed high risks (to pilots, for example) or costs (in cruise missiles, for another example) ${ }^{179}$ The Predator's unmanned nature, low flying capabilities, and munitions costs greatly reduced the threshold for undertaking such missions.

Beyond its influence on military operations, the Predator has acquired a level of public recognition that reaches an iconic level. Although the Predator has been generalized as a "drone" along with other UAVs, it was the first, most iconic, and most responsible for sparking the level of public discourse about the uses, limits, and abuses of highly responsive and economical ISR and precision strike. ${ }^{180}$ The depth and concern about the operational, political, legal, and moral impacts of drone strikes has reached a level not seen since the advent of nuclear weapons in the 1940s and 50s. The salient points of these discussions are beyond the scope of this case study, but it is clear that the Predator was an integral catalyst of that discussion.

178 Dusseault.

179

${ }^{180}$ The amount of writing on UAVs and their effect on warfare is too numerous to be cited in detail here. A good example though, can be found in Jane Mayer, "The Predator War," The New Yorker, October 262009. 


\section{Appendix E: MRAP Case Study}

\section{Description}

The MRAP (Mine Resistant Ambush Protected) is a class of troop-carrying vehicles that are designed to be especially survivable against improvised explosive devices (IEDs) and small arms fire.

MRAPs trade mobility for survivability. Originally developed by the South African military in the 1970s, MRAPs are characterized by their armored hulls, featuring a vshaped bottom to deflect underbody mine blasts. ${ }^{181}$ This design results in a heavy gross weight and large footprint. ${ }^{182}$ MRAPs are strictly wheeled vehicles, as vehicle tracks (e.g., tanks and armored personnel carriers) transfer more blast energy from a mine detonation to the crew compartment. ${ }^{183}$

\section{Investment Drivers}

In examining the influence of the two drivers that motivated the DoD to invest in MRAPs, the need to react to an enemy threat (IEDs, in this case) was most prevalent. There is little evidence that the second driver - a desire to capitalize on new and emerging technologies — played any significant role in the DoD's investment in MRAPs.

\section{Reacting to the IED Threat}

There is ample evidence that the DoD invested in MRAPs in reaction to an enemy threat. The timing of the DoD's investment and the nature of the MRAP requirement indicate that the reaction to an enemy threat was a strong driver of investment. In the case of the MRAP, that enemy threat was the frequent use of IED attacks by Iraqi (and later, Afghan) insurgents. IED attacks were particularly effective because insurgents could strike US forces without getting decisively engaged. This was particularly true for large buried IEDs that struck vehicle underbellies, where the armor of existing vehicles was

\footnotetext{
${ }^{181}$ William C. Schneck, After Action Report: Operation Restore Hope: Headquarters US Army Aviation and Troop Command, June 13, 1994.

182 The average MRAP purchased by the DoD weighed between 18-18 short tons. By comparison, an M1114 UAH weighs 4.9 short tons.

${ }^{183}$ Schneck.
} 
weakest or non-existent. ${ }^{184}$ The casualties that US troops suffered from increasingly sophisticated and deadly IEDs greatly impacted the US strategy in Iraq and Afghanistan.

\section{Timing}

The impetus for DoD investment in the MRAP occurred after combat operations commenced in 2003 in Iraq, implying that the DoD was reacting to a problem that had already manifested itself in a definite way. Although the DoD had previously attempted to counter the IED threat by investing in up-armored HMMWVs (particularly the M1114), these investments were also made after IEDs in Iraq had already become prevalent and were less effective against increasingly powerful IEDs. ${ }^{185}$ The first major agitation for the MRAP occurred in 2005, in a universal urgent needs statement (UUNS) submitted by the Marine Corps' I Marine Expeditionary Force (I MEF) to its service chain of command. ${ }^{186}$ After two years of consideration, the request began to be fulfilled in 2007. The timing of this first request indicates that the DoD collectively made its decision to invest in MRAPs only after forces in the field were engaged in combat with an adversary.

\section{Origin and Nature of MRAP Requirement}

Beyond the issue of timing, the justification for the 2005 UUNS itself is evidence that the DoD was investing in MRAPs to counter an enemy threat. At the time (and today), the Marine Corps defines a UUNS as a "request for a capability that, if not filled, places the accomplishment of the unit's mission in jeopardy or unduly increases the risk of casualties." 187 This strict definition confines requests (such as the MRAP) to only those that are responding to an existing operational condition-increasingly powerful and destructive IEDs, in the case of the MRAP.

\footnotetext{
${ }^{184}$ Matthew J. Schmidt Christopher J. Lamb, Berit G. Fitzsimmons, MRAPs, Irregular Warfare, and Pentagon Reform: National Defense University, June, 2009b, http://usacac.army.mil/cac2/cgsc/sams/media/MRAPs.pdf (as of December 2, 2014).

185 Inspector General, Procurement Policy for Armored Vehicles, Washington, DC: Department of Defense, D-2007-107, June 27, 2007.

${ }^{186}$ While the 2005 UUNS was the first major request, the first MRAP request came in December 2003, when the Marine Corps' I Marine Expeditionary Force (I MEF) requested a small number of Hardened Engineer Vehicles (HEVs) through the Marine Corps' urgent universal needs statement (UUNS) process. The Marine Requirements Oversight Council (MROC) approved funding for 15 HEVs in March 2004. The HEV would ultimately be developed into a Category III MRAP called the Joint EOD Rapid Recovery Vehicle (JERRV).In any case, this initial impetus for the MRAP occurred after combat operations began in March 2003. Like the 2005 UUNS, this also indicates enemy threat as an investment driver.

${ }^{187}$ United States Marine Corps, URGENT UNIVERSAL NEED STATEMENT (UUNS) PROCESS, Jan 26, 2006, http://www.marines.mil/News/Messages/MessagesDisplay/tabid/13286/Article/118075/urgentuniversal-need-statement-uuns-process.aspx (as of April 2, 2015).
} 
Indeed, this was the case for the 2005 MRAP request. The request, signed by BGen Dennis J. Hejlik of I MEF, noted that the request was being driven by the ". . . expanded use of IED/RPG [rocket-propelled grenade] and small arm[s] fire (SAF) in the AO [area of operations]. .." that required “. . . a more robust family of vehicles [emphasis added] capable of surviving the IED/RPG/SAF threat." 188 The clear way that the 2005 request articulated the threat environment and the inability of US forces to counter the threat with existing weapons show that the DoD investment in MRAPs was indeed driven by a need to react to an enemy threat.

Although the MRAP was eventually designated as a major defense acquisition program (MDAP) in 2007, the impetus of the demand remained rooted in the need to respond to an enemy threat. ${ }^{189}$ The MDAP designation only served to focus attention and resources on meeting the growing demand for MRAPs. The imperative for investment did not change - it remained the same as with the original 2005 UUNS request.

\section{Little Evidence for Capitalizing on New Technology}

While there is ample evidence that DoD investments in MRAPs were driven by the need to react to an enemy threat, there is little evidence the DoD chose to invest in MRAPs based on a desire to capitalize on new technological advances. The MRAP's distinguishing technological feature-its V-shaped, armored monocoque hull, is not a new technology. The design was pioneered by the Rhodesian (later Zimbabwe) military in 1975 and later perfected by South Africa. ${ }^{190}$ This design feature emphasized the dispersal of blast energy from a mine detonation.

These designs were perfected by the 1990s, during which the South African and Zimbabwean militaries deployed large numbers of MRAPs during the UN-sanctioned United Task Force (UNITAF) humanitarian relief operation in Somalia. ${ }^{191}$ US Army combat engineers observed these MRAPs in action there and advocated for DoD investment in such vehicles through the 1990s. ${ }^{192}$ By the time the DoD invested heavily

188 MINE RESISTANT AMBUSH PROTECTED (MRAP) VEHICLE, February 17, 2005,

http:/www.marines.mil/News/Messages/MessagesDisplay/tabid/13286/Article/118075/urgent-universalneed-statement-uuns-process.aspx (as of April 2, 2015).

${ }^{189}$ Michael J. Sullivan, Rapid Acquisition of MRAP Vehicles, Washington, D.C.: Government Accountability Office, GAO-10-155T, Oct 8, 2009, http://www.gao.gov/assets/130/123503.pdf (as of Nov 10, 2014).

190 Schneck.

191

192 During that time, the US military was involved in wide range of peacekeeping and peace enforcement operations in mined areas. Combat engineers tasked with ensuring the mobility of friendly forces were 
in MRAPs in 2007 though, this key design feature was already mature. US MRAPs at this time did not exhibit any additional innovations that would indicate that the DoD invested in MRAPs to take advantage of technological advances.

\section{Implementation Obstacles and Mitigations}

Unlike some of the other rapid acquisition programs covered in this research, the MRAP was beset by long, high-profile delays that had to be resolved through concentrated attention from DoD leaders. In this section, we will describe these delays and the steps that had to be taken to mitigate them.

\section{Obstacles}

The main reason why MRAPs were fielded so slowly was due to the long time it took the DoD (specifically, the Marine Corps) to decide that the MRAP was worth investing in. There were two main factors in the delay: an initial reluctance to invest in a reactionary solution to the IED threat and a mindset on behalf of DoD leaders who were socialized to think of procurement in terms of generalized value over a long period of time.

It is important to note that the delays in fielding the MRAP were related solely to validation. There was no disagreement about the effectiveness of the MRAP in protecting troops from IEDs, particularly in comparison to existing vehicles like the HMMWV. ${ }^{193}$ Defense leaders, Congress, and commanders on the ground were all in agreement on the effectiveness of the MRAP. Disagreements and implementation delays stemmed from differing perceptions between the commanders in the field and defense leaders in the Pentagon in regard to the value offered by the MRAP.

By responding to the IED threat defensively by adding more armor, the MRAP solution implied a reactionary mindset. For the DoD and the Marine Corps in particular, this idea of ceding the initiative to the enemy was contrary to their organizational cultures. Leaders felt that the enemy could easily respond by building progressively larger and more powerful IEDs. Additionally, other counter-IED initiatives, such as those being worked on by JIEDDO and the Army's Rapid Equipping Force (REF), were more technically elegant in that they largely focused on detecting and neutralizing IEDs before they exploded. Finally, the services' previous limited experience with wheeled armored

likely keen to advocate for MRAPs to help them fulfill this task. See Somalia AAR and also MCG article 1999.

193 Matthew J. Schmidt Christopher J. Lamb, Berit G. Fitzsimmons, MRAPs, Irregular Warfare, and Pentagon Reform, Washington, DC: Institute for National Strategic Studies, 2009a. 
vehicles in Somalia left some leaders pessimistic about the potential for marginal gains in protection at the cost of mobility. ${ }^{194}$ These three reasons combined to form an initial layer of reluctance in the minds of many defense leaders about the potential for an armor-based solution to the IED threat.

The statements and sentiments of the $\mathrm{DoD}$ and Marine Corps leaders regarding the shortcomings of the MRAP indicate that they valued different things in a weapons system compared to the field commanders who were requesting the MRAP, as well Congress and the general public.

The main difference in the preferences of commanders and DoD leaders was in the general utility of the MRAP. Whereas the commanders in the field requesting the MRAPs valued a capability that was optimized for a very specific threat, DoD and Marine Corps leaders were more focused on how the MRAP could fit into military force structures in the long run. During testimony to Congress, the Assistant Commandant of the Marine Corps (the second highest-ranking officer in the Marine Corps) General James F. Amos' statements clearly indicated that he was very concerned about the need for Marine Corps procurement to be flexible and able to be useful in the long-term. ${ }^{195}$ During a separate hearing, the Commandant of the Marine Corps, General James Conway, cautioned the Senate Armed Service Committee that the MRAP was "not the right vehicle for every purpose."

While the Marine Corps leadership was expressing discomfort about how the MRAP was not a good fit for the way that the Marine Corps fights, the service bureaucracy was also expressing different types of long-term concerns. The Marine Corps Combat Development Integration Board that was convened to consider the merits of the MRAP expressed concerns about the lifecycle costs of the system-reliability, maintenance costs, and other long-term costs that any responsible organization needs to carefully weigh when making a purchase for a weapons system that will be around for years to come. ${ }^{196}$ Less regard was given to the immediate need for better protection from IED blasts.

Lastly, DoD leaders' focus on the long-term procurement values is further evidenced by the concern that many DoD and service leaders voiced about how the size and scope

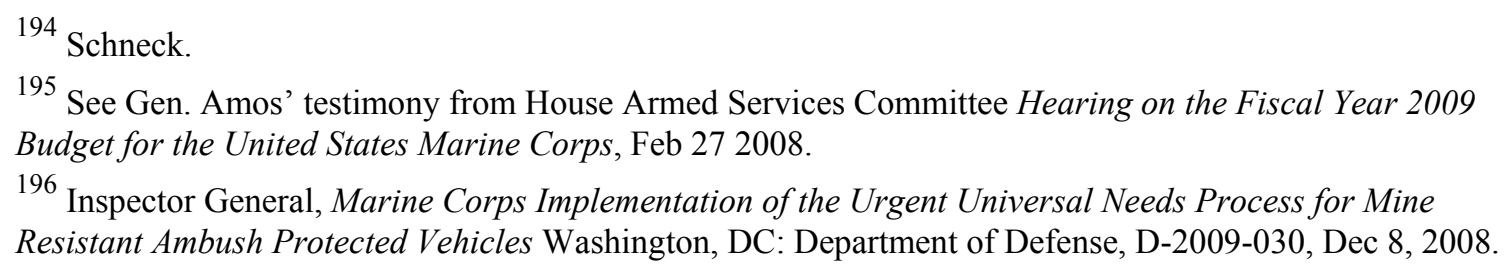


of the MRAP UUNS request would affect the development and anticipated fielding of the Joint Light Tactical Vehicle (JLTV). The JLTV program was meant to replace the HMMWV and had the potential to incorporate some of the MRAP's survivability design features. ${ }^{197}$ Since the leaders were focused on the long-term values that JLTV was more in line with (e.g., it would fit into warfighting doctrine, lifecycle costs, etc.), DoD and Marine Corps leaders collectively preferred to husband its financial and political resources for that vehicle, rather than purchase a large number of specialized vehicles to address a specific threat. ${ }^{198}$

The DoD leadership was not completely insensitive to the needs of troops in the field. In fact, the organization's initial response to the IED problem provides further evidence for the service's emphasis on long-term, generalizable procurement solutions.

The Army and Marine Corps initially chose to add armor to existing vehicles, such as the HMMWV (a process known as "up-armoring"). While this practice was originated in the field by troops using improvised materials, service leaders eventually developed armor kits and worked with the HMMWV manufacturer AM General to develop the M1114 up-armored HMMWV, which featured integrated armor and a more powerful engine, transmission, and improved suspension to support the additional weight. The Army began procuring the M1114 in 2004, prior to the initial request for MRAPs from the Marine Corps. ${ }^{199}$ For a period of time, while the MRAP debate raged, DoD leaders often pointed to the M1114 to demonstrate that they were responding to troops' needs.

Defense leaders argued for the M1114 over the MRAP for several reasons. First, DoD leaders asserted it was the fastest way to get armor in the hands of troops. ${ }^{200}$ The M1114 production line was already active when the initial 2005 MRAP request was submitted. In fact, the Marine Corps committed itself to replacing a large percentage of its in-theater HMMWV fleet with M1114s. ${ }^{201}$ This effort (which totaled 8,105 M1114s) had the support of the Secretary of Defense and was well underway when the 2005 MRAP request appeared. ${ }^{202}$

\footnotetext{
${ }^{197}$ Christopher J. Lamb, Impediments to Acquisition Excellence Illustrated by the MRAP Case: Institute for National Strategic Studies, Jun 24, 2014.

${ }^{198}$ Franz Gayl, "Protect JLTV Competition From Outside Influences " Defense News, October 152012.

${ }^{199}$ Inspector General.

200

${ }^{201}$ Lamb.

${ }^{202}$ Christopher J. Lamb.
} 
This commitment by the Marine Corps, and concurrent efforts by the Army to field the M1114, was expensive (over $\$ 4$ billion dollars) and suggests a second reason why the M1114 was preferred over the MRAP - cost. The existing cost of the M1114 program must have been an additional factor that weighed on the minds of defense leaders who were worried about the effect of a large-scale MRAP procurement on the JLTV. While no official expressed this sentiment explicitly in testimony or writing, it is unlikely that leaders were not concerned about these additional costs affecting the JLTV program.

\section{Mitigations}

The delay in validating the MRAP requirement was an obstacle that was eventually overcome by a maturing rapid acquisition process aided by outside intervention. Once the DoD collectively decided to make the immediate investment in the MRAP by validating the requirement, the ease of production and integration of the MRAP made up for the time lost during the delay in validation.

The proponents of the MRAP benefitted from a maturing rapid acquisition process that allowed their arguments for the MRAP to be heard. Specifically, the MRAP's supporters at I MEF submitted their request through their service's urgent needs request system, and then through the joint urgent needs request system (known as a Joint Urgent Operational Need, or JUON). ${ }^{203}$ This dual-tracked approach allowed the MRAP to be considered twice, by different authorities.

The scale of the MRAP request also benefitted from the maturing rapid acquisition process. Processes for weapons procured outside of the conventional acquisition process were originally meant for small programs. The IED threat spurred the creation of a multitude of DoD organizations chartered to develop and field quick materiel solutions to troops in the field. These organizations included the REF, the Joint Rapid Acquisition Cell (JRAC), and JIEDDO, among others. These organizations were meant to consider larger programs than pre-war processes. The combined efforts of these organizations to build processes for rapid acquisition and their acceptance within the DoD made the eventual decision to invest heavily in MRAPs easier to implement.

The biggest mitigating factor in the eventual institutional approval of the MRAP was the wide group of stakeholders that enabled it to overcome the DoD's slow and hesitant validation process. These groups included Congress, members of the press, and eventually DoD leaders such as the Secretary of Defense. These stakeholders recognized that the immediate need for investment in the MRAP to mitigate the effects of IED 
attacks was much more important than the DoD's institutional preference for long-term investments (such as the JLTV). Each group pushed the DoD to place greater emphasis on immediate investments through a variety of means.

Congress played a crucial direct and indirect role in overcoming the institutional resistance to the MRAP. In its direct role, it authorized the necessary funds to enable to the DoD to make immediate investments while preserving its long-term investment preferences. This funding allocation was crucial to preempting any possible resistance to the MRAP because it might interfere with the development of the JLTV.

Indirectly, Congress pressured service leaders to consider and reconsider the MRAP, using official correspondence as well as hearings and testimony to repeatedly express their desires about the MRAP. ${ }^{204}$ At one point, one member of Congress even had his staff build a mockup of an MRAP-like vehicle using materials from Home Depot that was wheeled over to the Pentagon for added emphasis. ${ }^{205}$ Several members of Congress also communicated their concerns to the President, as an additional way of underscoring their wishes.

Congress was aided by the media's focus on the MRAP as well. Reporters and correspondents recognized that the DoD was not organizationally ready to make immediate investments in MRAPs even as Congress was pushing it to do so. The press focused attention on the MRAP, particularly the aspects that made the DoD and service branches appear recalcitrant and slow-moving. This additional attention placed pressure on DoD to reconsider the MRAP, particularly after the combined pressure of Congressional and media interest forced the DoD to investigate the outcomes of the original I MEF UUNS. ${ }^{206}$ These combined efforts underscored the desire of many to see the DoD make better short-term investments, rather than long-term investments for "the next war". 207

Lastly, DoD leaders, particularly the incoming Secretary of Defense Robert Gates, learned to recognize the need to invest in MRAPs, with some help from the two aforementioned groups. It was particularly important for Secretary Gates to state unequivocally that the MRAP was the highest DoD investment priority in May 2007 and

\footnotetext{
204 See Carl Levin, June 26 2007,___ Jr. Joseph R. Biden, Chistopher S. Bond, June 282007.

205 Christopher J. Lamb.

206 Inspector General.

207 Gates, ed.
} 
to give it special priority for raw materials. ${ }^{208}$ Those moves, combined with the sustained attention provided by the MRAP Task Force, ensured that all levels of the organization understood that the MRAP and other immediate investments were necessary.

Some of the time lost from the extended debate about the validity of the MRAP requirement was recouped during production. Four factors contributed to this recoupment. First, the MRAP design requirements were stable and mature, allowing manufacturers to jump directly to production. Second, the MRAP program office contracted with multiple manufacturers for different MRAP designs, which sped up production at the cost of logistical complications afterwards. Third, the manufacturers themselves assumed some capital risk by placing orders for raw materials and setting up production lines prior to formal contracting, which reduced setup time prior to production. Lastly, final integration of $\mathrm{C} 2$ and accessory components was done by the DoD at its own facilities, reducing the supply chain burden and giving the DoD greater control over marginal changes.

The MRAP was also relatively easy to integrate into the force. Although drivers needed training to get accustomed to the MRAP's higher clearance and less forgiving handling compared to the HMMWV, they were employed no differently than the vehicles that they were replacing. No significant changes in tactics, techniques, or procedures were necessary. Troops in the field were able to quickly integrate the MRAP into their daily operations. This easy integration made the introduction of the MRAP into the force a relatively uncomplicated affair.

\section{Outcome}

Almost 20,000 MRAPs were eventually fielded. Although there was some debate about how effective the vehicle was in reducing casualties in light of other factors at the time (such as the Anbar Awakening), it was clear that the MRAP was a more survivable vehicle that blunted the enemy IED campaign at a strategic level.

At the end of each conflict though, there was significant debate about the ultimate role of the MRAP. The vehicle was not well-suited for general purpose operations, but it could also be argued that the IED world is one that is here to stay. Ultimately, the DoD decided to keep a decent proportion of MRAPs for itself. Curiously, the DoD began to justify these decisions by describing the need for the MRAP's protective cabin as a longterm, enduring requirement.

208 , ed. 


\section{Appendix F: CREW Case Report}

\section{Description}

CREW (Counter RCIED Electronic Warfare) systems are a class of electronic jammers that disrupt radio-controlled IED (RCIED) detonation signals. These jammers generate interference or confusing signals on the same frequency that an RCIED operates on, blocking the detonation command from reaching the IED and thus preventing detonation. Jammers were commonly installed in vehicles and in backpacks for dismounted operations and used extensively in the Iraq and Afghanistan Wwars to protect troops on patrol.

\section{Investment Drivers}

In this section, we discuss the degree to which DoD investments in IED jammers was driven by:

- A need to react to an enemy threat

- A desire to capitalize on technological advancements

We find that initial DoD investments in IED jammers were largely in response to an immediate RCIED threat, while later investments were informed by a desire to expand on technological advances in jamming, as well as non-defense advances in networking.

\section{IED Jammer Development as a Reaction to the Enemy}

In this section, we will describe the DoD's uneven investment in electronic warfare (EW) and how those choices left US forces vulnerable to enemy RCIEDs early in the Iraq War. We will then show how this necessitated an effort to cover this capability gap that was clearly a reaction to the enemy RCIED threat. Finally, we will show that the results of this immediate investment resulted in a renewed DoD appreciation for the need to make long-term investments in electronic warfare.

\section{DoD's Uneven Investment in Electronic Warfare}

Some components of the DoD have long invested electronic warfare capabilities. Since World War II, the Navy and Air Force (and the Marine Corps, to a lesser extent) have invested in maritime and aerial applications of electronic warfare. Protecting ships and aircraft from electronic detection, resisting enemy electronic interference, and launching these same attacks against enemy ships and aircraft are long-established 
missions for the Navy and Air Force. Since these services are organized around ships and aircraft that have inherently large electronic footprints, the need for constant investment in electronic warfare has always been present.

The Army and Marine Corps also made investments in electronic warfare capabilities after World War II. The Army built and maintained listening posts on the German border during the Cold War to intercept and exploit Soviet bloc signals. ${ }^{209}$ The Marine Corps developed similar eavesdropping and emissions analysis capabilities for its ground forces, as well as aerial capabilities similar to those of the Navy and the Air Force. ${ }^{210}$ Electronic warfare had a clear role in land operations against a conventional peer adversary that was expected to fight in the electromagnetic spectrum.

Once the Soviet Union collapsed however, the motivation for Army (and to a lesser extent, Marine Corps) investment in electronic warfare waned. During the 1990s, both services fought low-intensity conflicts against adversaries that had simple or minimal electronic footprints. At the same time, fiscal pressures motivated the Army to deemphasize electronic warfare and rely on other services' assets in case they were ever needed. ${ }^{211}$ Consequently, ground forces deemphasized electronic warfare and commanders no longer made it a part of their mission planning process.

By 2002, the state of electronic warfare in the DoD was uneven and remained focused on major combat operations. The Army had outsourced its electronic warfare needs to the other services, which had capabilities that were meant to be deployed in support of large formations fighting a peer or near-peer adversary. The USMC retained some electronic warfare assets, but only in its aviation units.

\section{A Gap in Tactical-Level Electronic Warfare}

This uneven electronic warfare investment left ground forces vulnerable during the first years of the Iraq and Afghanistan Wars to a new kind of electronic warfare threat. Although US and Coalition forces had successfully used electronic warfare capabilities to disrupt Iraqi Army command and control during the initial invasion, they did not foresee the proliferation of improvised explosive devices and their evolution into radio-controlled varieties.

\footnotetext{
209 "View From the Ground: The New Integrated Face of Land EW," IHS International Defence Review, 2010.

${ }^{210}$ United States Marine Corps, "MCWP 3-40.5: Electronic Warfare," (2002).

${ }^{211}$ Zachary Lum, "Beyond CREW: Army EW Fights For a Bigger Spectrum " The Journal of Electronic Defense, October, 2013.
} 
IEDs first appeared in late 2002 in Afghanistan, but they were more widely adopted by insurgents in Iraq. Early Iraqi IEDs were detonated by command wire. After US troops began to react more quickly to these IEDs, insurgents began to use a variety of remotely-controlled triggers (e.g., garage door openers and cell phones) that gave them more standoff (and thus more time to leave the scene of an attack). By 2006, 70\% of all IED attacks on US and Coalition forces were RCIED attacks. ${ }^{212}$

The United States struggled to respond to RCIEDs. Jamming the RCIED signal was one obvious response (others included heavier armor and earlier detection of IED emplacers). The DoD's emphasis on aerial and maritime-centric electronic warfare meant that existing jammers were either too big to be carried by ground units or operated at ranges that were too far away to be effective against the insurgents' remote detonators. Powerful Navy EA-6B Prowlers and Air Force EC-130H Compass Call aircraft were capable of jamming detonation signals, but these aircraft were limited (the Air Force only had 10 Compass Call aircraft) and meant to support larger formations, rather than the much smaller ground convoys and patrols in Iraq and Afghanistan. ${ }^{213}$ They were not responsive enough to support the ground commanders in Iraq and Afghanistan.

The DoD possessed some tactical-level jamming capability, but these were niche, ineffective systems. The Navy developed and retired a series of jammers (in response to a spate of terror attacks in the 1980s) known as the Channel series. Some of these jammers were adapted to jam a specific RCIED found in Afghanistan called the Spider. $^{214}$ However these refitted jammers, known as Acorns, were unable to jam other IEDs and had to be left on constantly, making it a very inefficient and ineffective device.

Another existing tactical asset that was modified to jam IEDs was the Army's Shortstop system. One of the Army's few electronic attack platforms, Shortstop was developed in the 1990s to confuse artillery proximity fuses into prematurely detonating. In 2002, Shortstop was modified to fit inside a HMMVW and dubbed Warlock Green. ${ }^{215}$

\footnotetext{
212 Rick Atkinson. "Left of Boom: The Struggle to Defeat Roadside Bombs in Iraq and Afgthanistan." (Place Published: The Washington Post Co, 2007.

${ }^{213}$ For more on aerial platform contributions to IED jamming, see Glenn W Goodman John Knowles, "COMPASS CALL: THE NEW AEA," Journal of Electronic Defense, Vol. 30, no. 5, May, 2007.

214 Noah Sachtman, "The Secret History of Iraq's Invisible War," Wired, April 112011.

215 The intent was to use Warlock Green to prevent the Iraqi Army from scuttling oil rigs by jamming remote detonation signals. This turned out to be unnecessary. See Jeffrey A. Dayton, "Risk of Using Past to Predict Future: A Case Study of Jamming RCIEDs" (Naval Postgraduate School, 2009).
} 
It was originally intended to prevent Iraqi forces from remotely destroying oil drilling platforms and was deployed to Iraq during the 2003 invasion.

Warlock Green was more elegant than the Acorn. It waited until it heard a trigger signal before emitting its own jamming signal (this is known as reactive jamming). However, insurgents began to change the frequencies in their remote detonators by switching between detonators like cellphones and garage door openers. Modifying the Warlock to deal with each frequency took time, making it slow to respond against a quickly-adapting enemy. Additionally, Warlock took several seconds to detect and jam a signal - an insurgent could set off an IED in a fraction of that time. ${ }^{216}$ Although Warlock was effective against some RCIEDs, it was had too many shortcomings to be a reliable, general purpose IED jammer.

\section{The Wartime Response and JIEDDO}

Since existing electronic warfare assets did not meet the demand for reliable, responsive IED jamming, the DoD (led by the Army) moved quickly to fill this capability gap. By the end of 2003, the Army had established a Counter-IED Task Force to rapidly develop and field equipment like IED jammers. ${ }^{217}$ That organization eventually grew to become the Joint IED Defeat Organization (JIEDDO), which funded the rapid development of multiple IED jammers, spending almost $\$ 17$ billion dollars by $2011 .^{218}$

JIEDDO's sizable effort eventually resulted in effective jammers that forced insurgents to turn away from RCIEDs. Jamming power, systems integration, and responsiveness problems were largely solved by 2009 . This activity was facilitated by JIEDDO's unique organization and authorities, which allowed it to manage and spend its budget in more flexible ways than is normally allowed in the DoD. ${ }^{219}$ As an acquisition organization, JIEDDO also had unusually close relationships with troops in the field, allowing it to tailor its products (including IED jammers) to user needs. These unique authorities and relationships were justified by the extremity of the problem, indicating

\footnotetext{
${ }^{216}$ Engineers calculated that the response time could be no longer than 100 milliseconds. See Patrick Nickel Jan Mietzner, Askold Meusling, Patrick Loos, Gerhard Bauch, "Responsive Communications Jamming Against Radio-Controlled Improvised Explosive Devices," IEEE Communications Magazine, October, 2012.

217 Sachtman. 218

${ }^{219}$ Committee on Armed Services: Subcommittee on Oversight \& Investigations, The Joint Improvised Explosive Device Defeat Organization: DOD's Fight Against IEDs Today and Tomorrow: U.S. House of Representatives, November, 2008.
} 
that the DoD's investment in IED jammers was in response to a specific IED threat posed by the enemy.

\section{IED Jamming: A Direct Response to an Enemy Threat}

It is clear that the DoD's investment in IED jamming capabilities was driven by the need to counter insurgent RCIEDs. The DoD lacked the capability to respond to the RCIED threat at the outset of the Iraq and Afghanistan Wars. Once the threat was recognized, it made its investments in IED jamming through an organization (JIEDDO) specifically chartered to confront this enemy threat and given special authorities and resources to do so.

\section{Jammer Investments Made to Capture Technological Advances}

DoD's wartime investment in IED jamming awakened it to the potential for new EW technologies and capability needs, particularly at the tactical level. In this section, we will explore how the DoD, through its experience with IED jammers in Iraq and Afghanistan, came to reconsider the need to make investments in electronic warfare capabilities such as IED jamming.

By 2010 CREW investments were beginning to pay off. New systems like Duke and CVRJ were quickly and effectively blocking remote detonation signals from a wide variety of triggers. Insurgents were turning away from RCIEDs and returning to command-detonated and pressure-plate IEDs. The effectiveness of Duke and CVRJ might have been considered comprehensive enough to warrant lesser emphasis and investment in IED jammers, as was the case when the DoD ended its investment in MRAPs.

Rather than turning away though, the DoD continued to invest in IED jammer technology. These new investments emphasized networked systems that could coordinate jamming with one another and send information on enemy signals to analysts for exploitation. $^{220}$ In 2013, the Army also launched a Multi-Functional Electronic Warfare (MFEW) program to develop a family of equipment that could conduct eavesdropping, spoofing, and other electronic warfare missions at the tactical level. ${ }^{221}$

This continued investment is not in response to an immediate enemy threat, but is due to the fact that the DoD had already made significant IED jammer investments and

\footnotetext{
${ }^{220}$ Joe Gould, "New gear puts electronic warfare on the offensive," Army Times, Oct 302013.

221 Jr. Sydney J. Freedberg, "Army Electronic Warfare Goes On The Offensive: New Tech Awaits Approval " Breaking Defense, Jan 292013.
} 
wished to push state-of-the-art technology forward. The plethora of CREW systems and the multiple iterations and refinements for the $40,000+$ systems fielded meant that the DoD had significant sunk costs that motivated them to continue investing. DoD realized that IEDs were going to be an enduring aspect of warfare and decided to capitalize on the momentum already gained in the previous decade of research and employment.

More significantly, the DoD is also moving forward with IED jammer investments absent the special wartime authorities that enabled its initial investment. For instance, IED jammer investments continue even as JIEDDO's budget, authorities, and even its charter are being dramatically curtailed. ${ }^{222}$ Whether investments will continue consistently in the future though, is uncertain.

More significantly than DoD's continued investment in IED jammer capabilities is its renewed emphasis on electronic warfare investments more generally. DoD learned that there is a need for electronic warfare capabilities, even in low-intensity conflict. In fact, low-intensity conflict requires more intensive capabilities at the tactical level that is responsive to the needs of brigade, battalion, and even company commanders. This new understanding compelled $\mathrm{DoD}$ to invest in new technologies that scale down existing electronic warfare functions (such as general purpose jamming, eavesdropping, and spoofing) into smaller packages that are more appropriate for the use by ground commanders.

This investment in tactical-level systems is particularly necessary, given that Air Force and Navy systems are limited and not responsive enough for tactical-level electronic warfare. According to an Army Combined Air Operations Center (CAOC) liaison officer for example, the Air Force and Navy only possesses enough electronic warfare aircraft and crews to fulfill $34 \%$ of validated requirements (to say nothing of requests that were not validated and outright rejected). ${ }^{223}$ The systems were also too blunt to be used by the tactical commander-EC-130H Compass Call jammers for instance, jammed over such a large area that it interfered with communications in multiple battalion-level battlespaces, making signal fratricide deconfliction nearly impossible to achieve. ${ }^{224}$ To address the need for tactical electronic warfare capabilities, investment in smaller and more responsive systems are necessary.

222 Dan Lamothe, "The legacy of JIEDDO, the disappearing Pentagon organization that fought roadside bombs," Washinton Post, March 17 2015a.

223 Sydney J. Freedberg.

${ }^{224}$ Rita Boland, "Dialing Up the Bandwidth Battle Against IEDs," Signal, Vol. 65, no. 8, April, 2011. 


\section{Implementation Obstacles and Mitigations}

\section{Obstacles}

At the outset, insurgent bomb makers were able to stay one step ahead of the United States' jamming efforts due to the immense variety of triggers available. The electromagnetic spectrum was unregulated in Iraq, providing a legal and plentiful supply of transmitters. ${ }^{225} \mathrm{An}$ insurgent bomb maker would only have to use one channel on which a US jammer was not operating to be successful. This was the very essence of asymmetric warfare.

Not only did insurgent bomb makers have a variety of transmitters to choose from, insurgents could also use robust transmitters such as long-range cordless telephones (LRCTs) that were more resistant to jamming to the US' existing tactical level jammers, such as Warlock Green. ${ }^{226}$ Finally, bomb makers and their collaborators could use inexpensive spectrum analyzers to determine what channels US jammers were using to more intelligently design their triggers around them, since they chose the time and place to collect information on active US jammers, or transmissions that would trigger reactive US IED jammers. ${ }^{227}$

Thus, the US began its search for a general-purpose jammer at a distinct advantage. The Navy's Acorn system deployed in 2002 was hardwired to jam a single channel used by one specific RCIED. ${ }^{228}$ The Warlock Green jammer deployed in 2003 was only able to jam a small number of frequencies and only after time-consuming analysis and modifications. ${ }^{229}$ Unlike the insurgents, the US had to manage and deconflict a significant portion of the electromagnetic spectrum so that its jammers could operate without interfering with other jammers, radios, and other military electronics. ${ }^{230}$

These factors initially allowed insurgent bomb makers to stay ahead of the US' RCIED jamming efforts. The large number of triggers and channels available to

\footnotetext{
225

Dayton.

${ }^{226}$ Long-range cordless telephone signals were designed to resist transmission issues such as dropped packets, reflected signals, and other errors that the Warlock Green was taking advantage of to jam trigger signals. See Sachtman.

${ }^{227}$ Dayton.

228 Sachtman.

${ }^{229}$ Conceptually, the US could develop a jammer that actively broadcast a jamming signal on a wide range of channels, but this would require too much power from a mounted platform to be operationally effective.

${ }^{230}$ US forces in Iraq initially tried to manage the spectrum using a shared Excel spreadsheet containing frequencies used by insurgents and by friendly forces. See Dayton.
} 
insurgents and the US' own uncoordinated use of the electromagnetic spectrum was a significant obstacle for US jammer development efforts to overcome.

Making matters worse, these ineffective jammers often disrupted operations by interfering with US radios and other electronics. This is known as signal fratricide. Early active IED jammers that constantly broadcasted their jamming signals would jam friendly communications. For example, Warlock Red systems commonly jammed three of the Army's most common tactical communications systems. ${ }^{231}$ Some jammers also affected bomb disposal robot remote controls, Blue Force Trackers, unmanned aircraft data links, and other electronics. ${ }^{232}$ Different jammers could also lock on to one another, resulting in a self-defeating embrace in which both jammers jammed each other's signal. ${ }^{233} \mathrm{With}$ 82,000 frequencies and 15 jammer types in use by US and Coalition forces in Iraq by 2007, it was no easy matter to avoid those particular frequencies (disregarding the possibility that they might also be used by an IED).

The upshot was that these shortcomings in initial jammers forced troops to make difficult decisions about using them, without any assurance that they would work. Troops had to choose between jamming and communicating, tracking friendly forces, or using aerial surveillance. This degraded troops' confidence in their equipment and hindered operations, all without effectively jamming RCIEDs.

The Army and Marine Corps' lack of investment in tactical electronic warfare left them ill-prepared to effectively employ the jammers that were available to them. The Army's expertise in electronic warfare had atrophied since the fall of the Soviet Union. ${ }^{234}$ Although the Marine Corps retained some expertise in its three radio battalions and three tactical electronic warfare squadrons, these capabilities were at higher echelons of command (the Marine Expeditionary Force level and Marine Air Group level, respectively) and ground commanders were not exposed to electronic warfare considerations during the majority of their careers. ${ }^{235}$

${ }^{231}$ David A. Fulghum, "Jamming Jam-Up: Iraq's electronagmentic environment is polluted to the point that it's interfering with the war," Aviation Week \& Space Technology, Nov 72005.

${ }^{232}$ Clay Wilson, Improvised Explosive Devices (IEDs) in Iraq and Afghanistan: Effects and Countermeasures: Congressional Research Service, RS22330, August 28, 2007. And Atkinson. (Place Published.

233 Fulghum.

${ }^{234}$ Kyle Borne, "US Army Electronic Warfare in the Post-Global War on Terrorism World," The Journal of Electronic Defense, Vol. 36, no. 10, October, 2013.

${ }^{235}$ United States Marine Corps. 
This unfamiliarity initially limited the effectiveness of US jamming efforts. The earliest jammers (Acorn and Warlock Green) were fielded to troops already deployed, so they did not have the opportunity to train with them and understand how they worked beyond simple operator functions such as turning them on and off. ${ }^{236}$ Commanders often did not understand the jammers' employment considerations and had no electronic warfare experts on their staffs who could advise them (e.g., how to spread jammers across a convoy for best coverage) ${ }^{237}$ In one particularly painful example, an Acorn jammer was installed on a water truck that never left its base in $2002 .{ }^{238}$ Since electronic warfare was a relatively arcane science and successful IED jamming left no visible evidence, the DoD faced steep obstacles not only to developing effective jammers, but effectively using them as well.

\section{Mitigation}

Despite the size of the technical challenge, the DoD made remarkably fast progress in overcoming or mitigating the obstacles that it faced in developing and employing IED jammers. Supported by plentiful and flexible funding, the DoD made technological advances and organizational changes that yielded an array of effective IED jammers and trained troops by 2009. In this section, we will discuss measures that the DoD took to overcome its slow reaction times, its lack of integrated systems, and its dearth of trained personnel.

Over the course of the two wars in question, the US sped up its ability to respond to the endless varieties of insurgent RCIED channels and triggers. Part of the response was technical. US jammers by 2009 perfected two key attributes that enabled them to cope with the variety of enemy triggers. First, jammers became programmable. This enabled engineers to make modifications and updates that could be rapidly and consistently disseminated to forces in the field with relatively little effort. As one engineer put it (when referring to the programmable CVRJ system), "for the first time ever, we had a canvas to create a painting." 239

Second, engineers improved the response time of reactive jammers, which bypassed several engineering problems in active jammers. Instead of constantly and inefficiently broadcasting a jamming signal, reactive jammers like the Duke system would scan the radio frequency spectrum for enemy RCIED signals and only begin jamming once a

\footnotetext{
236 Atkinson.

237

238

${ }^{239}$ Sachtman.
} 
signal was detected. ${ }^{240}$ This enabled reactive jammers to focus their jamming power on the threat signal only, enabling a stronger jamming signal and a higher chance of disrupting the RCIED. This also reduced the risk of insurgent threat analysis, since the jammer was not constantly broadcasting its jamming signal for insurgent analysis and exploitation.

Additionally, the variety of jammers developed (some 16 different types in 14 years) enabled technological advances. Some jammers were deployed simultaneously by different services, reducing technical risks. For instance, the Marine Corps deployed the Chameleon active jamming system in 2005, while the Army opted for the reactive Duke system in 2006. These two different approaches may not have been intentionally pursued, but the result was that both systems were deployed in large enough quantities that engineers could quickly understand the strengths and weaknesses of both systems in realistic settings that helped them fix problems and make refinements faster.

The US also made progress in understanding enemy threat channels and rapidly countering them. The DoD organized CIED Exploitation Cells (CEXC) and staffed JIEDDO with a robust intelligence analysis capability that meticulously catalogued and disseminated information about the latest enemy RCIEDs. ${ }^{241}$ Enemy frequencies were recorded in a Joint Restricted Frequency List (JRFL), which was an authoritative source of information for engineers and electronic warfare specialists. ${ }^{242}$

Armed with this fresh information, CIED engineers also improved their processes. For instance, a new systems engineering process was developed at Johns Hopkins University's Applied Physics Laboratory (APL) that sped up the design process. APL compressed design, testing, and evaluation procedures for developing new threat loads (the software changes necessary to reprogram jammers to react to new threats) by doing some steps simultaneously and using more frequent (but less formal) decision points to ensure that new threat load designs were developed quickly or abandoned. ${ }^{243}$ This cut response times to new enemy threat loads down from months to six to eight weeks. ${ }^{244}$

\footnotetext{
240 Dayton.

241 Sachtman.

242 Fulghum.

${ }^{243}$ Michael E. Pesci, "Systems Engineering in Counter Radio-Controlled Improvised Explosive Device Electronic Warfare," John Hopkins APL Technical Digest, Vol. 31, no. 1, 2012. 244
} 
Underpinning this improved ability react to enemy RCIEDs was the well-endowed and flexible Joint IED Defeat Fund. Established in 2006 by Congress, the fund has been consistently budgeted between $\$ 1-2 b n$ annually for its Defeat the Device budget line item. ${ }^{245}$ Unlike most federal budget authorities, the funds in the JIDF were "colorless", that is, this money could be spent or shifted into different accounts, giving JIEDDO a greater level of flexibility in addressing the IED threat. These loosened budget authorities allowed JIEDDO to take development risks that might have raised scrutiny in peacetime. It also funded the equally important, systematic analysis and exploitation of RCIED signals. Without such flexible funding, it is unlikely that the US could have kept up with insurgent RCIED advances.

Not only did the iterative process of improving IED jamming effectiveness result in more effective jamming against insurgent signals, it also increased the degree to which these systems were integrated with the other command and control systems that troops were using. Navy and Air Force electronic warfare experts were brought in to help manage the US electromagnetic spectrum, which reduced the chances of jammers interfering with communications equipment. ${ }^{246}$ Also, the increased use of programmable and reactive jammers made it easier to deconflict frequencies. ${ }^{247}$ Finally, as new jammers were being developed by contractors, JIEDDO facilitated the exchange of information that allowed contractors to design jammers that were less prone to locking on to one another. ${ }^{248}$ By 2009, most integration problems had been eliminated or mitigated. ${ }^{249}$

To address the lack of expertise in employing jammers, the Army first reached out to the other services for assistance. In 2006, the Navy deployed hundreds of its electronic warfare specialists to Iraq to assist the Army, and the Air Force followed suit soon after. ${ }^{250}$ The Navy and Air Force specialists were attached to units down to the battalion level, helping commanders understand how to best use their jammers. Electronic warfare specialists also helped manage the increasingly complex electromagnetic spectrum, which reduced signal fratricide and streamlined the process of threat signal data collection for engineers working to improve on jammers.

\footnotetext{
245 Author analysis of DoD budget justification documents

${ }^{246}$ Sachtman.

${ }^{247} \mathrm{~K}$. Wilgucki et al., "Selected aspects of effective RCIED jamming" (paper presented at the Communications and Information Systems Conference (MCC), 2012 Military, 8-9 Oct. 2012 2012).

248 Jan Mietzner.

249 Author'sown experience in OIF deconflicting Chamelon with communications equipment.

${ }^{250}$ Thom Shanker, "Army Developing Teams for Electronic Warfare," New York Times, March 72009.
} 
Eventually, the Army began to build its own electronic warfare expertise. In 2006, the Army established electronic warfare program offices at the service headquarters level to provide strategic guidance and top-level support for electronic warfare efforts. ${ }^{251}$ The Army then established an electronic warfare MOS in 2008 and began training officers, warrant officers, and enlisted personnel in electronic warfare techniques, including IED jamming. ${ }^{252}$ By 2014, the Army had established a career field that produced hundreds of soldiers trained to conduct electronic warfare and had promulgated updated doctrine called Cyber/Electromagnetic Activities (CEMA) that merged electronic warfare with aspects of cyber warfare into a cohesive package. ${ }^{253}$

\section{Outcome}

By the time major combat operations in Iraq and Afghanistan ended, the DoD's $\$ 17$ billion dollar investment in over 50,000 jammers appeared to have paid off. ${ }^{254}$ The jammers were operationally effective against RCIEDs, forcing most insurgents to return to command-wire or victim-initiated IEDs. There is much consternation about the cost of fielding such complex devices to thwart simple weapons like RCIEDs, but the effectiveness of the jammer is not in question. ${ }^{255}$

It is likely that IED jammers will become a lasting part of the DoD equipment inventory. Although most jammers were procured under various rapid acquisition authorities with no plans for sustainment, the Army's Duke system eventually transitioned to a program of record and is frequently being upgraded. The Army also plans to upgrade Duke to work with the dismounted Thor III and Baldr jammer systems and a fixed-site jammer called the Ground Auto Targeting Observation/Reactive (GATO/R) jammer, eventually linking them as part of what the Army calls a Multifunctional Electronic Warfare System (MFEW) by $2020 .^{256}$

\footnotetext{
${ }^{251}$ These included the Electronic Warfare Division in Headquarters Department of the Army (HQDA), the Electronic Warfare Proponent Office at the Combined Arms Center in Ft. Leavenworth KS, the electronic warfare capability manager at Training and Doctrine Command (TRADOC), and the electronic warfare program office within PEO (IEW\&S). See Lum.

252

253 Jr. Sydney J. Freedberg, "Army Electronic Warfare 'Is A Weapon' - But Cyber Is Sexier " Breaking Defense, Oct 162014.

${ }^{254}$ Sachtman.

${ }^{255}$ Investigations.

${ }^{256}$ Gould.
} 
The most lasting outcome of the DoD's investment in IED jammers is a renewed appreciation for electronic warfare. The large-scale deployment of IED jammers during the Iraq and Afghanistan Wars introduced an entire generation of soldiers and Marines to the concepts of and consideration for the role of electronic warfare in a lasting and compelling way. New jammers being developed are moving beyond simply jamming a set of frequencies to more advanced functions like eavesdropping and spoofing of enemy signals. ${ }^{257}$ To that end, the Army has committed to developing an entire military occupational specialty for electronic warfare, signaling a lasting commitment to this field. The outcome of the DoD's investment in IED jammers has yielded not only a new set of equipment and capabilities, but a significant change in operational concepts. 


\section{Appendix G: ABIS Case Study}

\section{Description}

The Automated Biometrics Information System (ABIS) is a system of software applications that confirms individual identities using biometric information. ABIS processes and stores biometric information, compares new data with stored information for matching, and helps human examiners evaluate ambiguous results.

\section{Investment Drivers}

In this section, we examine the extent to which DoD's investment in ABIS was in response to an opportunity to capture the benefits of technological advancements or if it was in response to a threat. We find that ABIS was unambiguously a threat-driven investment.

\section{Technology Capture Driven Drivers}

At first glance, it would appear that ABIS was the result of the DoD taking advantage of existing advances in biometrics technology. In fact, the DoD has long had an interest in biometrics. As far back as 1993, the DoD has invested in various biometrics efforts: a facial recognition program, a biometrics program office in 2000, and a DARPA program for multi-model matching (i.e. using a variety of biometric indicators at once to establish identification). ${ }^{258}$

However, the DoD's initial investment was minimal and not closely related to the need that drove the DoD to invest in ABIS. Congress appropriated only $\$ 10 \mathrm{~m}(\$ 13.3 \mathrm{~m}$ in 2012 dollars) for DoD biometrics efforts in $2000 .{ }^{259}$ DoD interest in the pre-9/11 era was mostly related to biometrics identity management as it related to physical access, disbursement of services, and other non-tactical applications. ${ }^{260}$

258 Biometrics in Government, Post 9/11: Advancing Science, Enhancing Operations: National Science and Technology Council, August, 2008.

259 Biometrics in Government, Post 9/11: Advancing Science, Enhancing Operations.

${ }^{260}$ See John E. Siedlarz, Biometric Identification Verification Technology Status and Feasibility Study, Alexandria, VA: Defense Nuclear Agency, DNA-TR-94-6, September, 1994. and Laura K. Donohue, Technological Leap, Statutory Gap, and Constituional Abyss: Remote Biometric Identifcation Comes of Age, Washington DC: Georgetown University Law Center, 12-123, 2012. 


\section{Threat Driven Drivers}

Rather, DoD interest in ABIS (and biometrics in general) was more related to its need to meet the demands of troops in Iraq and Afghanistan who did not have a reliable way of distinguishing friend from foe amongst the civilian population. ABIS' roots were as a response to a 2004 JUON submitted by CENTCOM to meet this specific need - a clear indicator of a threat-driven investment. ${ }^{261}$

ABIS did draw on existing technology, specifically the FBI's Integrated Automatic Fingerprint Identification System (IAFIS) database. However, CENTCOM's needs required the DoD to invest in a multi-modal system that could make use of a variety of biometric signatures - iris scans and facial recognition in addition to fingerprinting. ${ }^{262}$ Troops interacting with Iraqi and Afghan civilians (and possible insurgents) needed to confirm biometric identities at faster speeds and higher levels of reliability than singlemode biometrics systems could achieve. Multi-model matching, which draws on different biometric signatures and algorithms to pull them together, offered the greatest promise to fulfill that requirement. This necessitated a higher level of investment.

Additionally, such matching needed to be done in tactical environments without the infrastructure on which pre-9/11 biometrics systems relied. Connectivity to databases in CONUS was limited and the collection systems themselves had to be portable. The technology available (and that could be captured) did not exist. ${ }^{263}$ DoD was forced to make threat-driven investments to develop ABIS.

The amount of DoD investment and the biometrics industry's response to that investment is illustrative of the environment. From 2004-10, the DoD spent over \$2 billion on biometrics, or an average of $\$ 333$ million per year (compared to $\$ 13 \mathrm{~m}$ spent in 2000). ${ }^{264}$ Industry responded to this large investment. Between 1995 and 2001, fewer than 30 biometrics patents were filed. Approximately half of these patents were national security related. After 9/11 (and up to 2011), 251 biometrics patents with a national security focus were filed. Clearly, the DoD's investment in ABIS, and biometrics more

\footnotetext{
261 Tom Dee, "Disruptive Technologies: Presentation to National Defense Industrial Association," (2007).

262 Defense Resarch and Engineering, "The Road from a Quick Reaction Capability to a Program of Record," (Washington, DC: Biometrics Identity Management Agency (BIMA), 2011).

263 Two DoD-commissioned assessment projects showed that the technology to meet CENTCOM's reliability and speed demands did not exist in 1994 and that little progress towards these goals was made by 2003. See Siedlarz. and The National Biometrics Challenge: National Science and Technology Council, August, 2006.

${ }^{264}$ John R. Allen, "Keynote Speech to the Biometric Consortium Conference 2010," (Tampa, FL: 2010).
} 
generally, was threat-related. It also appears to have spurred activity in the biometrics industry as a whole, negating any thought of tech capture investments.

\section{Implementation Obstacles and Mitigations}

ABIS' status as a new opportunity investment created a myriad of implementation obstacles, both technical and organizational. These were only partially mitigated and are described in this section.

\section{Obstacles}

There were four significant obstacles to the implementation of ABIS: lag time between biometric data submission and match result, data integration within ABIS, insufficient training at the collection operator level, and a diffusion of authorities and funding for biometric systems within the DoD.

The first significant obstacle that ABIS and its tactical collection systems (used by the individual servicemember to collect biometric information in field) faced was that the lag between collection and identification takes far too long. This lag time varied widely-a 2012 GAO analysis of 1.1 million OEF biometrics submissions showed that responses could take anywhere from less than a day to more than 15 days (see Figure G.1). ${ }^{265}$

Figure G.1.: GAO Analysis of OEF Biometrics Transmission Timeliness (2009-11)

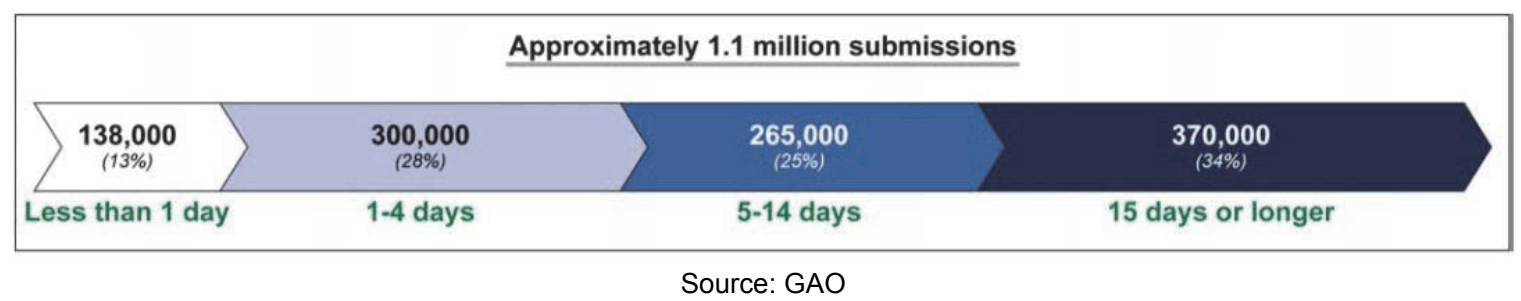

Much of this lag was in the time that it takes for the servicemember to transmit biometrics data to ABIS. Once the data arrived at ABIS' data warehouse in West Virginia, matching and reporting back to the unit averaged 22 minutes. ${ }^{266}$

This lag time was due to a variety of factors. The first was that connectivity between the collecting device and ABIS was spotty at best. In Iraq, no such connectivity existed-

265 Marc Schwartz Brian J. Lepore, Grace Coleman, Mary Coyle, Dav M. D'Agostino, Bethann E. Ritter, Amie Steele, Spencer Tacktill, Defense Biometrics: Additional Training for Leaders and More Timely Transmission of Data Could Enhance the Use of Biometrics in Afghanistan, Washington, DC: General Accountability Office, GAO-12-442, September, 2012. 266 
the collection devices operated in stand-alone mode while in the field. In Afghanistan, a pilot program to erect wireless towers in key areas was only partially successful, with challenging terrain often impeding connectivity. In fact, it was this very lack of connectivity that spurred investment in the PRC-117G wireless networking radio (another case selected for this study). ${ }^{267}$

Problems also arose in regard to existing arrangements to connect devices to ABIS. Bandwidth constraints at combat outposts and forward operating bases resulted in delayed submissions. ${ }^{268}$ Units collecting biometrics data could go on missions that kept them away from connectivity for days or weeks at a time. ${ }^{269}$ These impediments reduced ABIS' effectiveness. Delayed matches probably resulted in suspected insurgents or other persons of interest escaping detention and custody in both Iraq and Afghanistan. This could have dangerous impacts on troop safety and mission accomplishment.

The second obstacle was even more complicated. Data integration within ABIS proved to be a difficult obstacle to interagency data sharing and ABIS upgrades. Some of this problem was organizational. For a number of years, ABIS existed alongside other biometrics matching systems that were also the result of urgent needs at the service and joint level. Although the Army, as the biometrics executive agent (EA) ostensibly had responsibility for all of these programs, the demands of the war and the lack of mature biometrics technologies forced the EA to quickly field a variety of solutions, pilot projects, and other biometrics systems that were not necessarily compatible with one another. ${ }^{270}$ Integrating the data that was collected by these stove-piped systems with ABIS (which would improve its effectiveness) was difficult, if not impossible. Different systems collected different biometric data. Integrating the data such that the individual biometric markers could be accurately and reliably associated with the right individual is a challenging, if not impossible task.

Even data integration within versions of ABIS is proving to be challenging. This was evident when ABIS 1.0 (the final version of the 2004 prototype, in use in 2009) was upgraded to ABIS 1.2. The DoD attempted to go live with the upgrade three times between November 2010 and August 2013. Each time, the upgrade failed to reliably migrate all identities to the new system. This inconsistency resulted system congestion,

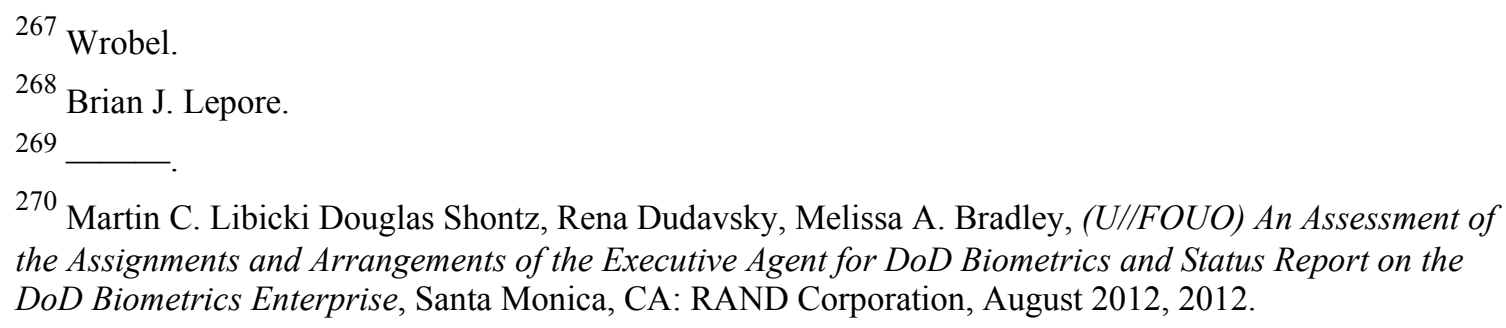
the Assignments and Arrangements of the Executive Agent for DoD Biometrics and Status Report on the DoD Biometrics Enterprise, Santa Monica, CA: RAND Corporation, August 2012, 2012. 
inability to enter new information, and different match results between the two systems. ${ }^{271}$ In each case, the DoD cancelled the upgrade and reverted to using ABIS 1.0.

Thirdly, the lack of training at the collector level was also a significant challenge. The collection systems used by ABIS are not complicated systems, but they do require users to understand why and how they work in order to make best use of them, particularly when the system is not working properly. Since ABIS and the collection systems it used were all rapid acquisition projects, the $\mathrm{DoD}$ (as a whole) was unable to invest in the deep training infrastructure needed to give users the level of understanding needed to make optimal use of the system. This was exacerbated by the fact that the system was not being operated by a dedicated group of individuals, but by general purpose forces with many other competing demands on their training time. ${ }^{272}$

In fact, the variety of systems meant that many troops trained with biometric systems that they did not deploy with, and were issued other systems in theater (all of which fed into ABIS, presumably) on which they lacked training. Training documentation was also inadequate. ${ }^{273}$ Viewed holistically, the lack of sufficient operator training hindered users from taking full advantage of ABIS' ability to distinguish friend from foe.

Lastly, these implementation obstacles were exacerbated by the lack of central direction and focus for biometrics within the DoD. The need for ABIS and biometrics for tactical applications more broadly was clear soon after the invasion of Iraq in 2003. However, it was not until 2006 that the $\mathrm{DoD}$ began to reorganize its biometrics enterprise to suit the urgency of the demand (Congress had decreed in 2000 that the Army would serve as the DoD's biometrics executive agent, but this was before the need for biometrics in tactical settings became clear). ${ }^{274}$ This reorganization was accomplished in 2008 and designated the Director of Defense Research and Engineering (DDR\&E) as the principal staff assistant (PSA) for DoD biometrics oversight. DDR\&E reported directly to

${ }^{271}$ Department of Defense, DOT\&E FY2012 Annual Report, 2013, http://www.dote.osd.mil/pub/reports/FY2012/ (as of June 2, 2015).

272 Brian J. Lepore.

${ }^{273}$ Institute of Defense Analyses, "Case Study: Automated Biometric Identification System (ABIS) Training Survey," (Arlington, VA: 2015).

${ }^{274}$ Lorelei St. James Davi M. D'Agostino Linda Kohn, David Artadi, Grace Coleman, Brian Kime, David Malkin, John Nelson, Bethann Ritter, Defense Management: DoD Needs to Establish Clear Goals and Objective,s Guidnace, and Designated Budget to Manage its Biometric Activities, Washington, DC: General Accountability Office, GAO-08-1065, September, 2008. 
the Under Secretary of Defense (AT\&L) and continued to use the Secretary of the Army as the DoD Executive Agent (EA). ${ }^{275}$

This consolidation was much needed, but still insufficient to bring all of the DoD's disparate biometrics efforts under one roof. The EA was unable to fully exercise management authority over the wide range of biometrics stakeholders across the DoD, the intelligence community (IC), and even within the Army itself due to unclear and redundant delegation of responsibilities. ${ }^{276}$ These stakeholders were able to do so because of the abundance of supplemental funding that allowed stakeholders to pursue their own programs outside of ABIS (which was supposed to be the central DoD repository for biometrics information). ${ }^{277}$

The result was that ABIS and the DoD biometrics enterprise were not used to their full advantage. Abundant supplemental funding allowed stakeholders to pursue redundant biometrics systems. These multiple systems made training and documentation difficult. ${ }^{278}$ The systems themselves, when used in Iraq and Afghanistan, diluted the effectiveness of ABIS by collecting and storing data that could not be shared with ABIS. ${ }^{279}$ ABIS and the DoD biometrics enterprise was effective because it was better than having no biometrics capabilities at all, but these organizational frictions kept it from being used to greater effect.

\section{Mitigations}

The obstacles that ABIS faced were all part of the costs of trying to implement a complicated system through rapid acquisition. In this section, we will discuss the mitigations to some of those obstacles.

Some tradeoffs were consciously made. Biometrics stakeholders decided that the ability to make matches was urgent enough that they could not wait to develop technologies to provide connectivity to the collection devices. This was partially addressed in Afghanistan with the Last Tactical Mile pilot project, which erected wireless towers to provide connectivity in a small area. The PRC-117G also partially addressed the problem with its ability to provide mobile, ad-hoc networking.

\footnotetext{
275 Department of Defense, "DoD Directive 8521.01E Department of Defense Biometrics," (2008b).

${ }^{276}$ Douglas Shontz.

${ }^{277}$ Department of Army Biometrics Civilian, Aug 122015.

278

279
} 
However, the lack of connectivity was simply accepted for the most part as an operational obstacle. Troops downloaded part of the ABIS database onto their collection devices prior to patrols and missions, in order to have some chance of making matches immediately. This required troops to pick and choose the slice of the ABIS database they wanted to download very carefully. This helped in some instances, but lag time was ultimately accepted.

In other areas such as training and data integration, the performance sacrifices made to enable faster procurement were not consciously made. While it is unlikely that ABIS' rapid acquisition roots were the only source of the training and data integration problems, the DoD's haste in procuring and fielding ABIS did not help. Operators were left to cope with these obstacles on their own-collecting device operators tried to keep up with the myriad of new models and system upgrades being fielded, sometimes while they were in theater. Engineers tried repeatedly to improve data integration, to little avail. No mitigation appears to have alleviated these obstacles.

Finally, the organizational obstacles that hindered more effective use of ABIS still exist. The DoD has recognized that "expeditionary forensics" (as DoD currently refers to biometrics for tactical applications) will be an enduring need. However, USD (AT\&L) and the PSA have not yet managed to fully consolidate and exercise management authority over the DoD's biometrics efforts. It is still unclear how much the DoD as a whole is spending on biometrics. ${ }^{280}$ It has not been able to establish clear metrics and measures for success. ${ }^{281}$ While it is making efforts to do so, the DoD biometrics enterprise is still in need of reorganization and consolidation to bring it from its roots as a series of rapid acquisition efforts to a more enduring capability.

\section{Outcomes}

Despite the fact that ABIS had many flaws, it was still an effective tool. ${ }^{282}$ This judgment may be because ABIS was a new investment. While there were plenty of problems with missing and incoherent data, operators lacking the most up-to-date

\footnotetext{
${ }^{280}$ Marc Schwartz Brian J. Lepore, Grace Coleman, Latrealle Lee, Alberto Leff, Amber Lopez Roberts, Tim Persons, Terry Richardson, Amie Steele, Sabrina Streagle, John Van Schaik, Nicole Willems, Defense Forensics: Additional Planning and Oversight Needed to Establish an Enduring Expeditionary Forensic Capability, Washington, DC: General Accountability Office, GAO-13-446, June, 2013.

${ }^{281}$ The DoD's biometrics enterprise plan was supposed to establish these metrics and measures, but the GAO pointed out that it was not able to do so. See Department of Defense, "Biometrics Enterprise Strategic Plan, 2008-2015," August 27, 2008a. and Brian J. Lepore.

282 Even the head of the Biometrics Task Force admitted so in a published article. See Jr John D. Woodward, "How do you know friend from foe?," Homeland Science and Technology, December 2004.
} 
training, and slow processing times, ABIS still was better than nothing. This is an important point-ABIS made the tactical situation better for forces in Iraq and Afghanistan at the end of the day. Although there were most certainly cases when operators did not know how to operate the system or a suspected insurgent escaped custody because of slow processing times, ABIS still had some successes. It was better than the status quo. In the case of a new investment, this may the best that can be hoped for. 


\section{Works Cited}

Allen, John R., "Keynote Speech to the Biometric Consortium Conference 2010," Tampa, FL, Sept 23, 2010.

Art, Robert J., The TFX Decision: McNamara and the Military, Boston: Little Brown, 1968.

Ashlee Vance, Brad Stone, "Palantir, the War on Terror's Secret Weapon," Bloomberg Businessweek, November 22, 2011. As of 11/9/2015:

http://www.bloomberg.com/bw/magazine/palantir-the-vanguard-of-cyberterrorsecurity-11222011.html\#p1

Atkinson, Rick, "Left of Boom: The Struggle to Defeat Roadside Bombs in Iraq and Afgthanistan," Electronic Book: The Washington Post Co, 2007.

Belasco, Amy, The Cost of Iraq, Afghanistan, and Other Global War on Terror Operations Since 9/11, Washington, D.C.: Congressional Research Service RL33110, March 29, 2011.

Biometrics in Government, Post 9/11: Advancing Science, Enhancing Operations, National Science and Technology Council, August, 2008.

Boland, Rita, "Dialing Up the Bandwidth Battle Against IEDs," Signal, Vol. 65, No. 8, April, 2011, pp. 25-27.

Borne, Kyle, "US Army Electronic Warfare in the Post-Global War on Terrorism World," The Journal of Electronic Defense, Vol. 36, No. 10, October, 2013, pp. 48-52.

Brian J. Lepore, Marc Schwartz, Grace Coleman, Latrealle Lee, Alberto Leff, Amber Lopez Roberts, Tim Persons, Terry Richardson, Amie Steele, Sabrina Streagle, John Van Schaik, Nicole Willems, Defense Forensics: Additional Planning and Oversight Needed to Establish an Enduring Expeditionary Forensic Capability, Washington, DC: General Accountability Office, GAO-13-446, June, 2013.

Brian J. Lepore, Marc Schwartz, Grace Coleman, Mary Coyle, Dav M. D'Agostino, Bethann E. Ritter, Amie Steele, Spencer Tacktill, Defense Biometrics: Additional 
Training for Leaders and More Timely Transmission of Data Could Enhance the Use of Biometrics in Afghanistan, Washington, DC: General Accountability Office, GAO-12442, September, 2012.

Burton, James G., The Pentagon Wars: Reformers Challenge the Old Guard, Annapolis, MD.: Naval Institute Press, 1993.

Carr, Lee, Kristen Lambrecht, Scott Shaw, Greg Whittier, and Catherine Warner, Unmanned Aerial Vehicle Operational Test and Evaluation Lessons Learned, Institute for Defense Analyses, P-3821, December, 2003.

Joint Rapid Acquisition Cell, "Interview with Author," Jan 14, 2014.

Christopher J. Lamb, Matthew J. Schmidt, Berit G. Fitzsimmons, MRAPs, Irregular Warfare, and Pentagon Reform, Washington, DC: Institute for National Strategic Studies, 2009a.

—, MRAPs, Irregular Warfare, and Pentagon Reform, National Defense University, June, 2009b. As of December 2, 2014:

http://usacac.army.mil/cac2/cgsc/sams/media/MRAPs.pdf

Cohen, Elliot A., "Change and Transformation in Military Affairs," Journal of Strategic Studies, Vol. 27, No. 3, Sept, 2004, pp. 395-407.

Danzig, Richard, Driving in the Dark: Ten Propositions About Prediction and National Security, Washington, D.C.: Center for a New American Security, October, 2011. As of March 16, 2016:

http://www.cnas.org/files/documents/publications/CNAS_Prediction_Danzig.pdf

Davi M. D'Agostino Linda Kohn, Lorelei St. James, David Artadi, Grace Coleman, Brian Kime, David Malkin, John Nelson, Bethann Ritter, Defense Management: DoD Needs to Establish Clear Goals and Objective,s Guidnace, and Designated Budget to Manage its Biometric Activities, Washington, DC: General Accountability Office, GAO08-1065, September, 2008.

Dayton, Jeffrey A., Risk of Using Past to Predict Future: A Case Study of Jamming RCIEDs, Naval Postgraduate School, 2009. 
Dee, Tom, "Disruptive Technologies: Presentation to National Defense Industrial Association," Sept 5, 2007.

Defense Resarch and Engineering, "The Road from a Quick Reaction Capability to a Program of Record," Washington, DC: Biometrics Identity Management Agency (BIMA), January, 2011.

Defense Science Board, Report of the Defense Science Board Task Force on the Fulfillment of Urgent Operational Needs, July 2009.

Department of Army, "Army Regulation 71-9: Materiel Requirements," April 30, 1997.

_ , "Army Regulation 71-9: Warfighting Capabilities Determination," December $28,2009$.

Department of Army Biometrics Civilian, "Interview with Author," Aug 12, 2015.

Department of Defense, "Mission Need Statement (MNS) for the Joint Tactical Radio (JTR)," August 21, 1997. As of May 1, 2015:

http://fas.org/man/dod-101/sys/land/mns_jtrs.htm

__, "Biometrics Enterprise Strategic Plan, 2008-2015," August 27, 2008a.

— , "DoD Directive 8521.01E Department of Defense Biometrics," February 21, $2008 b$.

- Selected Acquisition Report (SAR): MQ-1B UAS Predator, Washington D.C., DD-A\&T(Q\&A)823-271, June 30, 2010.

—_, "DoD 8000.14-R DoD Financial Management Regulation," June, 2011. http://comptroller.defense.gov/FMR/fmrvolumes.aspx

—, DOT\&E FY2012 Annual Report, 2013. As of June 2, 2015:

http://www.dote.osd.mil/pub/reports/FY2012/

Department of Defense Inspector General, Air Force Did Not Justify the Need for MQ-9 Reaper Procurement Quantities, Washington D.C. , DODIG-2014-123, September 30, 2014. 
Deutch, John M., "Endurance Unmanned Vehicle (UAV) Program " to Assistant Secretary of the Navy for Research, Development, and Acquisition, July 12, 1993.

Donohue, Laura K., Technological Leap, Statutory Gap, and Constitutional Abyss: Remote Biometric Identification Comes of Age, Washington DC: Georgetown University Law Center, 12-123, 2012.

Douglas Shontz, Martin C. Libicki, Rena Dudavsky, Melissa A. Bradley, (U//FOUO) An Assessment of the Assignments and Arrangements of the Executive Agent for DoD Biometrics and Status Report on the DoD Biometrics Enterprise, Santa Monica, CA: RAND Corporation, August 2012, 2012.

Drew, James, "USAF plans to end MQ-1 Predator operations in 2018," Flight Global, August 14, 2015. As of October 15, 2015:

https://www.flightglobal.com/news/articles/usaf-plans-to-end-predator-predatoroperations-in-2018-415742/

GA-ASI Official, "Interview with Author," Oct 28, 2015.

Erwin, Marshall Curtis, Intelligence, Surveillance, and Reconnaissance (ISR) Acquisition: Issues for Congress, Washington D.C.: Congressional Research Service, R41284, April 16, 2013.

Erwin, Sandra I., "Army, Marines Buying Loads of Radios," National Defense, September, 2005. As of Jan 20 2015:

http://www.nationaldefensemagazine.org/archive/2005/September/Pages/UFArmy_Marines3118.aspx

_ , "Delays in 'joint tactical radio' program cast doubts on future" National Defense February, 2007. As of March 10, 2015:

http://www.nationaldefensemagazine.org/archive/2007/February/Pages/DelaysJoint27 31.aspx

Department of the Air Force, "Air Force Instruction 63-114: Rapid Response Process," May 5, 1994.

Fox, J. Ronald, Defense Acquisition Reform, 1960-2009: An Elusive Goal, Washington, D.C.: Center for Military History, 2011. As of Jan 4, 2015:

http://history.army.mil/html/books/051/51-3-1/CMH_Pub_51-3-1.pdf 
Fulghum, David A., "Jamming Jam-Up: Iraq's electromagnetic environment is polluted to the point that it's interfering with the war," Aviation Week \& Space Technology, Nov 7, 2005.

Gallagher, Sean, "How to blow $\$ 6$ billion on a tech project," Ars Technica, June 18, 2012a. As of Jan 9 2015:

http://arstechnica.com/information-technology/2012/06/how-to-blow-6-billion-on-atech-project/

Gates, Robert M., Duty: Memoirs of a Secretary at War, New York: Knopf, 2014.

Gayl, Franz, "Protect JLTV Competition From Outside Influences " Defense News, October 15, 2012.

Gery W. Ryan, H. Russell Bernard, "Techniques to Identify Themes," Field Methods, Vol. 85, No. 15, 2003. As of Nov 29, 2014:

http://research.fit.edu/sealevelriselibrary/documents/doc_mgr/922/Ryan_et_al._2003. _Techniques_to_Identify_Themes.pdf

Gorman, Siobhan, "How Team of Geeks Cracked Spy Trade," Wall Street Journal, Sept 4, 2009. As of 11/9/2015:

http:/www.wsj.com/articles/SB125200842406984303

Gould, Joe, "New gear puts electronic warfare on the offensive," Army Times, Oct 30, 2013. As of June 12, 2015:

http://archive.armytimes.com/article/20131030/NEWS04/310300014/New-gear-putselectronic-warfare-offensive

Government Accountability Office, Department of Defense Needs Framework for Balancing Investments in Tactical Radios, Government Accountability Office, GAO-08877, August, 2008.

—, DOD's Urgent Needs Processes Need a More Comprehensive Approach and Evaluation for Potential Consolidation, Government Accountability Office, GAO-11-273, March 2011.

Guerrieri, Matthew D., "Buying a Better Radio," Army AL\&T Magazine, September 2012. As of Oct 22, 2015: 
Hardy, Quentin, "Unlocking Secrets, if Not Its Own Value," New York Times. As of Sept 212015 :

http://www.nytimes.com/2014/06/01/business/unlocking-secrets-if-not-its-ownvalue.html?_r=0

Harris RF Communications, "AN/PRC-117G(V)1(C): Type-1 Wideband Multiband Multimission Radio with Internal SAASM GPS." As of May 4, 2015:

http://rf.harris.com/media/AN-PRC-117G(V)1(C)\%2012-10_tcm26-9017.pdf

_- "Harris Corporation Completes Successful Interoperability Testing of Falcon III Manpack Radio with Mobile User Objective System," March 19, 2014. As of July 20, 2015:

http://rf.harris.com/news/view_pressrelease.asp?act=lookup\&pr_id=3684

Harris, Shane, "Palantir Technologies spots patterns to solve crimes and track terrorists," Wired UK, July 31, 2012. As of October 5, 2015:

http://www.wired.co.uk/magazine/archive/2012/09/features/joining-the-dots

Headquarters Marine Corps (Installations and Logistics), "Ground Equipment Reset Playbook," Oct 19, 2012. As of May 12, 2015:

http://www.iandl.marines.mil/Resources/GroundEquipmentResetPlan.aspx

Hiar, Corbin, House offers budget boost to troubled Pentagon agency fighting roadside bombs, The Center for Public Integrity, May 19, 2014. As of Nov 16, 2014:

http://www.publicintegrity.org/2011/07/14/5223/house-offers-budget-boost-troubledpentagon-agency-fighting-roadside-bombs

House Permanent Select Committee on Intelligence, Performance Audit of

Department of Defense Intelligence, Surveillance, and Reconnaissance, April, 2012.

Hoyle, Jeff, "Joint and Coalition Tactical Networking - There's an App for That!," US Naval Institute Proceedings, July, 2012. As of June 24, 2015:

http://news.usni.org/2012/07/19/joint-and-coalition-tactical-networking-theres-app

In-Q-Tel, "Portfolio," 2015. As of November 21: https://www.iqt.org/

Inspector General, Procurement Policy for Armored Vehicles, Washington, DC: Department of Defense, D-2007-107, June 27, 2007. 
- Marine Corps Implementation of the Urgent Universal Needs Process for Mine Resistant Ambush Protected Vehicles Washington, DC: Department of Defense, D2009-030, Dec 8, 2008.

Institute of Defense Analyses, "Case Study: Automated Biometric Identification System (ABIS) Training Survey," Arlington, VA, May 22, 2015.

Intelligence Science Board, Report of the Joint Defense Science Board Intelligence Science Board Task Force on Integrating Sensor-Collected Intelligence November 2008. As of November 30, 2015:

https://fas.org/irp/agency/dod/dsb/sensors.pdf

Investigations, Committee on Armed Services: Subcommittee on Oversight \&, The Joint Improvised Explosive Device Defeat Organization: DOD's Fight Against IEDs Today and Tomorrow, U.S. House of Representatives, November, 2008.

Isaac R. Porche III, Bradley Wilson, Matthew J. Schneider, Chuck Stelzner, J. R. Lockwood, Shawn McKay, Kate Giglio, (U//FOUO) Assessing the Performance of Mobile Ad Hoc Networks Using Statistical Analysis Techniques, Santa Monica: RAND Corporation, RR-494-OSD, November, 2014.

James M. Utterback, William J. Abernathy, "A Dynamic Model of Process and Product Innovation," The International Journal of Management Science, Vol. 3, No. 6, 1975.

Jan Mietzner, Patrick Nickel, Askold Meusling, Patrick Loos, Gerhard Bauch, "Responsive Communications Jamming Against Radio-Controlled Improvised Explosive Devices," IEEE Communications Magazine, October, 2012, pp. 38-46.

John D. Woodward, Jr, "How do you know friend from foe?," Homeland Science and Technology, December, 2004.

John Knowles, Glenn W Goodman, "COMPASS CALL: THE NEW AEA," Journal of Electronic Defense, Vol. 30, No. 5, May, 2007, pp. 30-37.

Joint IED Defeat Organization, Annual Report, 2008. As of Sept 21, 2015: https://www.jieddo.mil/content/docs/20090625_FULL_2008_Annual_Report_Unclassifi ed_v4.pdf 
Joint Tactical Networking Center, "About JTNC," 2015a. As of July 21:

http://jtnc.mil/Pages/AboutJTNC.aspx

—

Joseph R. Biden, Jr., Christopher S. Bond, to Gates, Hon. Robert M., June 28, 2007.

Kendall, Frank, "Notification of the Termination of the Joint Tactical Radio System (JTRS) Ground Mobile Radio (GMR) Program," to Hon. Carl Levin, Oct 13, 2011. As of Feb 16, 2015:

http://assets.fiercemarkets.com/public/sites/govit/jtrs_kendall_letter.pdf

University of Iowa Professor., "Email to the Author," Oct 7, $2015 \mathrm{a}$.

—_, "Interview with Author," Nov 5, 2015 b.

Lamb, Christopher J., Impediments to Acquisition Excellence Illustrated by the MRAP Case, Institute for National Strategic Studies, Jun 24, 2014.

Lamothe, Dan, "The legacy of JIEDDO, the disappearing Pentagon organization that fought roadside bombs," Washington Post, March 17, 2015a. As of June 5, 2015:

http://www.washingtonpost.com/news/checkpoint/wp/2015/03/17/the-legacy-ofjieddo-the-disappearing-pentagon-organization-that-fought-roadside-bombs/

—, "The legacy of JIEDDO, the disappearing Pentagon organization that fought roadside bombs," Washington Post, March 17, 2015b. As of May 27, 2015:

http://www.washingtonpost.com/news/checkpoint/wp/2015/03/17/the-legacy-ofjieddo-the-disappearing-pentagon-organization-that-fought-roadside-bombs/

Lawrence N. Goeller, David M. Tate, A Technical Review of Software-Defined Radios: Vision, Reality, and Current Status, Institute for Defense Analyses, NS D-4878, May, 2013.

Levin, Carl, to Hon. Joseph R. Biden, Jr., June 26, 2007.

Lum, Zachary, "Beyond CREW: Army EW Fights For a Bigger Spectrum " The Journal of Electronic Defense, October, 2013, pp. 36-46. 
Luttwak, Edward N., The Pentagon and the Art of War, New York: Simon \& Schuster, 1985.

Mark V. Arena, Irv Blickstein, Daniel Gonzales, Sarah Harting, Jennifer Lamping Lewis, Michael McGee, Megan McKernan, Charles Nemfakos, Jan Osburg, Rena Duavsky, Jerry M. Solinger, DoD and Commercial Advanced Waveform Developments and Programs with Multiple Nunn-McCurdy Breaches, Santa Monica: RAND Corporation, MG-1171/5-OSD, 2014.

Mayer, Jane, "The Predator War," The New Yorker, October 26, 2009. As of Nov 4 http://www.newyorker.com/magazine/2009/10/26/the-predator-war

McLeary, Joe Gould; Paul, "Army may work with Palantir on intel software," Navy Times, Jan 3, 2013. As of September 1, 2015:

http://archive.navytimes.com/article/20130103/NEWS/301030333/Army-may-workPalantir-intel-software

McLeary, Paul, "Army Orders Intelligence Servers Shut Down, Threatens Palantir, Continues 3rd ID Probe," DefenseNews, Sept 21, 2012. As of September 1, 2015:

http://archive.defensenews.com/article/20120921/DEFREG02/309210005/ArmyOrders-Intelligence-Servers-Shut-Down-Threatens-Palantir-Continues-3rd-ID-Probe

McNaugher, Thomas L., New Weapons Old Politics: America's Military Procurement Muddle, Washington, D.C.: Brookings, 1989.

The National Biometrics Challenge, National Science and Technology Council, August, 2006.

Newell, COL Peter E., "Response to USFOR-A Global Knowledge Management capability query" to Dicks, Hon. Norm, July 28, 2010.

Norman R. Baker, James R. Freeland, "Information and Innovation in Research Organizations," paper presented at ORSA National Meeting, Detroit, MI, October, 1970.

Office of the Director of Defense Research and Engineering, Project HINDSIGHT Final Report, Washington D.C.: Department of Defense, October, 1969. 
Office of the Director, Operational Test and Evaluation, Operational Test and Evaluation Report on the Predator Medium-Altitude Endurance Unmanned Aerial Vehicle (UAV), September, 2001.

Pesci, Michael E., "Systems Engineering in Counter Radio-Controlled Improvised Explosive Device Electronic Warfare," John Hopkins APL Technical Digest, Vol. 31, No. 1, 2012, pp. 58-65.

Pete Modigliani, Su Chang, Defense Agile Acquisition Guide: Tailoring DoD IT Acquisition Program Structures and Processes to Rapidly Deliver Capabilities, The MITRE Corporation, 14-0391, March, 2014.

Harris Corporation Officer, "Email to the Author," Nov 10, 2015.

Report of the Defense Science Board Task Force on Defense Intelligence Counterinsurgency (COIN) Intelligence, Surveillance, and Reconnaissance (ISR) Operations, Washington D.C.: Department of Defense, February, 2011.

Report of the Defense Science Board Task Force on the Fulfillment of Urgent Operational Needs, Washington, D.C.: Defense Science Board, July, 2009. As of Dec 14, 2014:http://www.acq.osd.mil/dsb/reports/ADA503382.pdf

Former I MEF Officer, "Email to the Author," Nov 9, 2015.

Robotham, Rojan J, Predator Acquisition Program Transition From Rapid To Standard Processes, Ft. Leavenworth, KS: U.S. Army Command and General Staff College, 2012.

Rosen, Stephen Peter, Winning the Next War: Innovation and the Modern Military, Ithaca, NY: Cornell University Press, 1991.

Rosenberg, Barry, "JTRS Business Model Opens Doors to Innovation," Defense Systems, July, 2010.

S.S. Kamal, John T. Armantrout, "The U.S. Military's Joint Tactical Radio System: Why is it More Relevant than Ever for the US Navy?," CHIPS: The Department of the Navy's Information Technology Magazine, January-March, 2013. As of Oct 22, 2015: http://www.doncio.navy.mil/CHIPS/ArticleDetails.aspx?ID=4344 
Sachtman, Noah, "The Secret History of Iraq's Invisible War," Wired, April 11, 2011. As of March 4, 2015:

http://www.wired.com/2011/06/iraqs-invisible-war/all/1

Schick, Allen, The Federal Budget: Politics, Policy, Process, Washington DC: Brookings, 2007.

Schneck, William C., After Action Report: Operation Restore Hope, Headquarters US Army Aviation and Troop Command, June 13, 1994.

Scott Stephenson, "The Revolution in Military Affairs: 12 Observations on an Out-ofFashion Idea," Military Review, May-June, 2010, pp. 38-46.

Seffers, George I., "Making Battlefield Intelligence "iPad Easy" " Signal, July, 2012. As of December 4, 2015:

http://www.afcea.org/content/?q=node/3004

Shanker, Thom, "Army Developing Teams for Electronic Warfare," New York Times, March 7, 2009. As of June 21 2015:

http://www.nytimes.com/2009/03/08/washington/08army.html

Siedlarz, John E., Biometric Identification Verification Technology Status and Feasibility Study, Alexandria, VA: Defense Nuclear Agency, DNA-TR-94-6, September, 1994.

Sloggett, Dave, Drone Warfare: The Development of Unmanned Aerial Conflict, New York: Skyhorse, 2014.

Smith, Richard, "The Roots of Innovation," British Medical Journal (Clinical Research Edition), Vol. 295, No. 6609, November 21, 1987, pp. 1335-1338.

Strickland, Frank, "The Early Evolution of the Predator Drone: An Insider's Perspective on Innovation During Fiscal Austerity," Studies in Intelligence, Vol. 57, No. 1, 2013, p. 6.

Sullivan, Michael J., Rapid Acquisition of MRAP Vehicles, Washington, D.C.: Government Accountability Office, GAO-10-155T, Oct 8, 2009. As of Nov 10, 2014 :

http://www.gao.gov/assets/130/123503.pdf 
Sydney J. Freedberg, Jr., "Army Electronic Warfare Goes On the Offensive: New Tech Awaits Approval " Breaking Defense, Jan 29, 2013. As of June 3, 2015:

http://breakingdefense.com/2013/01/army-electronic-warfare-new-tech/

_ , "Army Electronic Warfare 'Is A Weapon' - But Cyber Is Sexier" Breaking Defense, Oct 16, 2014. As of June 3, 2015:

http://breakingdefense.com/2014/10/army-electronic-warfare-is-a-weapon-but-cyberis-sexier/

Thirtle, Michael R., Robert V. Johnson, and John L. Birkler, The Predator ACTD: A Case Study for Transition Planning to the Formal Acquisition Process, Santa Monica: RAND Corporation, MR-899-OSD, 1997.

http://www.rand.org/pubs/monograph_reports/MR899.html

United States Air Force, United States Air Force RPA Vector: Vision and Enabling Concepts 2013-2038, February 17, 2014.

United States House of Representatives, Hearing on the Fiscal Year 2009 Budget for the United States Marine Corps: Hearing Before the House Armed Services Committee 2008 WL 542644 (F.D.C.H.), CQ Transcriptions, Feb 27, 2008.

PL 107-314, Bob Stump National Defense Authorization Act for Fiscal Year 2003, 2003.

United States Marine Corps, "MCWP 3-40.5: Electronic Warfare," August, 2002. As of June 1, 2015: http://www.marines.mil/Portals/59/Publications/MCWP\%20340.5\%20Electronic\%20Warfare.pdf

- MINE RESISTANT AMBUSH PROTECTED (MRAP) VEHICLE, February 17, 2005. As of April 2, 2015:

http://www.marines.mil/News/Messages/MessagesDisplay/tabid/13286/Article/11807 5/urgent-universal-need-statement-uuns-process.aspx

, URGENT UNIVERSAL NEED STATEMENT (UUNS) PROCESS, Jan 26, 2006. As of April 2, 2015:

http://www.marines.mil/News/Messages/MessagesDisplay/tabid/13286/Article/118075/u rgent-universal-need-statement-uuns-process.aspx 
"View From the Ground: The New Integrated Face of Land EW," IHS International Defence Review, 2010.

Whittle, Richard, Predator's Big Safari, Air Force Association, August, 2011.

- Predator: The Secret Origins of the Drone Revolution, New York: Holt, 2014.

Wildavsky, Aaron, The New Politics of the Budgetary Process, Second ed., New York: Harper Collins, 1992.

Wilgucki, K., R. Urban, G. Baranowski, P. Gradzki, and P. Skarzynski, "Selected aspects of effective RCIED jamming," Communications and Information Systems Conference (MCC), 2012 Military, 2012, pp. 1-5.

William Schneider Jr., Francis P. Hoeber, Norman Polar, Arms, Men, and Military Budgets: Issues for Fiscal Year 1981, New York: Transaction, 1980.

Wilson, Clay, Improvised Explosive Devices (IEDs) in Iraq and Afghanistan: Effects and Countermeasures, Congressional Research Service, RS22330, August 28, 2007.

Wilson, James Q., Bureaucracy: What Government Agencies Do and Why They Do It, New York: Basic 1989.

Harris Corporation Executive, "Email to the Author," Nov 2, 2015a.

__, "Interview with Author," Oct 13, 2015 b.

Yauch, Charlene, "Measuring agility as a performance outcome," Journal of Manufacturing Technology, Vol. 22, No. 3, 2011, pp. 384-404.

Yin, Robert K., Case Study Research: Design and Methods, Third ed., Applied Social Research Methods Series, Thousand Oaks: Sage Publications, 2003.

Yiwei Gong, Marjin Janssen, "Measuring process flexibility and agility," paper presented at Proceedings of the 4th International Conference on Theory and Practice of Electronic Governance, Beijing, ACM, January 2010. 
Zmud, Robert W., "An Examination of 'Push-Pull' Theory Applied to Process

Innovation in Knowledge Work," Management Science, Vol. 30, No. 6, June, 1984, pp. 727-738. 